\title{
Implementação e análise do protocolo de Katz e Yung para estabelecimento de chaves de grupo
}

\author{
Jorge Alves Tonami
}

DisSERTAÇÃo APRESENTADA AO INSTITUTO DE Matemática e Estatística da Universidade de São Paulo para obtenção do grau de Mestre em Ciência da Computação

Área de Concentração: Ciência da Computação Orientador: Prof. Dr. Routo Terada

São Paulo, Dezembro de 2004 


\section{Implementação e análise do protocolo de Katz e Yung para estabelecimento de chaves de grupo}

Este exemplar corresponde à redação final da dissertação devidamente corrigida e defendida por Jorge Alves Tonami e aprovada pela comissão julgadora.

São Paulo, dezembro de 2004.

Banca Examinadora:

- Prof. Dr. Routo Terada (Orientador) - IME-USP

- Prof. Dr. Marco Dimas Gubitoso - IME-USP

- Profa. Dra. Tereza Cristina Melo de Brito Carvalho - POLI-USP 
Aos meus pais, Cyro e Neide. 


\section{Agradecimentos}

Ao meu orientador Prof. Dr. Routo Terada que me auxiliou na escolha do tema e na elaboração do trabalho, além de me apresentar a criptologia, uma ciência até então pouco conhecida por mim.

Aos amigos que fiz durante este curso, Celina M. Takemura, Ney B. Luz, Fabio C. Xavier, Mehran Misaghi e em especial ao Cesar A. M. Paixão e ao Eduardo T. Ueda, que me auxiliaram durante todo o curso e principalmente durante a elaboração da dissertação de mestrado.

Ao meu amigo Alex K. Hamassaki, que me incentivou e apoiou desde o o início do curso.

Aos amigos que fiz na $\mathrm{ABC} 71$, Fernando Correa, Alexandre Nishiyama, Fred Ricardo, Arnaldo Marinho e Julio Bertolini, que me apoiaram nos momentos difíceis, e ao Gustavo Fabbro, que me auxiliou durante a implementação do protocolo.

À minha namorada Aline C. Ceron que sempre esteve ao meu lado principalmente nos momentos difíceis, além de sua paciência e compreensão.

À toda minha família, e em especial aos meus pais, que também sempre estiveram ao meu lado, me apoiando financeira e psicologicamente e me dando forças para superar as dificuldades e para nunca desistir de meus sonhos. 


\section{Resumo}

O estabelecimento de uma chave de grupo entre duas ou mais entidades que estão se comunicando em uma rede pública é algo que já vem sendo estudado há muito tempo. A segurança e eficiência de um algoritmo criptográfico para a comunicação entre um grupo de entidades torna-se totalmente vulnerável se um intruso descobrir a sua chave de sessão. Hoje em dia é cada vez mais necessário adquirir um bom desempenho em um sistema de comunicação e, apesar da garantia de segurança apresentada por mecanismos "fora-debanda" ou mecanismos como o RSA, fica evidente que, para o caso de uma comunicação com muitos participantes, estes tipos de mecanismos não obtém um bom desempenho. $\mathrm{E}$ é através de um protocolo de estabelecimento de chaves de grupo que se garante uma melhora neste desempenho, garantindo também a segurança de um algoritmo criptográfico e a privacidade na comunicação entre um grupo de usuários. O estabelecimento de uma chave de sessão entre dois usuários é um caso já bem estudado pela comunidade criptográfica; por outro lado, para um grupo de participantes maior, ainda existem dificuldades com relação à segurança. Existem alguns protocolos que se baseiam em conceitos semelhantes para o estabelecimento desta chave para o caso de uma comunicação entre três ou mais entidades. O principal objetivo deste documento é relatar os resultados obtidos da análise de um dos últimos protocolos de estabelecimento de chaves que surgiram recentemente, mostrando informações obtidas de sua implementação, relacionadas com o funcionamento, o desempenho e a segurança. 


\section{Abstract}

The Group Key Exchange between two or more entities communicating in a public network has been studied for a long time. The security and efficiency in a cryptographic algorithm for a communication among a group of entities become completely vulnerable if an adversary finds this session key. Today it is more and more necessary to obtain a good performance in a system communication, and in spite of the security's guarantee showed by "out-of-band" mechanism or like RSA, it is evident that, for a case of the communication with a lot of participants, this type of mechanism can't get a good performance. A protocol for group key exchange may guarantee a better performance, and security of the cryptographic algorithm and privacy in the communication among a group of users too. The establishment of the session key between two users is fairly well-understood by cryptographic community; but, for a larger number of users, there are difficulties in security analysis. There are some protocols that are based on similar concepts for the establishment of a key among three or more entities. The main goal of this document is to give a report of the results obtained by the analysis of the most recent protocols for group key exchange, showing information obtained by implementation, related to functioning, performance and security. 


\section{Sumário}

Resumo iii

Abstract iv

1 Introdução 1

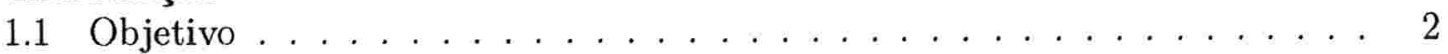

1.2 Contribuições . . . . . . . . . . . . . . . . . . 3

1.3 Organização do documento . . . . . . . . . . . . . . 3

2 Conceitos básicos $\quad 4$

2.1 Problema do Logaritmo Discreto (PLD) . . . . . . . . . . . . . . . . 4

2.2 Protocolo de Diffie-Hellman . . . . . . . . . . . . . . . . . 4

2.3 Protocolos de Estabelecimento de Chave . . . . . . . . . . . . . . . 5

2.4 Protocolos de Estabelecimento de Chave Autenticadas . . . . . . . . . . . 5

2.5 Escalabilidade . . . . . . . . . . . . . . . . . . . 5

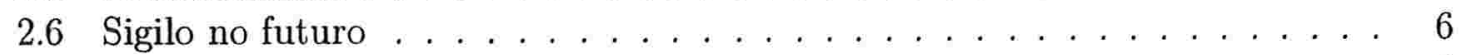

2.7 Suposições de Diffie-Hellman . . . . . . . . . . . . . . . . . . . . . . 6

$2.7 .1 \mathrm{CDH}$ (Computacional Diffie-Hellman) . . . . . . . . . . . . . 6

2.7.2 DDH (Decisional Diffie-Hellman) . . . . . . . . . . . . 6

2.8 Lema do Aniversário . . . . . . . . . . . . . . . . . . . . . . . 6

3 Histórico de Protocolos $\quad 8$

3.1 Protocolo de Ingemarsson _ . . . . . . . . . . . . . . . . . . 8

3.2 Protocolo de Burmester e Desmedt . . . . . . . . . . . . . . . . . . 9

3.3 Protocolo de Bellare . . . . . . . . . . . . . . . . . . . . . . . . 9

3.4 Protocolo de Steiner . . . . . . . . . . . . . . . . . . . . . . . 11

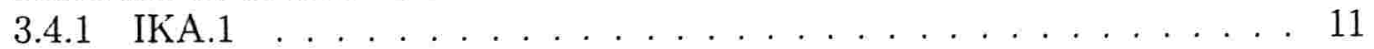

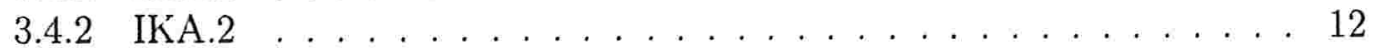

3.5 Protocolo de Bresson . . . . . . . . . . . . . . . . . . . . . . . 14

3.6 Tabela comparativa . . . . . . . . . . . . . . . . . . . . . . . . . 15 
4 O Modelo de segurança $\quad 17$

4.1 Considerações iniciais . . . . . . . . . . . . . . . . . . . . . . . . . 17

4.2 Modelo do Adversário . . . . . . . . . . . . . . . . . . . . . . . . 17

4.2 .1 Funções . . . . . . . . . . . . . . . . . . . . . . . 18

4.3 Sociedade . . . . . . . . . . . . . . . . . . . . . . . 18

4.4 Freshness . . . . . . . . . . . . . . . . . . . . . . . . . . 19

4.5 Definições de Segurança . . . . . . . . . . . . . . . . . . . . . . . . . . 19

4.6 Protocolos sem sigilo no futuro . . . . . . . . . . . . . . . . . . . 19

4.7 Observações . . . . . . . . . . . . . . . . . . . . . . . . . . 19

5 Compilador para protocolos de estabelecimento de chaves de grupo 20

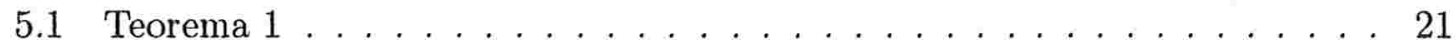

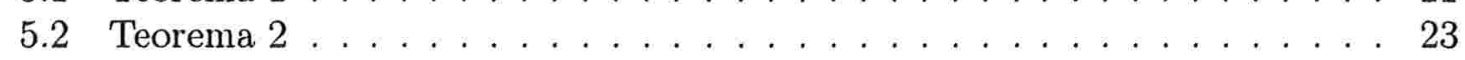

6 Um protocolo de estabelecimento de chaves de grupo 24

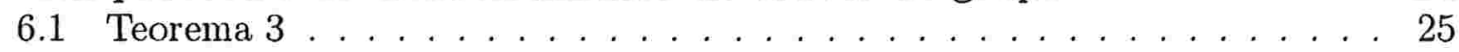

6.2 Exemplo . . . . . . . . . . . . . . . . . . . 28

$\begin{array}{lll}7 & \text { Ferramentas e metodologias utilizadas } & 31\end{array}$

7.1 Hardware e Dados de Entrada e Saída . . . . . . . . . . . . . . . . . . . . 31

7.1.1 Tamanho dos Módulos . . . . . . . . . . . . . . . . . . . 31

7.1 .2 Medidas de desempenho . . . . . . . . . . . . . . . 32

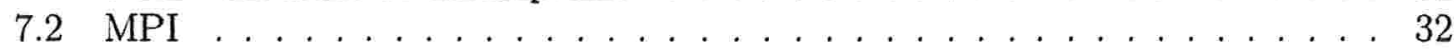

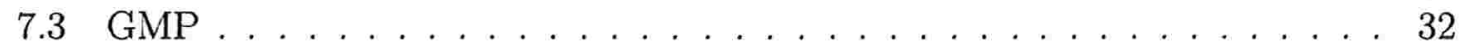

8 Implementação e Análise $\quad \mathbf{3 5}$

8.1 Conceitos gerais . . . . . . . . . . . . . . . . . . . 35

8.1.1 Geração das Informações para a Análise . . . . . . . . . . . . . . 35

8.1.2 Visualização das Informações para a Análise . . . . . . . . . . . . 35

8.2 Implementação do Protocolo . . . . . . . . . . . . . . . . . . . . . . 36

8.3 Execução do Protocolo . . . . . . . . . . . . . . . . . . . . . 36

8.4 Análise dos Resultados Obtidos . . . . . . . . . . . . . . . . . 38

8.5 Execução dos programas . . . . . . . . . . . . . . . . . . . . . 39

8.5 .1 O programa spagke.exe . . . . . . . . . . . . . . 40

8.5 .1 O programa pkres.exe . . . . . . . . . . . . . . . . 40

8.5 Dificuldades encontradas . . . . . . . . . . . . . . . . . . . 41

9 Conclusão $\quad 46$

$\begin{array}{lll}\text { A } & \text { Listagem do programa Spagke } & 48\end{array}$

$\begin{array}{lll}\text { B Listagem do programa PKRes } & 58\end{array}$

$\begin{array}{ll}\text { Glossário } & 65\end{array}$ 
Índice Remissivo

Referências Bibliográficas 


\section{Lista de Figuras}

1 Execução do protocolo para $g=2, S_{A}=3$ e $S_{B}=2 \ldots \ldots \ldots$

2 Ingemarsson - Execução do protocolo para quatro participantes $(n=4)$. . 9

3 Burmester e Desmedt - $1^{a}$ Rodada . . . . . . . . . . . . . . . . . . . . . . . 10

4 Burmester e Desmedt - $2^{a}$ Rodada . . . . . . . . . . . . . . . . . . . . . . . 10

5 Burmester e Desmedt - Chave de sessão obtida . . . . . . . . . . . . . . . 10

6 Bellare - Chave de sessão obtida pelos 4 participantes . . . . . . . . . . . . . 11

$7 \quad$ IKA.1 - $1^{a}$ Etapa . . . . . . . . . . . . . . . . . . 12

$8 \quad$ IKA.1 $-2^{a}$ Etapa e Resultado final . . . . . . . . . . . . . . . 12

$9 \quad$ IKA. $2-1^{a}$ Etapa . . . . . . . . . . . . . . . . . . . . . 13

10 IKA.2 - $2^{a}$ e $3^{a}$ Etapas . . . . . . . . . . . . . . . . . . . 13

11 IKA.2 - $4^{a}$ Etapa e Resultado final . . . . . . . . . . . . . . . . . . . . 14

12 Bresson - Rodadas do $1^{\circ}$ Estágio . . . . . . . . . . . . . . . . . 14

13 Bresson - $2^{\circ}$ Estágio e Resultado final . . . . . . . . . . . . . . . . . 15

14 Katz e Yung $-1^{a}$ Rodada . . . . . . . . . . . . . . . . . . . . 25

15 Katz e Yung $-2^{a}$ Rodada . . . . . . . . . . . . . . . . . . . . . 25

16 Katz e Yung - Chave de sessão obtida . . . . . . . . . . . . . . . . . . 26

17 Exemplo - $1^{a}$ Rodada . . . . . . . . . . . . . . . . . . . . . . . . 29

18 Exemplo - $2^{a}$ Rodada . . . . . . . . . . . . . . . . . . . . . . . . 29

19 Exemplo - Chave de sessão obtida . . . . . . . . . . . . . . . . . . 30

20 Execução do Protocolo - Arquivo de parametrização . . . . . . . . . . . . 37

21 Execução do Protocolo - Reconhecimento do número de participantes . . . 38

22 Execução do Protocolo - Cálculo da Chave de Sessão . . . . . . . . . . . . . 39

23 Execução do Protocolo - Dados Estatísticos . . . . . . . . . . . . . . . . . 40

24 Análise dos Resultados Obtidos - Arquivo result.txt . . . . . . . . . . . . 41

25 Análise dos Resultados Obtidos - Arquivo pkchaves.txt . . . . . . . . . . . 42

26 Análise dos Resultados Obtidos - Arquivo result.txt depois de várias execuções . . . . . . . . . . . . . . . . . . . . 4 43

27 Análise dos Resultados Obtidos - Arquivo pkchaves.txt depois da segunda execução . . . . . . . . . . . . . . . . . . . . . . . . 44 44

28 Análise dos Resultados Obtidos - Gráfico de desempenho . . . . . . . . . . 44

29 Pkres - Guia "Dados" . . . . . . . . . . . . . . . . . . . . . . . . . . . 45

30 Pkres - Guia "Gráfico" . . . . . . . . . . . . . . . . . . . . . . 45 


\section{Lista de Tabelas}

1 Tabela comparativa dos protocolos ................ 15 


\section{Introdução}

Os protocolos para estabelecimento de chaves autenticadas ( $A K E$ - Authenticated Key Exchange) permitem a um grupo de parceiros dentro de uma grande rede pública completamente insegura estabelecerem uma chave secreta comum (uma chave de sessão) e, além disso, garantem que eles estão realmente compartilhando esta chave mutuamente (ou seja, com seus companheiros pretendidos). Estes tipos de protocolos são fundamentais para a criptografia e para a segurança de rede.

No início da década de 70, Whitfield Diffie e Martin Hellman [16] desenvolveram a idéia da chave pública. A criptografia da chave pública é uma técnica de criptografar e decriptografar uma mensagem utilizando um par de chaves assimétricas. Uma chave pública seria capaz apenas de criptografar uma mensagem, e esta poderia ser decriptografada apenas pela chave privada correspondente (deduzida a partir da chave pública), permitindo assim que a chave pública possa ser divulgada sem comprometer a segurança da chave privada. Com isso, no final da década de 70, Ronald Rivest, Adi Shamir e Leonard Adleman criaram o RSA, um algoritmo de criptografia assimétrica que resolvia o problema da distribuição das chaves, que comprometia a segurança dos algoritmos simétricos. Por outro lado, na prática, o RSA demanda muito processamento para encriptar uma mensagem, e somente grandes companhias têm capital para investir em máquinas com alta capacidade de processamento.

Uma alternativa para solucionar o problema da distribuição das chaves seria então a de utilizar mecanismos fora-de-banda para estabelecer estas chaves para um algoritmo de criptografia simétrica, ou então utilizar sistemas assimétricos similares ao RSA, mas com um custo menor (ou zero), como por exemplo o PGP (Pretty Good Privacy), encontrado gratuitamente na Internet, e que inclusive utiliza algumas vantagens do RSA. O problema é que estas alternativas possuem um desempenho ruim para uma comunicação com muitos participantes. Sendo assim, os protocolos de estabelecimento de chaves passaram a ser boas soluções para quem precisa de sistemas com bom desempenho, tanto na criptografia quanto na decriptografia, algo que pode ser alcançado com algoritmos simétricos.

Os protocolos de estabelecimento de chaves são cruciais para permitir que a criptografia de chave simétrica faça a codificação e/ou autenticação dos dados dentre as partes sem que precise de um mecanismo "fora-de-banda" para fazer o acordo de uma chave em comum. Além disso, eles são utilizados para o desenvolvimento de "canais seguros" no topo de protocolos de alto-nível que podem ser projetados, analisados, e implementados de uma forma modular. Assim, uma compreensão detalhada do $A K E$ - especialmente para o 
projeto de protocolos comprovadamente seguros - é essencial.

$\mathrm{O}$ caso do protocolo de estabelecimento de chaves autenticadas entre dois participantes foi amplamente estudado dentro da comunidade criptográfica e está bem compreendido. Além disso, existe uma variedade de protocolos $A K E$ eficientes e comprovadamente seguros para duas partes. Por outro lado, ainda não foi dada muita atenção para o caso em que um protocolo de estabelecimento de chaves de grupo estabelece uma chave de sessão para mais de dois participantes (ou seja, $n>2$ ). Os protocolos de estabelecimento de chaves de grupo são essenciais para diversas aplicações, como, por exemplo, vídeo-conferência e aplicações multi-ponto que envolve um grande número de usuários.

As pesquisas recentes de Bresson $[6,7,10]$, foram as primeiras que apresentaram um modelo formal de segurança para um protocolo de estabelecimento de chaves de grupo e as primeiras que forneceram demonstrações de segurança para protocolos particulares. Isto representa um passo inicial importante, mas existe ainda muito trabalho a fazer para se melhorar a eficiência e a escalabilidade ${ }^{1}$ de soluções existentes. Bresson [10] também obteve uma das soluções mais eficientes e comprovadamente seguras no modelo padronizado, que adapta as prévias de trabalho de Steiner [26]. Infelizmente, esses protocolos não são escaláveis: para estabelecer uma chave dentre os n participantes, eles precisam de $n$ rodadas $^{2}, O(n)$ exponenciações modulares e comunicação em $O(n)$.

A principal contribuição do protocolo de Katz e Yung [20] é o fato de ser o primeiro protocolo de estabelecimento de chaves de grupo com número de rodadas constante e totalmente escalável, sendo comprovadamente seguro no modelo padronizado. A segurança é demonstrada através da redução para a suposição de decisão de Diffie-Hellman (DDH). $\mathrm{O}$ protocolo também não permite que um usuário antigo se comunique com o grupo. $\mathrm{O}$ protocolo possui três rodadas e é eficiente também para grupos com elevado número de participantes: isto requer unicamente $O(1)$ para a comunicação, três exponenciações modulares e $O(n)$ verificações de assinatura pelo usuário. Será mostrado um compilador que transforma qualquer protocolo de estabelecimento de chave de grupo seguro contra um adversário passivo para um seguro contra um mais forte (e mais realístico) adversário ativo que controla toda comunicação na rede. Se o protocolo original impossibilita o acesso de um usuário antigo, então o protocolo compilado também não permite. Será apresentada então uma adaptação do trabalho de Burmester e Desmedt [12], que é um protocolo de estabelecimento de chaves de grupo de duas rodadas e com demonstrações de segurança - contra um adversário passivo - sob a suposição de DDH. Aplicando o compilador para este protocolo obtém-se o resultado principal: um protocolo de três rodadas eficiente para os casos em que o número de participantes é maior que dois.

\subsection{Objetivo}

Esta dissertação tem como objetivo apresentar de uma forma detalhada todo o estudo feito em cima do protocolo estabelecimento de chaves de grupo de Katz e Yung, desde um

\footnotetext{
${ }^{1}$ Relacionada com o número de casos em que o protocolo pode funcionar. Veja mais detalhes no capitulo 4

${ }^{2}$ Passos ou iteraçōes ocorridos durante a execução
} 
histórico dos protocolos ancestrais até a implementação e análise, passando pelo levantamento de suas características principais de funcionamento, e também por suas vantagens e desvantagens.

\subsection{Contribuições}

Como contribuições deste trabalho, pode-se citar:

- Um histórico dos principais protocolos de estabelecimento de chaves de grupo já estudados, que têm influência não apenas no protocolo de Katz e Yung, mas também em diversos outros protocolos que possuem uma importância significativa na comunidade criptográfica hoje em dia.

- Uma implementação didática do protocolo estudado, com bibliotecas que facilitam a utilização e permitem um maior aproveitamento de código, além do que abre caminho para que mais testes em plataformas Windows e Unix possam ser feitos em um futuro próximo.

- Uma análise de desempenho aplicada sobre a implementação, que acarretou na descoberta de que o número de exponenciações não é constante.

- Uma documentação detalhada e em língua portuguesa de todo o estudo feito, desde o histórico até a análise da implementação, algo ainda escasso na comunidade criptográfica brasileira.

\subsection{Organização do documento}

No capítulo 2, serão citados alguns conceitos básicos utilizados no trabalho. No capítulo 3, serão mostradas as principais características de protocolos anteriores que tiveram influência nos estudos de Katz e Yung [20], sendo exibido também uma tabela comparativa entre estes protocolos. No capítulo 4 será mostrado um modelo de segurança que se baseia no modelo padrão de Bresson [10]. O compilador de Katz e Yung [20] será mostrado no capítulo 5 e no capítulo 6 será descrito um protocolo de duas rodadas, seguro contra adversários passivos. O capítulo 7 apresenta as ferramentas utilizadas na implementação do protocolo, que é descrita no capítulo 8. Por fim, o capítulo 9 conclui de uma forma geral todo o trabalho.

$\mathrm{O}$ anexo A apresenta a listagem de todo o código desenvolvido em ANSI C para a implementação do protocolo de Katz e Yung e o anexo B apresenta a listagem de todo o código desenvolvido em $\mathrm{C}++$ para o programa de visualização dos resultados.

No glossário estão todos os termos criptográficos utilizados nesta dissertação. 


\section{Conceitos básicos}

\subsection{Problema do Logaritmo Discreto (PLD)}

Definição segundo Routo Terada [28]: Dados um primo $p$ e inteiros $g, t<p$, calcular um inteiro $s$ tal que $t=g^{s} \bmod p$.

Exemplo: vamos supor que $p=5, g=3$ e $t=4$. Uma solução, para este caso, será $s=2$.

Quando $p$ é relativamente longo (por exemplo, 1024 bits), ninguém até hoje descobriu um algoritmo eficiente, isto é, de tempo polinomial, para resolver este problema, ou seja, este problema é computacionalmente inviável de ser resolvido.

\subsection{Protocolo de Diffie-Hellman}

Protocolo desenvolvido por W. Diffie e M. Hellman [16] que, baseado no Problema do Logaritmo Discreto, estabelece uma chave secreta entre duas pessoas que pretendem se comunicar ${ }^{3}$. Abaixo estão os passos do protocolo para a combinação de uma chave secreta entre A e B:

1. A escolhe um número aleatório $S_{A}, 1 \leq S_{A} \leq p-2$

2. $B$ escolhe um número aleatório $S_{B}, 1 \leq S_{B} \leq p-2$

3. $A$ calcula $t_{A}=g^{S_{A}} \bmod p$ e envia para $B$.

4. $B$ calcula $t_{B}=g^{S_{B}} \bmod p$ e envia para $A$.

5. $A$ calcula $\left(t_{B}\right)^{S_{A}} \bmod p=K_{A B}$.

Note que $\left(t_{B}\right)^{S_{A}}=\left[g^{S_{B}} \bmod p\right]^{S_{A}}=g^{S_{B} S_{A}} \bmod p$.

6. $B$ calcula $\left(t_{A}\right)^{S_{B}} \bmod p=K_{A B}$.

Note que $\left(t_{A}\right)^{S_{B}}=\left[g^{S_{A}} \bmod p\right]^{S_{B}}=g^{S_{A} S_{B}} \bmod p$.

${ }^{3}$ As informaçōes que serão trocadas entre ambas as partes passarão por um canal inseguro, sendo portanto consideradas de conhecimento público 
Percebe-se que o Problema do Logaritmo Discreto tem a função de proteger as chaves secretas de $A$ e $B$. Após a execução deste protocolo, $A$ e $B$ poderiam se comunicar trocando informações através de um algoritmo de chave secreta.

Exemplo:

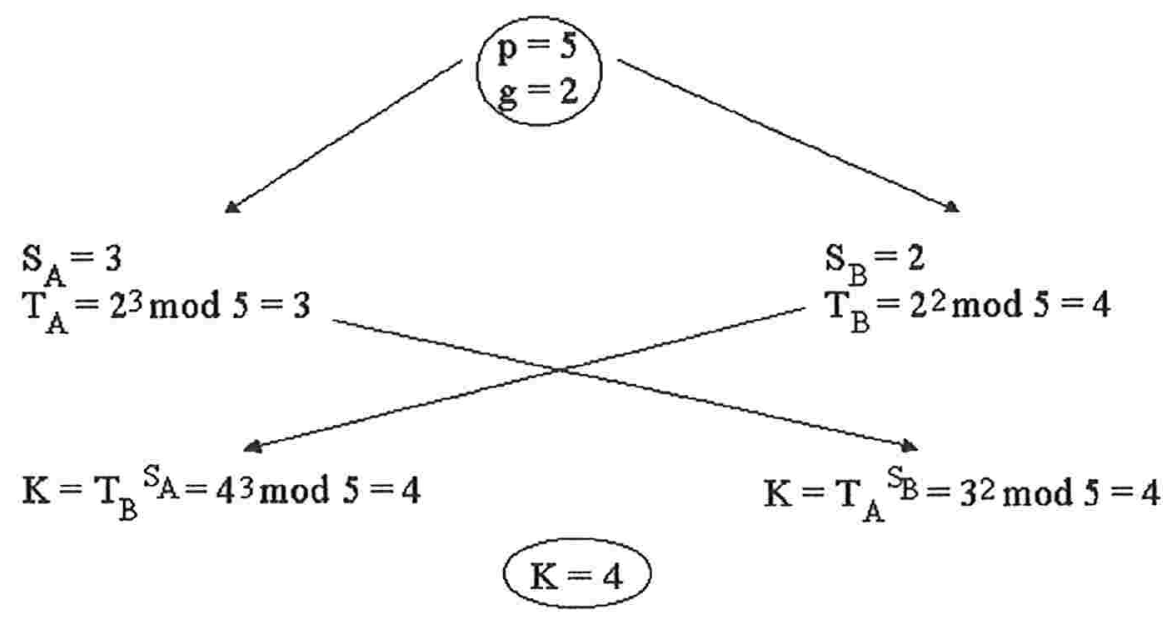

Figura 1: Execução do protocolo para $g=2, S_{A}=3$ e $S_{B}=2$

\subsection{Protocolos de Estabelecimento de Chave}

Estabelecem uma chave de sessão para um grupo de participantes se comunicando em uma rede, protegendo-os de adversários passivos, ou seja, que apenas observam as informações trocadas entre eles.

\subsection{Protocolos de Estabelecimento de Chave Autentica- das}

Estabelecem uma chave de sessão para os membros de um grupo, protegendo-os de adversários ativos que controlam toda a comunicação na rede.

\subsection{Escalabilidade}

Termo utilizado para distinguir se um protocolo possui a mesma eficiência e segurança em mais de um caso.

Um protocolo de estabelecimento de chaves de grupo é considerado escalável se o mesmo consegue gerar chaves de sessão de forma segura para qualquer grupo, independente do 
número de participantes. Ou seja, o protocolo funciona não apenas para o caso de dois participantes estabelecerem uma chave, mas também para o caso de $n$ participantes, onde $n>2$.

\subsection{Sigilo no futuro}

Garantia de que membros que abandonaram ou deixaram de fazer parte da comunicação do grupo não tenham acesso às futuras chaves de sessão .

\subsection{Suposições de Diffie-Hellman}

O "Problema Diffie-Hellman Computacional"e o "Problema Diffie-Hellman de Decisão"podem ser considerados computacionalmente difíceis de serem resolvidos, pelo fato de não se conhecer nenhum algoritmo em tempo polinomial que obtenha um resultado. Desta forma, ambos podem ser utilizados como base em demonstrações de segurança de um determinado algoritmo.

\subsubsection{CDHP (Computacional Diffie-Hellman Problem):}

Dado um grupo $G$, um gerador $g$ de $G$ e dois elementos $a=g^{x}, b=g^{y} \epsilon G$, onde $x$ e $y$ são desconhecidos, calcule o valor $c=g^{x y} \in G$.

\subsubsection{DDHP (Decisional Diffie-Hellman Problem):}

Dado um grupo $G$, um gerador $g$ de $G$ e três elementos $a, b, c \in G$, decidir sobre a existência de inteiros $x, y$ tal que $a=g^{x}, b=g^{y}, c=g^{x y}$.

\subsection{Lema do Aniversário:}

Define a probabilidade de se ocorrer dois aniversários em um mesmo dia durante o ano (365 dias) dentro de um grupo de 23 pessoas.

Lema. A probabilidade de se ocorrer pelo menos uma colisão em uma função de hash $h$ é igual ao produtório de 1 até $k-1$ em $\left(1-\frac{1}{n}\right)$, onde $k$ é o número de pessoas e $n$ o número de dias ao ano.

O Lema acima responde a pergunta a seguir:

Quantas pessoas devem estar em uma sala antes de existir uma chance de $50 \%$ de duas delas terem nascido no mesmo dia do ano? 
Demonstração. Seja uma função de hash $h$, que calcula um valor $y=h(x)$, onde $x$ é um texto legível de comprimento $|x|$, que é da ordem de centenas de bytes, e $y$ é o resumo de $x$, cujo o comprimento é da ordem de 128 bits. Uma colisão é definida como sendo a ocorrência de se aplicar em dois textos $x_{1}$ e $x_{2}$ a mesma função $h$ e se obter o mesmo resumo $y$.

A probabilidade de não ocorrer colisão em $h$ é definida como:

$$
\left(1-\frac{1}{n}\right) \cdot\left(1-\frac{2}{n}\right) \ldots\left(1-\frac{k-1}{n}\right)=\prod_{i=1}^{k-1}\left(1-\frac{1}{n}\right)
$$

Considerando a aproximação $1-\alpha \cong e^{-\alpha}$, se $\alpha$ for pequeno, temos:

$$
\prod_{i=1}^{k-1}\left(1-\frac{1}{n}\right) \cong \prod_{i=1}^{k-1} e^{-1 / n}=e^{\frac{-k(k-1)}{2 n}}
$$

A probabilidade de ocorrer pelo menos uma colisão é aproximadamente igual a 1 $\alpha^{\frac{-k(k-1)}{2 n}}$, que é igual a $\beta$ (notação):

$$
\begin{gathered}
1-\beta=e^{\frac{-k(k-1)}{2 n}} \\
\frac{-k(k-1)}{2 n}=-\ln (1-\beta)=\ln (1-\beta)^{-1} \\
k^{2}-k=2 n \cdot \ln \left(\frac{1}{1-\beta}\right)
\end{gathered}
$$

Ignorando $k$, temos que:

$$
\begin{aligned}
& k^{2}=2 n \cdot \ln \left(\frac{1}{1-\beta}\right) \\
& k \cong \sqrt{2 n \cdot \ln \left(\frac{1}{1-\beta}\right)}
\end{aligned}
$$

Para $\beta=\frac{1}{2}$, obtém-se: $k \cong 1.17 \sqrt{n}$

Lema do aniversário: $n=365, \beta=\frac{1}{2} \Rightarrow k \cong 23$ 


\section{Histórico dos Protocolos}

Existem diversos estudos que têm procurado estender o protocolo de duas partes de Diffie-Hellman [16] para um protocolo de várias partes. A maioria desses trabalhos supõem um adversário passivo, e apenas alguns fornecem uma demonstração de que o protocolo é seguro. Os protocolos de estabelecimento de chave de grupo são projetados para que sejam seguros contra invasores que, além de observarem, também controlam toda comunicação na rede. Existem alguns protocolos que sugerem este tipo de segurança, mas que não fornecem demonstrações de que são seguros, aumentando assim a desconfiança para com os mesmos.

A seguir, estão relacionados os principais estudos de outros autores que tiveram influência nos estudos de Katz e Yung [20]. Serão citadas as principais características, assim como algumas vantagens e desvantagens.

\subsection{Protocolo de Ingemarsson}

Projetado em 1982, por I. Ingemarsson [19], este protocolo foi uma das primeiras tentativas de se estender o protocolo de Diffie-Hellman [16] para o caso de múltiplos participantes (o número de participantes $n$ é maior que dois). Disposto na forma de um anel lógico, o protocolo exige que cada participante gere um número aleatório secreto $S_{i}$ e envie $g^{S_{i}}$ para o próximo participante, na seqüência do anel. De rodada ${ }^{4} \mathrm{em}$ rodada, cada participante considera como base o valor recebido na rodada anterior, e calcula a potência, sendo $S_{i}$ o expoente. Depois disso, o resultado é enviado ao próximo participante, ocorrendo assim a transmissão de $n$ mensagens entre os membros do grupo, sendo, portanto, uma das desvantagens deste protocolo. Ao final das $n-1$ rodadas, todos os participantes obtém a mesma chave de grupo $K_{n}=g^{S_{1} \cdot S_{2} \cdot S_{3} \ldots \cdot S_{n}}$

Apesar do número elevado de transmissões e também da grande quantidade de exponenciações, o protocolo de Ingemarsson [19] serviu como base de estudos para muitos outros projetos, não apenas por ser um dos pioneiros, mas também porque o seu funcionamento é bastante interessante.

\footnotetext{
${ }^{4}$ Passo ou iteração do protocolo
} 

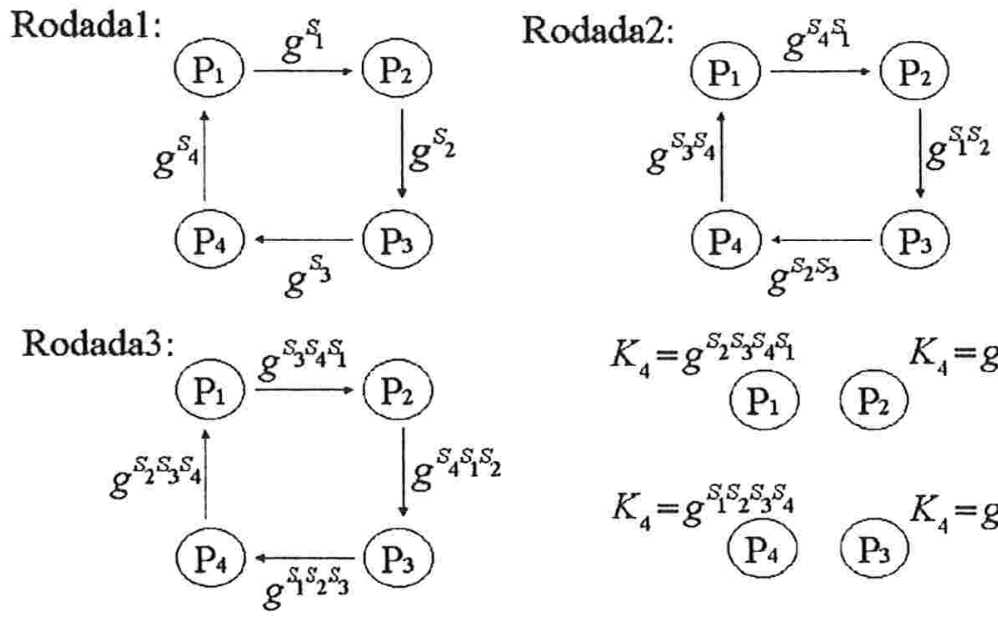

$$
\begin{aligned}
& K_{4}=g_{2}^{S_{2} S_{3} S_{4} S_{1}} \mathrm{P}^{\mathrm{P}_{2}}=g^{\mathrm{P}_{3} S_{4} S_{1} S_{2}} \\
& K_{4}=g_{\mathrm{P}_{1} S_{1} S_{2} S_{4}}^{\mathrm{P}_{3}} \mathrm{P}^{\mathrm{P}_{3} S_{1} S_{2} S_{3}}
\end{aligned}
$$

Figura 2: Ingemarsson - Execução do protocolo para quatro participantes $(n=4)$

\subsection{Protocolo de Burmester e Desmedt}

Surgiu em 1994, onde M. Burmester e Y. Desmedt [12] aproveitaram as características de segurança do protocolo de Diffe-Hellman para desenvolver um protocolo que estabelece uma chave de grupo em duas rodadas, onde, na primeira rodada, cada participante $i$ gera seu número aleatório secreto $S_{i}$ e envia $z_{i}=g^{S_{i}}$ aos demais, e na segunda rodada é calculado o valor $X_{i}=\left(\frac{z_{i+1}}{z_{i-1}}\right)^{S_{i}}$. Ao final da segunda rodada, cada participante obtém a chave de sessão $K_{n}$, que é calculada através da expressão

$$
K_{n}=z_{i-1}^{n \cdot S_{i}} \cdot X_{i}^{n-1} \cdot X_{i+1}^{n-2} \cdot \ldots \cdot X_{i-2} .
$$

Considera-se que $z_{0}=z_{n}$ e $z_{n+1}=z_{1}$.

As figuras 3, 4 e 5 apresentam um exemplo de funcionamento do protocolo, para quatro participantes.

Uma das principais vantagens, além do número constante de rodadas, é o aproveitamento das características de segurança do protocolo de Diffie-Hellman [16]. Por outro lado, este protocolo apresenta a desvantagem de necessitar $O(n)$ transmissões por rodada, além de um elevado número de operações de exponenciação.

\subsection{Protocolo de Bellare}

Os estudos de M. Bellare [1, 2, 3, 4] iniciados em 1993 contribuíram para o surgimento de um protocolo muito eficiente não apenas no número de rodadas, mas também no 

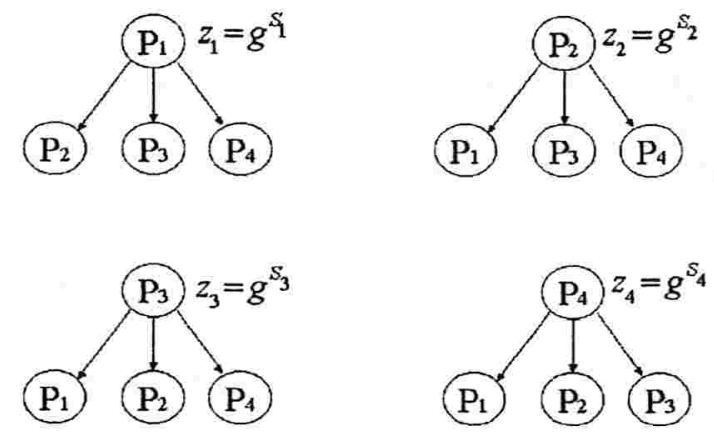

Figura 3: Burmester e Desmedt - $1^{a}$ Rodada
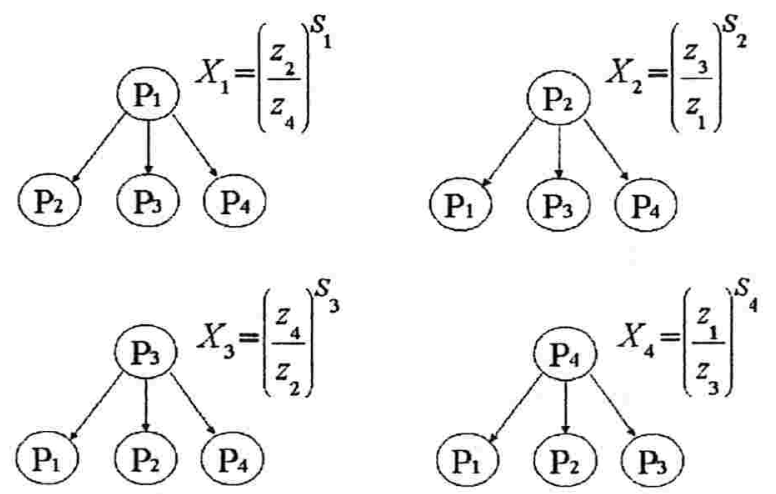

Figura 4: Burmester e Desmedt - $2^{a}$ Rodada

$$
\begin{aligned}
& K_{4}=Z_{4}^{4 \cdot s} \cdot X_{1}^{3} \cdot X_{2}^{2} \cdot X_{3}^{1}=Z_{4}^{4 s_{1}} \cdot\left(\frac{z_{2}}{z_{4}}\right)^{3 s} \cdot\left(\frac{z_{3}}{z_{3}}\right)^{2 s} \cdot\left(\frac{z_{1}}{z_{2}}\right)^{s}=g_{1}^{s} S_{1} S_{2}+S_{2} S_{3}+S_{3} S_{4}+S_{4} S_{1}
\end{aligned}
$$

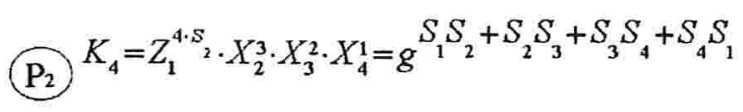

$$
\begin{aligned}
& \text { (P3) } K_{4}=Z_{2}^{4 \cdot S_{3}} \cdot X_{3}^{3} \cdot X_{4}^{2} \cdot X_{1}^{1}=S_{1} S_{2}+S_{2} S_{3}+S_{3} S_{4}+S_{4} S_{1} \\
& \text { (P4) } K_{4}=Z_{3}^{4 \cdot S_{4}} \cdot X_{4}^{3} \cdot X_{1}^{2} \cdot X_{2}^{1}=g_{1} S_{1} S_{2}+S_{2} S_{3}+S_{3} S_{4}+S_{4} S_{1}
\end{aligned}
$$

Figura 5: Burmester e Desmedt - Chave de sessão obtida

número de transmissões por participante e no número de operações de exponenciação. O protocolo de Bellare [4] foi projetado para o caso de três partes, onde um dos três participantes é responsável pelo estabelecimento da chave de sessão entre os outros dois. Na primeira rodada, o participante $A$ gera seu número aleatório $R_{A}$ secreto e envia para 
B. Na segunda rodada, $B$ envia seu número aleatório $R_{B}$ para $C$, juntamente com o número aleatório de $A$, na forma $R_{A} \cdot R_{B}$. Na terceira rodada, $C$ calcula e envia a chave de sessão para $A$ e $B$, aplicando algum algoritmo de segurança e de assinatura em ambos, conforme a figura 6 .
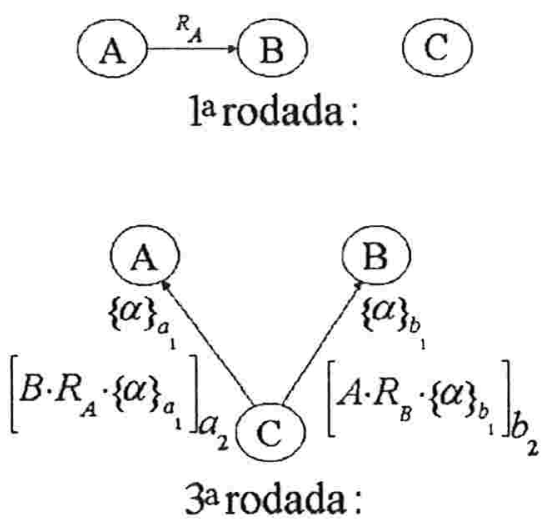
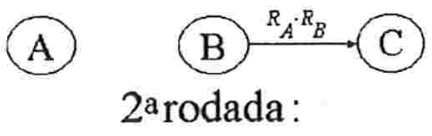

$$
a=\left(a_{1}, a_{2}\right)
$$$$
b=\left(b_{1}, b_{2}\right)
$$

$\{x\}_{a}=$ Algum algorituno de segurança em $\mathrm{x}$

$\left(\left.x\right|_{a_{2}}=\mathrm{x}\right.$ junto comalgum esquema de assinatura de $\mathrm{x}$

Figura 6: Bellare - Chave de sessão obtida pelos 4 participantes

Percebe-se, portanto, que este protocolo é muito eficiente, já que é executado em 3 rodadas, e necessita de apenas $\mathrm{O}(1)$ transmissões e $\mathrm{O}(1)$ exponenciações. Por outro lado, sua principal desvantagem é a limitação quanto ao número de participantes, pois o protocolo funciona apenas para um caso específico.

\subsection{Protocolo de Steiner}

Em 2000, M. Steiner [26] criou a família de protocolos CLIQUES, que é composta por protocolos de gerenciamento de chaves para grupos dinâmicos. Desta família, dois protocolos são utilizados para o estabelecimento de chave de grupo. Os outros executam outras operações ${ }^{5}$, entre elas a adição e exclusão de membros do grupo. Os dois protocolos de estabelecimento de chaves de grupo são chamados por Steiner [26] de IKA.1 e IKA.2 (IKA significa Initial Key Agreement - Acordo de Chaves Inicial)

\subsubsection{IKA.1}

O protocolo IKA.1 é executado em duas etapas: na primeira, os $n-1$ membros do grupo geram suas chaves aleatórias secretas $S_{1}, \ldots, S_{n-1}$. A cada rodada desta primeira etapa, um dos participantes recebe um conjunto de informações do participante anterior. Este conjunto de informações é composto por um valor que armazena o total de chaves enviadas pelo participante anterior e outros valores intermediários. O participante

\footnotetext{
${ }^{5}$ São também propostas versōes com suporte à autenticação, mas aqui será considerada uma versão mais básica, por simplicidade
} 
então inclui sua chave neste conjunto e envia ao próximo participante. Ao receber as informações do penúltimo participante (entre elas, o valor $g^{S_{1} \cdot S_{2} \cdot \ldots \cdot S_{n-1}}$ ), o último participante (responsável pela geração da chave) calcula a chave de grupo $K_{n}=g^{S_{1} \cdot S_{2} \cdot \ldots \cdot S_{n-1} \cdot S_{n}}$. Sendo assim, na segunda etapa, o controlador de grupo inclui sua chave a cada um dos valores intermediários, distribuindo esta informação aos demais. Cada participante, ao recebê-la, calcula a chave de grupo, utilizando o valor intermediário que não possui sua chave secreta, obtendo assim a chave $K_{n}$.

As figuras 7 e 8 mostram o funcionamento básico do protocolo de IKA.1, para quatro participantes.

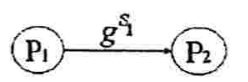

(P4)

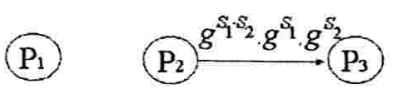

\section{(P4)}

(a) la etapa, la rodada

(b) 1a etapa, 2a rodada

(P1)

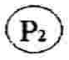<smiles>[C+]1[C+]CC1</smiles>
$g^{s_{1} s_{2} s_{3}} \cdot g^{S_{1} s_{2}} \cdot g^{S_{1} s_{3}} \cdot g^{s_{2} s_{3}}$<smiles>[C+]1[C+]CC1</smiles>

(c) la etapa, 3 rodada

Figura 7: IKA.1 - $1^{a}$ Etapa

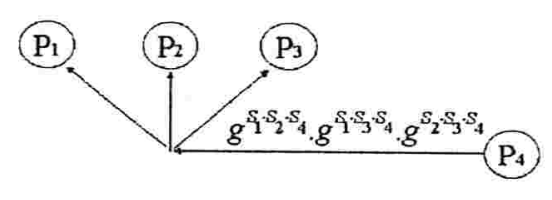

(d) 2aetapa

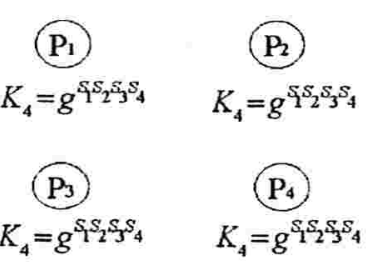

(e)Resultado final

Figura 8: IKA.1 - $2^{a}$ Etapa e Resultado final

\subsubsection{IKA.2}

O protocolo IKA.2 foi desenvolvido para suprir as necessidades do IKA.1, que necessita de $i+1$ operações de exponenciação para o participante $i$. Para um caso em que ocorre um elevado número de participantes, o protocolo IKA.1 perde em eficiência, ainda mais 
se os equipamentos utilizados na comunicação forem limitados com relação à capacidade de memória e processamento.

A execução do IKA.2 é similar ao IKA.1, com apenas algumas diferenças, como, por exemplo, o número de etapas, que passou de duas para quatro. Na primeira etapa, os $n-2$ participantes geram suas chaves secretas aleatórias. A cada rodada, um dos participantes recebe um conjunto de chaves do participante anterior, que é composto por um valor que foi calculado com todas a chaves anteriores, e com outros valores intermediários. $\mathrm{O}$ participante inclui então sua chave secreta e envia ao próximo participante. $\mathrm{Na}$ segunda etapa, o penúltimo participante distribui as chaves recebidas, juntamente com a sua própria chave, para todos os outros. Na terceira etapa, após receber as informações do penúltimo participante, os $n-1$ membros retiram sua chave da informação recebida e enviam o resultado ao último participante. Na quarta etapa, o último participante, controlador do grupo, calcula a chave de sessão (incluindo sua chave também) com este valor recebido e envia aos demais.

As figuras 9, 10 e 11 mostram um exemplo do funcionamento para cinco participantes.

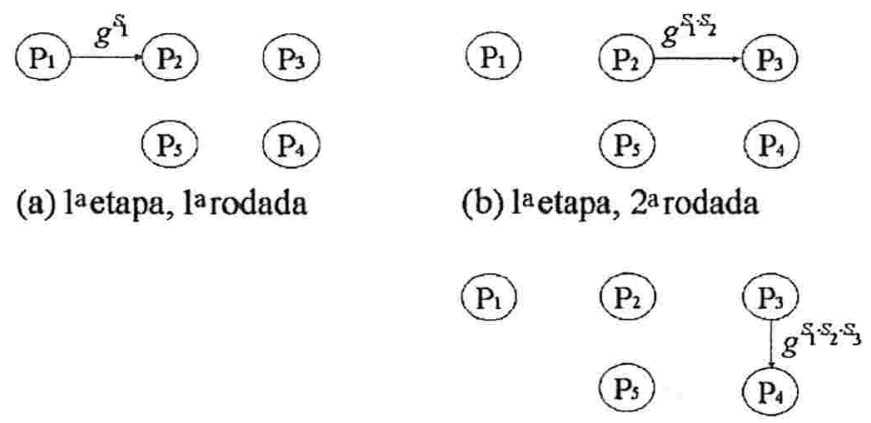

(c) 1a etapa, 3a rodada

Figura 9: IKA.2 - $1^{a}$ Etapa

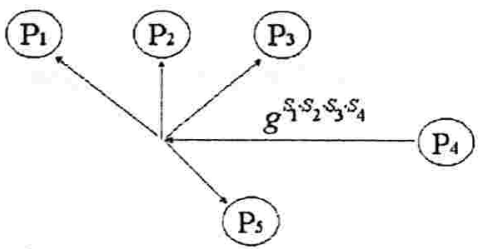

(d) 2a etapa

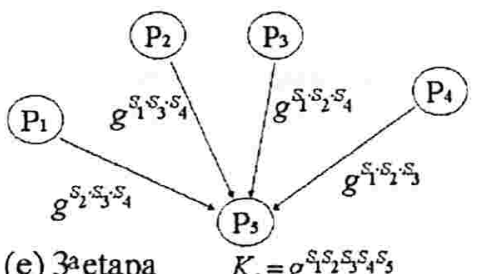

(e) 3a etapa $\quad K_{5}=g^{S} S_{2} S_{3} S_{4} S_{3}$

Figura 10: IKA.2 - $2^{a}$ e $3^{a}$ Etapas

Apesar de possuírem a vantagem de não necessitarem de sincronismo entre os parti- 


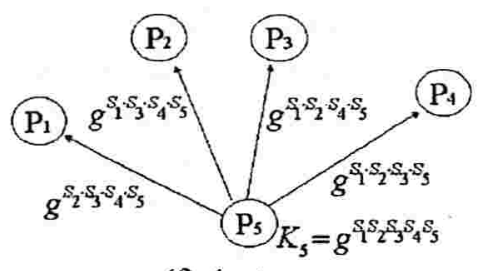

(f) $4^{\text {a etapa }}$

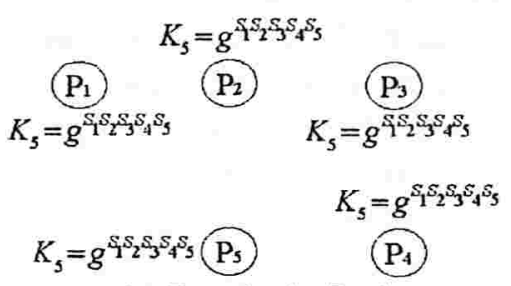

(g) Resultado final

Figura 11: IKA.2 - $4^{a}$ Etapa e Resultado final

cipantes, e permitirem a adição e exclusão de membros, os protocolos de IKA.1 e IKA.2 necessitam de $O(n)$ rodadas, $O(n)$ transmissões e $O(n)$ operações de exponenciação.

\subsection{Protocolo de Bresson}

Bresson $[6,10]$ forneceu, em 2001, o primeiro modelo formal de segurança e o primeiro protocolo de estabelecimento de chaves de grupo autenticadas que apresenta demonstrações de segurança. O protocolo de Bresson [10] se baseia nos conceitos dos protocolos de Steiner [26], e utiliza $n$ rodadas para estabelecer uma chave entre um grupo de $n$ usuários. O primeiro trabalho de Bresson [10] mostra um protocolo estático (número de participantes fixo) que é seguro sob a suposição do DDH.

O protocolo é executado em dois estágios sobre o grupo de participantes, que estão dispostos na forma de um anel lógico. O funcionamento é similar ao protocolo IKA.1 [26], como pode ser visto nas figuras 12 e 13 (supondo quatro participantes), mas Bresson [10] não utiliza protocolos auxiliares (para tratamento de adição e exclusão de participantes). Por outro lado, Steiner [26] não utiliza um modelo formal de segurança.

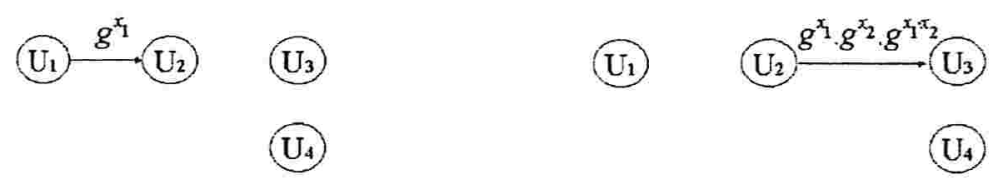

$\begin{array}{ll}\text { (a) 1oestágio, 1a rodada } & \text { (b) 10estágio, } 2^{\mathrm{a}} \text { rodada }\end{array}$

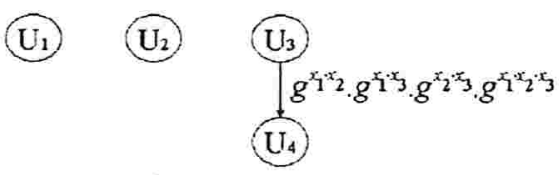

(c) loestágio, 3a rodada

Figura 12: Bresson - Rodadas do $1^{\circ}$ Estágio 


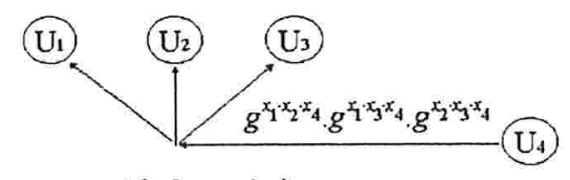

(d) 2oestágio

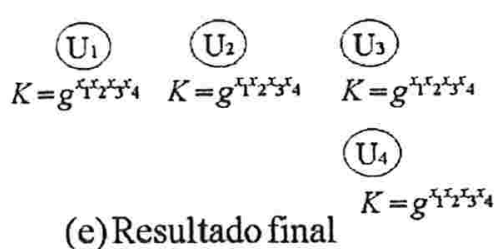

(e) Resultado final

Figura 13: Bresson - $2^{o}$ Estágio e Resultado final

Apesar de seu protocolo possuir algumas desvantagens, como a execução do protocolo em $n$ rodadas, e também a necessidade de $\mathrm{O}(\mathrm{n})$ transmissões entre os participantes e $\mathrm{O}(\mathrm{n})$ exponenciações, Bresson [10] contribuiu para trabalhos futuros com seu modelo formal de segurança, que teve influência, por exemplo, nos estudos de Katz e Yung [20].

\subsection{Tabela comparativa}

A tabela 1 mostra o desempenho dos protocolos citados neste capítulo, com relação ao número de rodadas, passos de comunicação ${ }^{6}$, operações de exponenciação e número de participantes.

\begin{tabular}{|c|c|c|c|c|}
\hline & Rodadas & Passos de Comunic. & Oper. de Expon. & Particip. \\
\hline Ingemarsson & $n-1$ & $n$ & $O(n)$ & $n$ \\
\hline Burmester e Desmedt & 2 & $O(n)$ & $O(n)$ & $n$ \\
\hline Steiner & $O(n)$ & $O(n)$ & $O(n)$ & $n$ \\
\hline Bellare & 3 & $O(1)$ & $O(1)$ & 3 \\
\hline Bresson & $n$ & $O(n)$ & $O(n)$ & $n$ \\
\hline Katz e Yung & 3 & $O(1)$ & $O(1)$ & $n$ \\
\hline
\end{tabular}

Tabela 1: Tabela comparativa dos protocolos

A última linha da tabela refere-se ao trabalho de Katz e Yung [20], que será explicado mais adiante. Mas, apenas com as informações acima, já é possível notar um melhor

\footnotetext{
${ }^{6} \mathrm{~A}$ transmissāo dos dados é feita de forma similar a um esquema de broadcast, ocasionando assim um relevante tráfego na rede, sendo considerado então, para efeito de análise, apenas os passos de comunicação
} 
desempenho deste protocolo em relação aos demais. O protocolo de Bellare [4] chega a possuir o mesmo desempenho, no entanto, é limitado em três participantes. 


\section{O Modelo de segurança}

O modelo de segurança utilizado para o desenvolvimento do protocolo de Katz e Yung [20] é baseado no padrão de Bresson [10] , que foi utilizado por ele em um projeto de um protocolo para dois participantes, e que tem sido amplamente utilizado para a análise de protocolos de estabelecimento de chaves de grupo. Abaixo estão citados os principais conceitos que são utilizados neste trabalho.

\subsection{Considerações iniciais}

Supõe-se, por simplicidade, um tamanho fixo para o conjunto de participantes $P$, onde $P=U_{1}, \ldots, U_{l}$. Qualquer subconjunto de $P$ pode decidir por estabelecer uma chave de sessão, sendo que estes subconjuntos podem possuir tamanhos e participantes diferentes. Antes de se estabelecer uma chave de sessão, o protocolo executa primeiramente uma fase de inicialização, durante a qual cada participante $U$ pertencente a $P$ executa um algoritmo $G\left(1^{k}\right)$ para gerar um par de chaves pública/privada $\left(P K_{U}, S K_{U}\right)$. Cada participante $U$ armazena $S K_{U}$, e o vetor $\left\langle P K_{i}\right\rangle_{1 \leq i \leq|P|}$ é conhecido por todos participantes (e é também conhecido pelo adversário).

\subsection{Modelo do Adversário}

No mundo real, um protocolo determina como que seus participantes se comportarão para responder aos sinais (mensagens) de seu ambiente. Neste modelo, estes sinais são enviados pelo adversário. Cada participante pode executar o protocolo múltiplas vezes com diferentes parceiros; isto é modelado para permitir a cada participante um número ilimitado de instâncias/solicitações com as quais é executado o protocolo. A instância $i$ do usuário $U$ é definida como sendo $\Pi_{U}^{i}$. Uma dada instância pode ser utilizada apenas uma vez. Cada instância está relacionada com as seguintes variáveis:

- $a c c_{U}^{i}$ : utilizada para a verificação de uma mensagem recebida por uma instância, indicando se a execução do protocolo deverá ou não ser abortada (maiores detalhes no capítulo 5).

- sid $d_{U}^{i}$ : identificador da sessão da instância $\Pi_{U}^{i}$, na qual é atribuída a concatenação de todas as mensagens enviadas e recebidas por $\Pi_{U}^{i}$ durante a sua execução. 
- $p i d_{U}^{i}$ : identificador do parceiro da instância $\Pi_{U}^{i}$, contém as identidades dos participantes do grupo com quem $\Pi_{U}^{i}$ pretende estabelecer uma chave de sessão, incluindo o próprio $U$.

- $s k_{U}^{i}$ : armazena o valor da chave de sessão, objetivo principal do protocolo.

Supõe-se que o adversário tem o controle total da comunicação na rede. Uma interação de um adversário com os participantes da rede (mais especificamente, com as várias instâncias) é modelado pelas funções (ou consultas) a seguir.

\subsubsection{Funções do Modelo do Adversário:}

- $\operatorname{Send}(U, i, M)$ : Envia a mensagem $M$ para a instância $\Pi_{U}^{i}$, e mostra a resposta gerada por esta instância. É permitido ao adversário a solicitação de uma nova instância $\Pi_{U}^{i}$ para iniciar o protocolo com os parceiros $U_{2}, \ldots, U_{n}$ através da chamada $\operatorname{Send}\left(U, i,<U_{2}, \ldots, U_{n}>\right)$.

- Execute $\left(U_{1}, \ldots, U_{n}\right)$ : Faz a execução do protocolo para as instâncias novas dos participantes $U_{1}, \ldots, U_{n}$ pertencente a $P$ e retorna a transcrição da execução.

- Reveal $(U, i)$ : Mostra a chave de sessão $s k_{U}^{i}$.

- Corrupt $(U)$ : Mostra a chave secreta de longo-período ${ }^{7} S K_{U}$ do participante $U$.

- Test $(U, i)$ : Esta consulta é permitida apenas uma vez (por definição de Bresson $[6,10])$, a qualquer momento, durante a execução do adversário. É gerado um bit $b$ aleatório; se $b=1$, o adversário recebe a $s k_{U}^{i}$, e se $b=0$ o adversário recebe uma chave de sessão aleatória.

Para um adversário passivo é dado acesso ao Execute, Reveal, Corrupt, e Test, enquanto que para um adversário ativo é dado acesso também ao Send.

\subsection{Sociedade}

A sociedade é definida através dos ID's de sessões e através dos ID's de parceiros. As instâncias $\Pi_{U}^{i}$ e $\Pi_{U}^{j}$ são parceiras ou sócias se (1)pid $d_{U}^{i}=p i d_{U}^{j}$ e (2)sid $d_{U}^{i}=s i d_{U}^{j}$. A definição de sociedade usada neste documento é mais simples que a definição de Bresson [10], pois todas as mensagens são enviadas para todos os outros membros do grupo que participam no protocolo.

\footnotetext{
${ }^{7}$ Chave secreta de longo-período: chave não atualizada pelos participantes por um tempo relativamente grande, durante uma comunicação.
} 


\subsection{Freshness}

A definição de "freshness" (nova) está relacionada ao conceito de sigilo no futuro. Uma instância $\Pi_{U}^{i}$ é nova a menos que uma das condições seguintes seja verdadeira ( $\Pi_{U}^{j}$ é qualquer instância parceira de $\left.\Pi_{U}^{i}\right):(1)$ em algum ponto, o adversário consulta Reveal $(U, i)$ ou Reveal $(U, j)$; ou (2) uma consulta $\operatorname{Corrupt}(V)$ (com o $V$ pertencente a pid $d_{U}^{i}$ ) foi feita antes de um $\operatorname{Send}(U, i, *)$ ou $\operatorname{Send}(U, j, *)$.

\subsection{Definições de Segurança}

Seja o evento Succ, que ocorre se o adversário executar Test em uma instância nova e adivinhar corretamente o valor do bit $b$. A vantagem de um adversário $A$ ao atacar o protocolo $P$ é definida, segundo Bresson [10], como sendo $A d v_{A, P}(k)=|2 \cdot \operatorname{Prob}[S u c c]-1|$. O protocolo $P$ é um protocolo de estabelecimento de chaves de grupo seguro se o mesmo fornecer proteção contra um adversário passivo, e um protocolo $P$ de estabelecimento de chaves de grupo autenticadas é seguro se o mesmo proteger contra um adversário ativo; em ambos os casos, um protocolo é seguro se $A d v_{A, P}(k)$ for desprezível. Define-se como $A d v_{P}^{K E-f s}\left(t, q_{e x}\right)$ como sendo a vantagem máxima de qualquer adversário passivo atacando $P$, executando em tempo $t$ e fazendo $q_{e x}$ chamadas de Execute. Similarmente, definese $A d v_{P}^{A K E-f s}\left(t, q_{e x}, q_{s}\right)$ como sendo a vantagem máxima de qualquer adversário ativo atacando $P$, executando em tempo $t$ e fazendo $q_{e} x$ chamadas de Execute e $q_{s}$ chamadas de Send.

\subsection{Protocolos sem sigilo no futuro}

O trabalho de Katz e Yung [20] tem interesse primeiramente com protocolos que tratam do sigilo no futuro; as definições acima já incorporam este requisito desde que o adversário acesse o Corrupt em cada caso. Entretanto, o compilador pode também ser aplicado para protocolos de estabelecimento de chaves de grupo que não tratam o sigilo no futuro. Para completar, define-se $A d v_{P}^{K E}\left(t, q_{e x}\right)$ e $A d v_{P}^{A K E}\left(t, q_{e x}, q_{s}\right)$ de uma forma análoga à de cima, com a exceção de que o adversário, no primeiro caso, não terá acesso ao Corrupt.

\subsection{Observações}

Embora a definição acima seja padrão para a análise de protocolos de estabelecimento de chaves de grupo, existem restrições que não são tratadas, como, por exemplo, proteção contra as pessoas mal intencionadas, ou participantes que não seguem honestamente o protocolo. Além disso, estas definições não protegem contra ataques de "negação de serviço", porque o modelo permite ao adversário recusar entregar mensagens para qualquer solicitação. 


\section{Compilador para protocolos de estabelecimento de chaves de grupo}

Neste capítulo será mostrado um compilador que transforma qualquer protocolo $P$, de estabelecimento de chaves de grupo, em um protocolo $P^{\prime}$, de estabelecimento de chaves de grupo autenticadas. Com relação a $P$, é suposto que:

- (1) Cada mensagem enviada por uma instância $\Pi_{U}^{i}$ durante execução de $\mathrm{P}$ inclui a identidade do remetente de $\mathrm{U}$ assim como um número de seqüência que começa em 1 e é incrementado cada vez que $\Pi_{U}^{i}$ envia uma mensagem (em outras palavras, a $j$-ésima mensagem enviada por uma instância $\Pi_{U}^{i}$ tem a forma $\left.U|j| m\right)$;

- (2) toda mensagem do protocolo é enviada - via links ponto-a-ponto - para todos os membros do grupo que participam da execução do protocolo (ou seja, $\Pi_{U}^{i}$ envia cada mensagem para todos os usuários em $\left.p i d_{(I)}^{i}\right)$.

Seja $\Sigma=($ Gen, Sign, Vrfy) um esquema de assinatura que é impossível de ser atacado e forjado, e seja $\operatorname{Succ}_{\Sigma}(t)$ a máxima vantagem de qualquer adversário forjar em tempo $\mathrm{t}$ uma nova mensagem/assinatura.

Dado $P$ como citado acima, o compilador constrói o protocolo $P^{\prime}$ da seguinte maneira:

- 1. Durante a fase de inicialização, cada participante $U$ pertencente a $P$ gera suas chaves de verificação/assinatura $\left(P K_{U}^{\prime}, S K_{U}^{\prime}\right)$ através da execução do gerador $\operatorname{Gen}\left(1^{k}\right)$.

- 2. Sejam $U_{1}, \ldots, U_{n}$ as identidades (em ordem lexicográfica) de usuários que desejam estabelecer uma chave comum, e $\mu=U_{1}|\ldots| U_{N}$. Cada usuário $U_{i}$ escolhe um nonce ${ }^{8}$ $r_{i}$ aleatório que pertence a $\{0,1\}^{k}$ e envia para todos na forma $U_{i}|0| r_{i}$ (note que esta mensagem inicia com o número de seqüência "0"). Depois de todos receberem a mensagem inicial das outras partes, cada instância armazena $\mu$ e $r_{1}|\ldots| r_{n}$.

- 3. Os membros do grupo agora executam $P$ com as seguintes mudanças:

Sempre que a instância $\Pi_{U}^{i}$ for transmitir para todos a informação $U|j| m$, ela assina $j|m| \mu\left|r_{1}\right| \ldots \mid r_{n}$ usando $S K^{\prime}{ }_{U}$ para obter a assinatura $\sigma$, e envia para todos $U|j| m \mid \sigma$.

\footnotetext{
${ }^{8}$ NONCE: Number Used Once. O número escolhido pelo usuário será distinto dos demais.
} 
Quando a instância $\Pi_{U}^{i}$ recebe a mensagem $V|j| m \mid \sigma$, é checado se: (1) $V$ pertence a $p i d_{U}^{i}$, (2) j é o próximo número da seqüência das mensagens de $V$, e (3) (usando $\left.P K_{V}^{\prime}\right) \sigma$ é uma assinatura correta de $V$ em $j|m| U\left|r_{1}\right| \ldots \mid r_{n}$. Se qualquer uma destas verificações estiver incorreta, $\Pi_{U}^{i}$ aborta a execução do protocolo e atribui $a c c_{U}^{i}=$ FALSE e $s k_{U}^{i}=$ NULL. Caso contrário, $\Pi_{U}^{i}$ continua através de $P$ a receber a mensagem $V|j| m$.

- 4. Cada instância não-abortada calcula a chave de sessão como em $P$.

\subsection{Teorema 1}

Teorema 1. Se $P$ é um protocolo de estabelecimento de chaves de grupo seguro (com sigilo no futuro), então $P^{\prime}$ dado pelo compilador acima é um protocolo de estabelecimento de chaves autenticadas de grupo seguro (com sigilo no futuro), onde:

$A d v_{P^{\prime}}^{A K E-f s}\left(t, q_{e x}, q_{s}\right) \leq\left(q_{e x}+q_{s}\right) \cdot A d v_{P}^{K E-f s}(t, 1)+|P| \cdot \operatorname{Succ} \Sigma(t)+\left(q_{s}^{2}+\frac{2 q_{e x} q_{s}+|P| q_{e x}{ }^{2}}{2^{k+1}}\right)$

Demonstração. Dado um adversário ativo $A^{\prime}$ atacando $P^{\prime}$, será montada uma situação de um adversário passivo $A$ atacando $P$ onde $A$ faz apenas um simples Execute; relacionando as probabilidades de sucesso de $A^{\prime}$ e $A$ obtém-se o resultado.

Antes de descrever $A$, serão definidos os eventos Forge e Repeat, e suas respectivas probabilidades de ocorrência. Seja Forge o evento que gera para $A^{\prime}$ uma nova e válida mensagem/assinatura relacionada à chave pública $P K_{U}^{\prime}$ de algum participante $U$ pertencente a $P$ antes de rodar $\operatorname{Corrupt}(U)$, e seja $\operatorname{Prob}\left[\right.$ Forge] denotado por $\operatorname{Pr}_{A^{\prime}, P}[$ Forge $]$. Usando $A^{\prime}$, é possível construir um algoritmo $F$ que forja uma assinatura respeitando o esquema de assinatura $\Sigma$ : dado uma chave pública $P K, F$ escolhe de forma aleatória um participante $U$ pertencente a $P$, sendo $P K^{\prime}{ }_{U}=P K$, e gera todas as outras chaves públicas e privadas para o sistema. $F$, então, simula as consultas de $A^{\prime}$ de uma forma natural (acessando sua assinatura quando necessário); este resultado é uma simulação perfeita a menos que $A^{\prime}$ execute o Corrupt $(U)$. Se isto ocorrer, $F$ simplesmente aborta. Por outro lado, se $A^{\prime}$ sempre gerar um novo e válido par (mensagem/assinatura) respeitando $P K^{\prime}{ }_{U}=P K$, então $F$ gera este par como sua falsificação. A probabilidade de sucesso de $F$ é exatamente $\operatorname{Prob}[F$ orge $] /|P|$; isto imediatamente implica que

$$
\operatorname{Prob}[\text { Forge }] \leq|P| \cdot \operatorname{Succ}_{\Sigma}(t)
$$

Seja Repeat um evento que é utilizado duas vezes por um participante em particular; ou seja, existe um participante $U \in P$ e $i, j(i \neq j)$ tal que o nonce utilizado pela instância $\Pi_{U}^{i}$ é igual ao nonce utilizado pela instância $\Pi_{U I}^{j}$. O "Lema do aniversário" mostra que 
Prob $[$ Repeat $] \leq \frac{|P|\left(q_{e x}+q_{s}\right)^{2}}{2^{k+1}}$, desde que cada $U \epsilon P$ escolha mais de $\left(q_{e x}+q_{s}\right)$ nonces de $\{0,1\}^{k}$. Uma análise mais cuidadosa de fato mostra que

$$
\operatorname{Prob}[\text { Repeat }] \leq \frac{q_{s}^{2}+2 q_{e x} q_{s}+|P| q_{e x}^{2}}{2^{k+1}}
$$

Baseado nestas definições acima, é construído o adversário passivo $A$ atacando o protocolo $P$. Sabe-se que, como parte da atribuição inicial, ao adversário são dadas as chaves públicas $\left\{P K_{U}\right\}_{\left\{U_{\epsilon} P\right\}}$ se algo estiver definido como parte do protocolo $P$. Inicialmente, temos $A$ obtendo todas as chaves secretas $\left\{S K_{U}\right\}_{\left\{U_{\epsilon} P\right\}}$ usando múltiplos Corrupt's . Em seguida, $A$ executa $G e n\left(1^{k}\right)$ para gerar as chaves $\left(P K_{U}^{\prime}{ }_{U}, S K^{\prime}{ }_{U}\right)$ para cada $U \epsilon P$; o conjunto de chaves públicas $\left\{P K_{U}^{\prime}, P K_{U}\right\}_{U \epsilon}$ é então dado para $A^{\prime}$. Sendo assim, agora $A$ executa $A^{\prime}$, simulando as consultas de $A^{\prime}$ conforme descrito baixo.

Seja $Q=q_{e x}+q_{s}$ o número total de Execute's e Send's chamados por $A^{\prime}$. A escolhe um $\alpha \in 1, \ldots, Q$ representando uma sugestão para que uma chamada Send/Execute de $A^{\prime}$ ative a instância quando $A^{\prime}$ executar Test. . Para a $\alpha$-ésima sugestão de $A^{\prime}$, têmse $A$ respondendo através de um Execute, obtendo uma cópia de uma execução de $P$, modificando esta cópia para obter uma cópia válida para $P^{\prime}$, e então retornando uma resposta apropriada para $A^{\prime}$. Para qualquer outra consulta Send/Execute de $A^{\prime}$, têm-se $A$ respondendo diretamente através da execução do protocolo $P^{\prime}$; note que $A$ pode fazer isto desde que tenha as chaves secretas para todos os participantes. $A$ aborta e gera um bit aleatório se. sua sugestão estiver incorreta, ou se os eventos Forge ou Repeat ocorrerem. Por outro lado, $A$ gera qualquer bit que é gerado por $A^{\prime}$.

Seja Good $=\overline{\text { Forge }} \wedge \overline{\text { Repeat }}$ e $B a d=\overline{\text { Good }}$, e relembrando que $Q=q_{e x}+q_{s}$ representa o número total de consultas Send/Execute executadas por $A^{\prime}$, calcula-se então a seguinte probabilidade:

$2 \cdot \mid \operatorname{Pr}_{A, P}[$ Succ $]-\frac{1}{2} \mid=$

$=2 \cdot \mid \operatorname{Pr}_{A^{\prime}, P^{\prime}}[$ Succ $\wedge$ Guess $\wedge$ Good $]+\frac{1}{2} \operatorname{Pr}_{A^{\prime}, P^{\prime}}[\overline{\text { Guess }} \vee$ Bad $]-\frac{1}{2} \mid=$

$=2 \cdot \mid \frac{1}{Q} \operatorname{Pr}_{A^{\prime}, P^{\prime}}[$ Succ $\wedge$ Good $]+\frac{1}{2} \operatorname{Pr}_{A^{\prime}, P^{\prime}}[$ Bad $]+\frac{1}{2} \operatorname{Prob}[\overline{\text { Guess }} \mid \overline{B a d}] \operatorname{Pr}_{A^{\prime}, P^{\prime}}[$ Bad $]-\frac{1}{2}=$

$=2 \cdot \mid \frac{1}{Q} \operatorname{Pr}_{A^{\prime}, P^{\prime}}[S u c c]-\frac{1}{Q} \operatorname{Pr}_{A^{\prime}, P^{\prime}}[\operatorname{Succ} \wedge B a d]+\frac{1}{2} \operatorname{Pr}_{A^{\prime}, P^{\prime}}[B a d]+\frac{1}{2}\left(\frac{Q-1}{Q}\right)\left(1-\operatorname{Pr}_{A^{\prime}, P^{\prime}}[B a d]\right)-$ $\frac{1}{2} \mid=$

$\geq \frac{1}{Q} \cdot\left|2 \cdot \operatorname{Pr}_{A^{\prime}, P^{\prime}}[S u c c]-1\right|-\frac{1}{Q} \mid 2 \cdot \operatorname{Pr}_{A^{\prime}, P^{\prime}}[\operatorname{Succ} \wedge B a d]-\operatorname{Pr}_{A^{\prime}, P^{\prime}}[$ Badd $] \mid$.

Desde que, por suposição, $2 \mid \operatorname{Pr}_{A, P}[S u c c]-\frac{1}{2} \leq Q \cdot A d v_{P}^{K E-f s}(t, 1)$, temos:

$$
A d v_{P^{\prime}}^{A K E-f s}\left(t, q_{e x}, q_{s}\right) \leq Q \cdot A d v_{P}^{K E-f s}(t, 1)+\operatorname{Pr}_{A^{\prime}, P^{\prime}}[\text { Forge }]+\operatorname{Prob}[\text { Repeat }]
$$


obtendo assim a declaração do teorema.

O teorema acima é um resultado genérico da aplicação do compilador sobre o protocolo arbitrário de estabelecimento de chaves de grupo $P$. Para protocolos específicos, uma melhor análise de segurança, mais precisa inclusive, pode ser obtida. Além disso, o compilador acima também é aplicado em protocolos de estabelecimento de chaves que não tratam do sigilo no futuro, conforme definição do teorema abaixo.

\subsection{Teorema 2}

Teorema 2. Se $P$ é um protocolo seguro de estabelecimento de chaves de grupo (sem sigilo no futuro), então $P^{\prime}$ dado pelo compilador acima é um protocolo autenticado e seguro de estabelecimento de chaves de grupo (sem sigilo no futuro). Ou seja:

$A d v_{P^{\prime}}^{A K E}\left(t, q_{e x}, q_{s}\right) \leq A d v_{P}^{K E}\left(t, q_{e x}+q_{s}\right)+|P| \cdot \operatorname{Succ}_{\Sigma}(t)+\frac{q_{s}{ }^{2}+2 q_{e x} q_{s}+|P| q_{e x}{ }^{2}}{2^{k+1}}$

A demonstração deste teorema é bem similar à do Teorema 1. Ela encontra-se na página 14 do artigo "Scalable Protocols for Authenticated Group Key Exchange", agosto de 2003, de Jonathan Katz e Moti Yung [20]. 


\section{$6 \mathrm{Um}$ protocolo de estabelecimento de chaves de grupo}

Seja $G$ qualquer grupo cíclico finito de uma seqüência de primos $q$ (por exemplo, seja $p, q$ primos, tal que $p=\beta q+1$, onde $\beta$ é um fator de distância entre $p$ e $q$; considera-se como sendo $G$ o sub-grupo de ordem $q$ em $Z_{p}{ }^{*}$ ), e seja $g$ um gerador arbitrário de $G$. Define-se $A d v_{G}{ }^{d d h}(t)$ como sendo o valor máximo entre todos os adversários $A$ rodando em tempo $t$, de:

$$
\left|\operatorname{Prob}\left[x, y \leftarrow Z_{q}: A\left(g, g^{x}, g^{y}, g^{x y}\right)=1\right]-\operatorname{Prob}\left[x, y, z \leftarrow Z_{q}: A\left(g, g^{x}, g^{y}, g^{z}\right)=1\right]\right|
$$

Considera-se que a suposição de DDH é válida em $G$ se $A d v_{G}^{d d h}(t)$ é razoavelmente "pequena" para valores de $t$.

Em seguida será descrito um eficiente protocolo de estabelecimento de chaves de grupo de duas rodadas cuja segurança é baseada na suposição de DDH em $G$. Aplicando o compilador do capítulo anterior neste protocolo, obtém-se um eficiente protocolo de estabelecimento de chaves de grupo autenticada, contendo três rodadas. Este protocolo é praticamente o mesmo desenvolvido por Burmester e Desmedt [12], exceto quando supõe-se que $G$ é um grupo cíclico finito de uma seqüência de primos, os quais validam a suposição de DDH.

Como exigência do compilador do capítulo anterior, este protocolo garante que os participantes enviam todas as mensagens para todos os membros do grupo via multi-ponto. Neste protocolo $P$, não são requisitadas chaves públicas mas, por simplicidade, supõe-se que existe um grupo $G$ e um gerador $g \in G$ conhecido por toda a rede. Percebe-se que esta suposição pode evitar um gasto adicional de uma rodada em que o primeiro participante simplesmente gera e transmite esses valores. Quando $n$ participantes $U_{1}, \ldots, U_{n}$ desejam gerar uma chave de sessão, eles seguem o procedimento abaixo (os índices são tomados do módulo $n$ de modo que o participante $U_{0}$ é $U_{n}$ e o participante $U_{n+1}$ é $U_{1}$ ):

- Rodada 1. Cada participante $U_{i}$ escolhe um aleatório $r_{i} \in Z_{q}$ e transmite $z_{i}=g^{r_{i}}$.

- Rodada 2. Cada participante $U_{i}$ transmite $X_{i}=\left(\frac{z_{i+1}}{z_{i-1}}\right)^{r_{i}}$. 
- Geração da Chave. Cada participante $U_{i}$ calcula sua chave de sessão da seguinte maneira:

$$
K_{i}=\left(z_{i-1}\right)^{n r_{i}} \cdot X_{i}^{n-1} \cdot X_{i+1}^{n-2} \cdot \ldots \cdot X_{i-2}
$$

Percebe-se que todos os participantes obtém a mesma chave de sessão $g^{r_{1} r_{2}+r_{2} r_{3}+\ldots+r_{n} r_{1}}$. As identidades do remetente e os números da seqüência não são incluídos explicitamente como é requerido pelo compilador do capítulo anterior; entretanto, é fácil de se modificar o protocolo para incluir esta informação. Cada participante calcula apenas três exponenciações, uma vez que, na prática, $n$ é muito menor que $q$.

As figuras 14,15 e 16 mostram o funcionamento do protocolo conforme o procedimento citado acima:

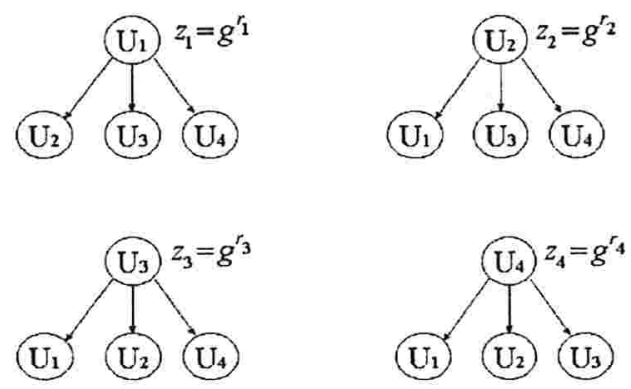

Figura 14: Katz e Yung - $1^{a}$ Rodada

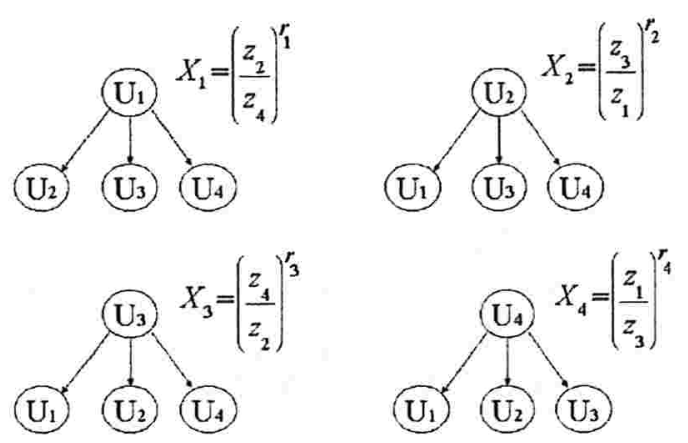

Figura 15: Katz e Yung - $2^{a}$ Rodada

\subsection{Teorema 3}

Teorema 3. O protocolo $P$ é um protocolo seguro de estabelecimento de chaves de grupo que trata o sigilo no futuro. Ou seja: 


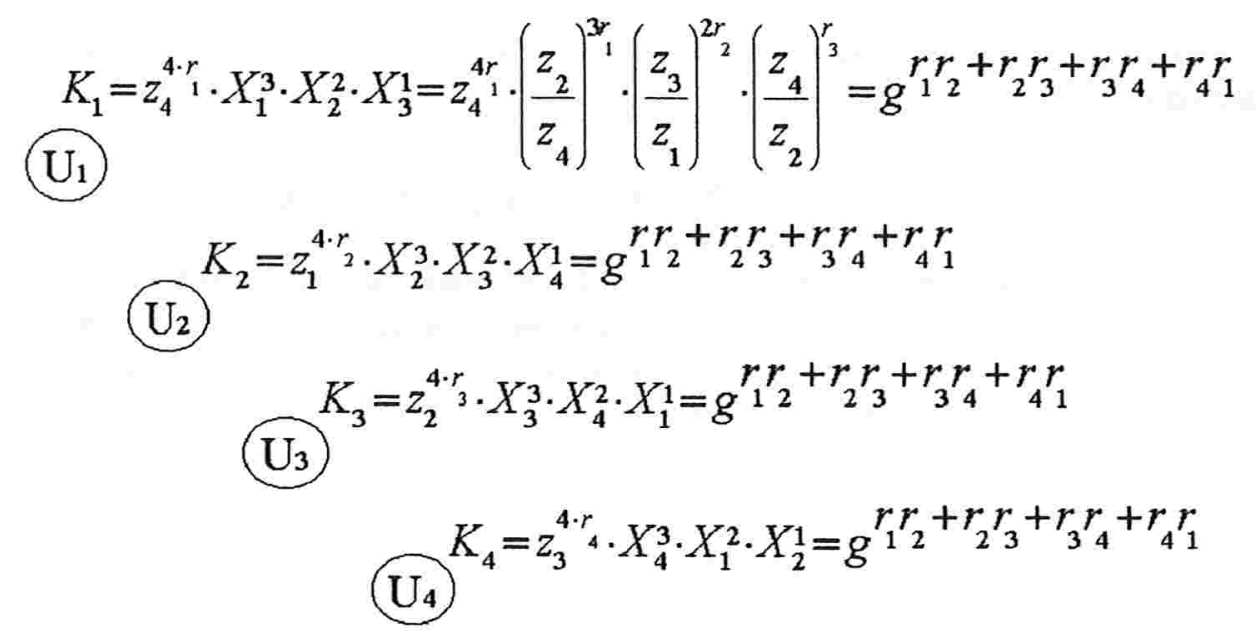

Figura 16: Katz e Yung - Chave de sessão obtida

$$
A d v_{P}^{K E-f s}\left(t, q_{e x}\right) \leq 4 \cdot A d v_{G}^{d d h}(t)
$$

Demonstração. Seja $\varepsilon(t)=A d v_{G}^{d d h}(t)$. Por simplicidade, será mostrada uma demonstração para o caso em que um adversário executa apenas um único Execute, e obtendo-se $A d v_{P}^{K E-f s}(t, 1) \leq 2|P| \varepsilon(t)$. Isto é o suficiente para se aplicar o Teorema 1, e também permite que $A d v_{P}^{K \bar{E}-f s}\left(t, q_{e x}\right) \cdot \leq 2 q_{e x}|P|(t)$.

Supondo, então, que um adversário $\bar{A}$ está executando um simples Execute $\left(U_{1}, \ldots, U_{n}\right)$. A distribuição de $T$ e o resultado da chave de sessão $s k$ é dado por:

$$
\text { Real } \stackrel{\text { def }}{=}\left[\begin{array}{cc}
r_{1}, \ldots, r_{n} \leftarrow Z_{q} ; z_{1}=g^{r_{1}}, z_{2}=g^{r_{2}}, \ldots, z_{n}=g^{r_{n}} & \\
X_{1}=\frac{g^{r_{2} r_{1}}}{g^{r_{1} n_{1}}}, X_{2}=\frac{g^{r_{3} r_{2}}}{g^{r_{1} r_{2}}, \ldots, X_{n}=\frac{g^{r_{1} r_{n}}}{g^{r_{n-1} r_{n}}}} & :(T, s k) \\
T=\left(z_{1}, \ldots, z_{n}, X_{1}, \ldots, X_{n}\right) & \\
s k=\left(g^{r_{1} r_{2}}\right)^{n} \cdot\left(X_{2}\right)^{n-1} \ldots X_{n} &
\end{array}\right]
$$

Considerando agora a seguinte distribuição modificada:

$$
\text { Fake }_{1} \stackrel{\text { def }}{=}\left[\begin{array}{cc}
w_{1,2}, r_{1}, \ldots, r_{n} \leftarrow Z_{q} ; z_{1}=g^{r_{1}}, z_{2}=g^{r_{2}}, \ldots, z_{n}=g^{r_{n}} & \\
X_{1}=\frac{g^{w_{1,2}}}{\left(g^{\left.g_{1}\right)^{r_{n}}}, X_{2}=\frac{\left(g^{r_{2}}\right)^{r_{3}}}{g^{w_{1}, 2}}, \ldots, X_{n}=\frac{\left(g^{r_{1}}\right)^{r_{n}}}{g^{r_{n}-1^{r_{n}}}}\right.} \\
T=\left(z_{1}, \ldots, z_{n}, X_{1}, \ldots, X_{n}\right) \\
s k=\left(g^{w_{1,2}}\right)^{n} \cdot\left(X_{2}\right)^{n-1} \ldots X_{n}
\end{array}\right]
$$


Baseando-se na definição do início deste capítulo, para qualquer algoritmo $A^{\prime}$ executado em tempo $t$, tem-se que:

$\mid \operatorname{Prob}\left[(T, s k) \leftarrow\right.$ Real $\left.: A^{\prime}(T, s k)=1\right]-\operatorname{Prob}\left[(T, s k) \leftarrow F_{a k e}: A^{\prime}(T, s k)=1\right] \mid \leq \varepsilon(t)$

Em seguida será acrescentada a seguinte modificação:

$$
\text { Fake }_{2} \stackrel{\text { def }}{=}\left[\begin{array}{cc}
w_{1,2}, w_{2,3}, r_{1}, \ldots, r_{n} \leftarrow Z_{q} ; z_{1}=g^{r_{1}}, z_{2}=g^{r_{2}}, \ldots, z_{n}=g^{r_{n}} & \\
X_{1}=\frac{g^{w_{1}, 2}}{g^{r_{1} r_{n}}}, X_{2}=\frac{g^{w_{2}, w_{3}}}{g^{w_{1,2}}}, \ldots, X_{n}=\frac{g^{r_{1} r_{n}}}{g^{r_{n} 1^{r_{n}}}} & :(T, s k) \\
T=\left(z_{1}, \ldots, z_{n}, X_{1}, \ldots, X_{n}\right) & \\
s k=\left(g^{w_{1,2}}\right)^{n} \cdot\left(X_{2}\right)^{n-1} \ldots X_{n}
\end{array}\right]
$$

onde, outra vez, a definição inicial mostra que:

$\mid \operatorname{Prob}\left[(T, s k) \leftarrow\right.$ Fake $\left._{1}: A^{\prime}(T, s k)=1\right]-\operatorname{Prob}\left[(T, s k) \leftarrow F a k e_{2}: A^{\prime}(T, s k)=1\right] \mid \leq \varepsilon(t)$.

Seguindo o raciocínio acima, obtem-se a seguinte distribuição:

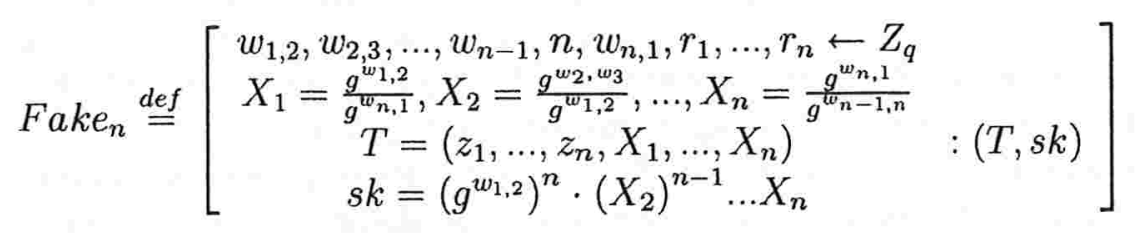

tal que, para qualquer $A^{\prime}$ executando em tempo $t$ obtém-se:

$\left|\operatorname{Prob}\left[(T, s k) \leftarrow \operatorname{Real}: A^{\prime}(T, s k)=1\right]-\operatorname{Prob}\left[(T, s k) \leftarrow F a k e_{n}: A^{\prime}(T, s k)=1\right]\right| \leq n \cdot \varepsilon(t)(1)$

Em Fake ${ }_{n}$, os valores $w_{1,2}, \ldots, w_{n, 1}$ são restritos por $T$ de acordo com as seguintes $n$ equações: 


$$
\begin{gathered}
\log _{g} X_{1}=w_{1,2}-w_{n, 1} \\
\vdots \\
\log _{g} X_{n}=w_{n, 1}-w_{n-1, n}
\end{gathered}
$$

das quais apenas $n-1$ destas são linearmente independentes. Além disso, sk pode ser expresso por $g^{w_{1,2}+w_{2,3}+\ldots+w_{n, 1}}$; equivalentemente, tem-se que:

$$
\log _{g} s k=w_{1,2}+w_{2,3}+\ldots+w_{n, 1}
$$

Desde que a equação final seja linearmente independente do conjunto de equações acima, o valor de $s k$ é independente de $T$. Isto implica que, para qualquer adversário $A$ :

$$
\operatorname{Prob}\left[\left(T, s k_{0}\right) \leftarrow F a k e_{n} ; s k_{1} \leftarrow G ; b \leftarrow 0,1: A\left(T, s k_{b}\right)=b\right]=\frac{1}{2}
$$

que, combinada com a Equação (1) e o fato de que $n \leq|P|$, permite que o resultado desejado seja $A d v_{P}^{K E-f s}(t, 1) \leq 2|P| \varepsilon(t)$.

\subsection{Exemplo}

A seguir, é mostrado um exemplo prático da aplicação do protocolo citado neste capítulo. Seja uma empresa $F_{1}$ qualquer, que pretende fazer o fechamento de estoque de todas as suas filiais $F_{2}, F_{3}$ e $F_{4}$, mas que, para isto, precisa se comunicar com elas através de uma rede pública totalmente insegura. A empresa sede e suas filiais compartilham suas informações através de um algoritmo de criptografia $C$ de chave secreta $s k$, que é totalmente seguro contra invasores. Mas, para que todos possam se comunicar, é preciso estabelecer uma chave secreta, sem correr o risco de algum intruso descobrí-la. Para isto, $F_{1}$ e suas filiais utilizam o protocolo $P$, de estabelecimento de chaves de grupo de Katz e Yung [20], que estabelece uma chave de sessão secreta conforme as figuras 17, 18 e $19\left(F_{1}\right.$, $F_{2}, F_{3}$ e $F_{4}$ obtiveram na $1^{a}$ rodada os números aleatórios $r_{1}, r_{2}, r_{3}$ e $r_{4}$ respectivamente):

Lembrando que, a cada rodada, toda mensagem é assinada antes de ser enviada por um usuário, e para cada mensagem recebida é verificada esta assinatura, garantindo a segurança do sistema contra intrusos.

Ao final de sua execução, $P$ estabeleceu para $F_{1}, F_{2}, F_{3}$ e $F_{4}$ a chave $K_{4}=2^{24}$, que será utilizada em $C$ para a estabelecimento de informações de fechamento de estoque, de forma segura. 

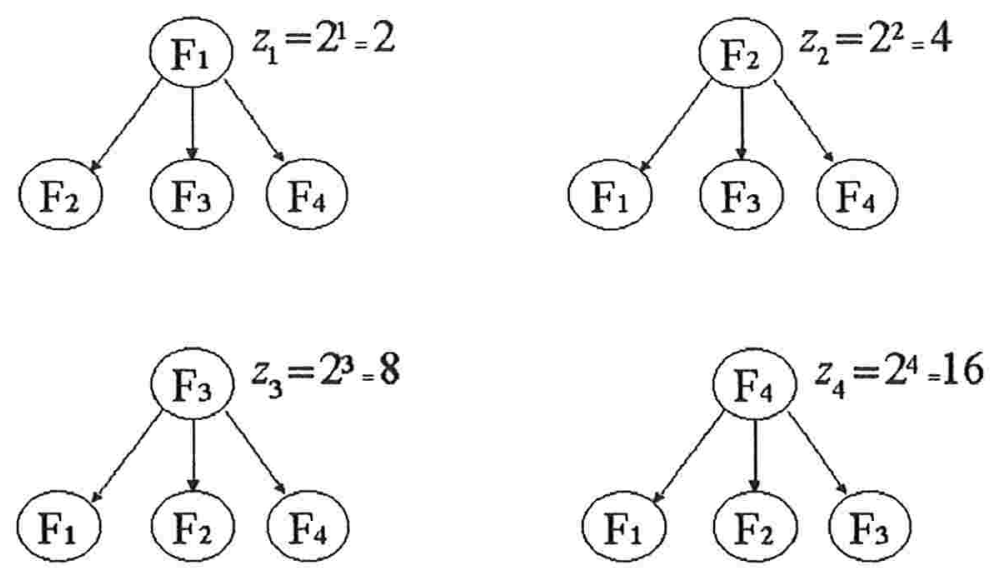

Figura 17: Exemplo - $1^{a}$ Rodada
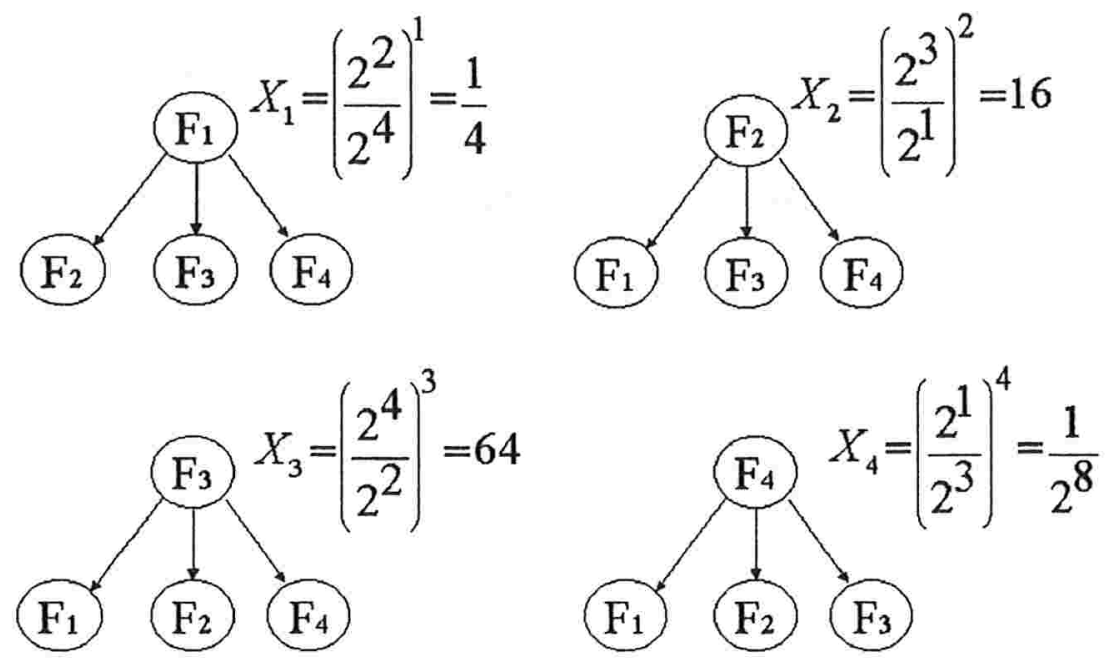

Figura 18: Exemplo - $2^{a}$ Rodada 


$$
\begin{aligned}
& \text { (F1 } K_{4}=Z_{4}^{4 \cdot S} \cdot X_{1}^{3} \cdot X_{2}^{2} \cdot X_{3}^{1}=2^{16} \cdot\left(\frac{1}{4}\right)^{3} \cdot(16)^{2} \cdot(64)^{1}=2^{24} \\
& \text { (F2) } K_{4}=Z_{1}^{4 \cdot S_{2}} \cdot X_{2}^{3} \cdot X_{3}^{2} \cdot X_{4}^{1}=2^{8} \cdot 16^{3} \cdot 64^{2} \cdot \frac{1}{2^{8}}=2^{24} \\
& K_{4}=Z_{2}^{4 \cdot S_{3}} \cdot X_{3}^{3} \cdot X_{4}^{2} \cdot X_{1}^{1}=2^{24} \cdot 2^{18} \cdot \frac{1}{2^{16}} \cdot \frac{1}{2^{2}}=2^{24} \\
& \text { F } \\
& K_{4}=Z_{3}^{4 \cdot S} \cdot X_{4}^{3} \cdot X_{1}^{2} \cdot X_{2}^{1}=2^{48} \cdot \frac{1}{2^{24}} \cdot \frac{1}{2^{4}} \cdot 2^{4}=2^{24}
\end{aligned}
$$

Figura 19: Exemplo - Chave de sessão obtida 


\section{Ferramentas e metodologias utilizadas}

Para a implementação do protocolo, foram utilizadas algumas ferramentas que auxiliaram no desenvolvimento dos algoritmos, e que contribuíram para uma melhor análise de desempenho.

Será descrita, inicialmente, a plataforma e a linguagem de programação utilizada, juntamente com a descrição dos dados de entrada e saída. Por fim, serão citadas as bibliotecas MPI e GMP, que são ferramentas para comunicação e suporte de números grandes, respectivamente.

\subsection{Hardware e Dados de Entrada e Saída}

A implementação e os resultados apresentados nos capítulos seguintes foram obtidos através de um computador AMD Duron $1200 \mathrm{MHz}$, com $128 \mathrm{Mb}$ de memória RAM, executando o sistema operacional Windows Me. Foi utilizada a linguagem ANSI C para o desenvolvimento dos algoritmos, com o compilador LCC Win32 versão 3.3 (para o programa auxiliar, que faz a visualização dos resultados obtidos pelo protocolo, foi utilizada a linguagem $\mathrm{C}++$, com o compilador $\mathrm{C}++$ Builder versão 6.0).

Como parâmetros de entrada, temos o tipo de comunicação (local ou em rede) e o número de processos participantes.

Para as informações de saída, além da chave de sessão obtida, é gerado um arquivo texto com a chave sessão gerada para cada processo e um outro arquivo texto com dados estatísticos levantados durante a execução que poderão ser usados em algum programa que visualize graficamente estas informações. Estes dados estatísticos (Quantidade de Mensagens, exponenciações e tempo de execução) são mostrados em tela ao final da execução do protocolo, juntamente com a chave de sessão obtida.

\subsubsection{Tamanho dos Módulos}

Para que se pudesse obter resultados mais expressivos durante a análise do protocolo implementado, foi fixado um módulo com um valor suficientemente grande para a execução do protocolo com até cinqüenta e cinco participantes. O tamanho do módulo a ser utilizado pode ser facilmente alterado para que se possa obter chaves de sessão de, por exemplo, 768, 1024 e 2048 bits, para uma aplicação mais específica deste protocolo. 


\subsubsection{Medidas de desempenho}

Para que se pudesse analisar o desempenho do protocolo de Katz e Yung, foram feitas medidas em cima da quantidade de mensagens trocadas entre os processos, do número de exponenciações, e também do tempo de execução, embora este último esteja relacionado com o desempenho do equipamento utilizado (processador, memória e Sistema Operacional), que influenciam diretamente no mesmo. Além disso, deve se levar em consideração o desempenho das bibliotecas utilizadas (MPI e GMP), que também são fatores que influenciaram diretamente nas medidas obtidas.

\subsection{MPI - Message Passing Interface}

O modelo de Message Passing é um conjunto de processos que possuem acesso à memória local. As informações são enviadas da memória local do processo para a memória local do processo remoto.

A comunicação dos processos é baseada no envio e recebimento de mensagens.

A transferência dos dados entre os processos requer operações de cooperação entre cada processo de forma que uma operação de envio consiga casar com uma operação de recebimento.

O MPI (Message Passing Interface) é uma biblioteca de Message Passing desenvolvida para ambientes de memória distribuída, máquinas paralelas massivas, NOWs (network of workstations) e redes heterogêneas.

O MPI define um conjunto de rotinas para facilitar a comunicação (troca de dados e sincronização) entre processos paralelos.

A biblioteca MPI é portável para qualquer arquitetura, tem aproximadamente 125 funções para programação e ferramentas para se analisar a performance. Ela possui rotinas para programas em Fortran 77 e ANSI C, portanto pode ser usada também para Fortran 90 e $\mathrm{C}++$. Os programas são compilados e linkados à biblioteca MPI.

Para a implementação do protocolo foi utilizada a WMPI versão 1.1, que é uma biblioteca padrão de Message Passing [22] para plataformas Windows.

\subsection{GMP - GNU Multiple Precision Arithmetic}

A biblioteca GMP, desenvolvida pela GNU Lesser General Public License [18], permite que sejam implementados algoritmos em $\mathrm{C} / \mathrm{C}++$ que exigem ou que necessitem trabalhar com números grandes, ou seja, módulos de 768, 1024 e 2048 bits, por exemplo. Esta biblioteca foi escolhida para ser utilizada na implementação pelo fato de possuir as seguintes características:

- (1) Possui distribuição gratuita pela GNU Lesser General Public Licence [18];

- (2) Permite a utilização de números de tamanhos ilimitados (ou limitados somente pela quantidade de memória disponível na máquina); 
- (3) Possui uma grande quantidade de funções, entre elas, funções de teoria de números;

- (4) As funções apresentam bom desempenho tanto para números pequenos quanto para números grandes;

- (5) Muito utilizadas em aplicações que envolvem algoritmos de criptografia, álgebra computacional e sistemas algébricos;

- (6) Atualizada e aprimorada constantemente pelos seus desenvolvedores, desde sua criação, em 1991.

Abaixo estão algumas das principais funções (e suas respectivas descrições) que pertencem à biblioteca GMP, entre elas algumas utilizadas na implementação do protocolo:

- void mpz_init (mpz_t var) - inicia a variável var, atribuindo a ela o valor 0 .

- void mpz_init_set_ui (mpz_t var, unsigned long op) - inicia a variável var, atribuindo $\overline{\text { da }}$ variável $\bar{o} p$ de tipo unsigned long.

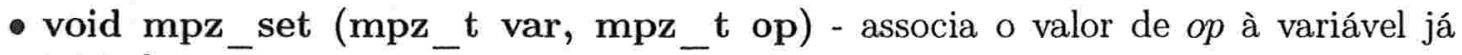
iniciada var.

- void mpz_set_ui (mpz_t var, unsigned long op) - associa o valor de uma variável do tipo unsigned long à já iniciada variável var.

- void mpz_set_str (mpz_t var, char *str, int base) - converte o valor da string str em um inteiro $m p \overline{z_{t}}$ na base base e armazena o resultado em var.

- void mpz_get_str (char *str, int base, mpz_t var) - converte o valor da variável var para uma string na base base e armazena o resultado em str.

- void mpz_add (mpz_t var, mpz_t op1, mpz_t op2) - armazena na variável var o valor de $o p 1+o p \overline{2}$.

- void mpz_add_ui (mpz_t var, mpz_t op1, unsigned long op2) - armazena na variável var o valor de $o \bar{p} 1+o p 2$.

- void mpz_sub (mpz_t var, mpz_t op1, mpz_t op2) - armazena na variável var o valor de $o p 1-o p \overline{2}$.

- void mpz_sub_ui (mpz_t var, mpz_t op1, unsigned long op2) - armazena na variável var o valor de $\bar{p} 1-o p 2$.

- void mpz_mul (mpz_t var, mpz_t op1, mpz_t op2) - armazena na variável var o valor de $o p 1 * o p 2$.

- void mpz_mul_ui (mpz_t var, mpz_t op1, unsigned long op2) - armazena na variável var o valor de $o \bar{p} 1 * o p 2$. 
- void mpz_mod (mpz_t var, mpz_t op1, mpz_t op2)) - Armazena na variável var o valor de $o p 1 \bmod o p 2$.

- void mpz_mod_ui (mpz_t var, mpz_t op1, unsigned long op2)) - Armazena na variável văr o valor $\overline{\mathrm{de}}$ op $1 \bmod o p \overline{2}$.

- void mpz_pow_ui (mpz_t var, mpz_t op1, unsigned long op2) - Armazena na variável $\operatorname{var}$ o valor de $o \bar{p} 1^{o p 2}$, onde $o p \overline{2}$ é do tipo unsigned long.

- void mpz_powm (mpz_t var, mpz_t op1, mpz_t op2, mpz_t op3) Armazena na variável var o valor de op $1^{o \overline{2}} \bmod$ op3.

- int mpz_invert (mpz_t var, mpz_t op1, mpz_t op2) - Armazena em var a inversa de $o p 1$ módulo op $\overline{2}$. Utiliza para isso o algoritmo de Euclides Estendido.

- void mpz_gcd (mpz t var, mpz t op1, mpz t op2) - Armazena na variável var o máximo divisor comum de op1 e op2.

- int mpz_probab_prime_p (mpz_t var, int op1) - Retorna 2 se var é primo, 1 se var é um provável primo, ou 0 se composto. Utiliza o teste probabilístico de Miller-Rabin. O número de testes a serem feitos são controlados por $o p 1$.

- int mpz_cmp (mpz_t op1, mpz_t op2) - Compara op1 com op2. Retorna um número positivo se $o p 1>o p 2$, negativo se $o p 1<o p 2$ e zero caso $o p 1=o p 2$.

As funções acima apresentadas atuam apenas com operandos inteiros. Também foram utilizadas na implementação funções que utilizam operandos fracionários (numerador/denominador), que são similares às funções citadas acima.

Para a implementação do protocolo, foi utilizada a versão 4.1 .2 desta biblioteca. 


\section{Implementação e Análise}

Neste capítulo será mostrado de que forma o protocolo de Katz e Yung [20] foi implementado e analisado. Basicamente, durante toda a implementação e durante toda a análise foram utilizadas as ferramentas citadas no capítulo anterior.

\subsection{Conceitos gerais}

Basicamente, a nossa implementação recebe de um arquivo de entrada passado como parâmetro o número de processos que estarão participando de uma comunicação coletiva. Este arquivo pode ser facilmente alterado pelo usuário responsável por executar o protocolo. O nome do arquivo é informado através da linha de comando (Maiores detalhes serão vistos ainda neste capítulo). Com esta informação, é alocada memória para cada processo participante, e é calculada a chave de sessão, que é então repassada para todos os processos ao final da execução. Com esta chave, os processos poderão então se comunicar através de um sistema de criptografia de chave simétrica.

\subsubsection{Geração das Informações para a Análise}

O protocolo gera também dois arquivos de saída: um deles, criado com o nome "pkchaves.txt", que armazena o valor de todas as chaves de sessão calculadas para cada processo participante, e o outro, criado com o nome "result.txt", armazena informações estatísticas (número de processos participantes, total de mensagens enviadas, total de mensagens recebidas, total de exponenciações e tempo gasto), separadas umas das outras por vírgula. A cada execução do protocolo, estes dois arquivos são atualizados, concatenando todas as informações já gravadas, ou seja, sem recriar o arquivo. Desta forma, o arquivo "result.txt", por exemplo, pode ser usado para se montar uma tabela com informações de várias execuções para diferentes números de participantes, obtendo dados estatísticos gerados pelo próprio protocolo.

\subsubsection{Visualização das Informações para a Análise}

Para a visualização dos resultados, foi implementado um programa auxiliar - PKRes.exe - que recebe como entrada o arquivo "result.txt", lendo todas as informações obtidas pelo 
protocolo e convertendo-as para uma tabela e para um gráfico. Este programa tem como principal objetivo facilitar a análise de desempenho do protocolo de Katz e Yung, fornecendo informações dos principais pontos da implementação.

Pelo fato de ser um aplicativo específico para a análise da execução do protocolo em uma plataforma Windows, o programa PKRes foi implementado com outro compilador, o $\mathrm{C}++$ Builder, que permite a criação de um ambiente gráfico, executado dentro do Windows, diferentemente do programa que executa o protocolo, que possui um ambiente de console (DOS).

\subsection{Implementação do Protocolo}

Por se tratar de uma implementação didática, voltada para a análise de funcionamento e desempenho, certas parametrizações - que poderiam ser definidas em tempo de execução pelo usuário - foram fixadas com valores compatíveis para o esquema de testes utilizado. Entre eles, estão o tamanho do módulo e o número de processos participantes. Além destes dois, também têm os dois arquivos de saída, que são especificamente criados objetivando informar apenas o que exatamente foi gerado pelo protocolo. Em uma situação real, estes arquivos não existiriam.

Outro detalhe da implementação é a não utilização de uma ferramenta visual, sendo gerado um aplicativo de console, ou seja, sem recursos gráficos. O principal motivo de se implementar o protocolo desta maneira é a portabilidade da compilação e da "ligação" do código, que pode ser migrado, sem muitas dificuldades, de uma plataforma Windows para uma plataforma Unix/Linux.

\subsection{Execução do Protocolo}

Para que fosse possível analisar o desempenho e os recursos de uma forma mais abrangente, o protocolo foi executado mais de uma vez, sendo que, a cada nova execução, o número de participantes era incrementado. Inicialmente, o protocolo foi executado para dois participantes, em seguida, foi executado para três, quatro e cinco. Após a execução do protocolo para cinco participantes, o número de participantes passou a ser incrementado de cinco em cinco, até chegar aos cinqüenta e cinco processos participantes, montando assim um arquivo de saída com dados estatísticos suficientemente consistentes para que fosse possível gerar uma tabela e um gráfico das informações obtidas. De imediato, o arquivo de saída "pkchaves.txt" serviu principalmente para verificar se todos os participantes receberam uma chave de sessão de mesmo valor.

Inicialmente, o protocolo lê o arquivo de entrada passado como parâmetro na linha de comando e inicializa a biblioteca MPI, que alocará o número de processos necessários, conforme a parametrização informada no conteúdo do arquivo. A figura 20 ilustra um exemplo de um arquivo que indica que quatro processos estarão participando da execuçâo do protocolo (o termo "local" indica que todos os processos estarão sendo executados 


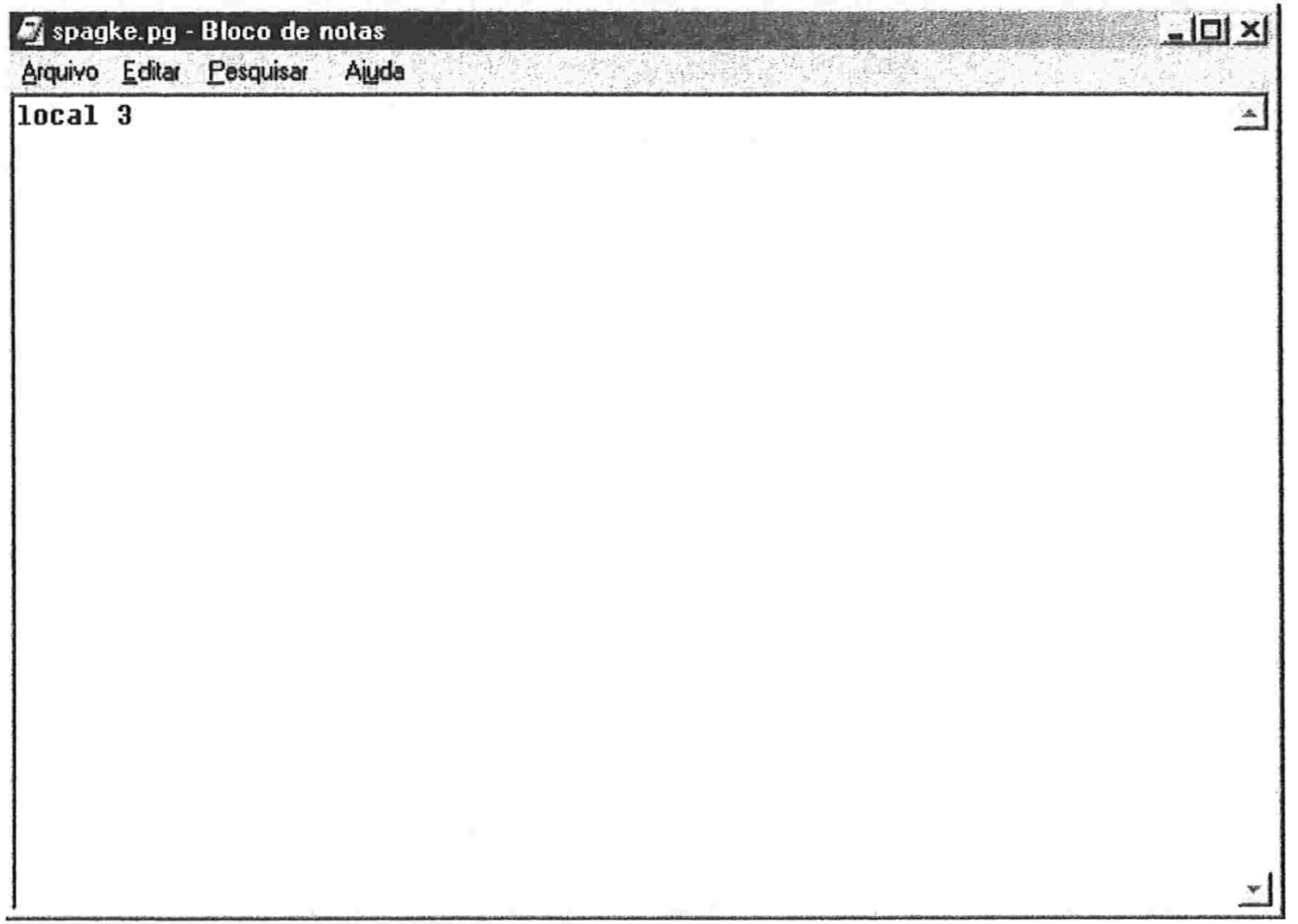

Figura 20: Execução do Protocolo - Arquivo de parametrização

localmente em um mesmo computador). Uma vez iniciada, a interface da comunicação paralela (MPI) já permite que sejam enviadas mensagens entre os processos participantes. Na figura 21, percebe-se que esta comunicação estará começando.

Em seguida, é gerada a chave de sessão para os processos, seguindo os passos do algoritmo criado por Katz e Yung. Por motivos de simplicidade, foram utilizadas funções pré-definidas pela biblioteca GMP para gerar os números aleatórios de cada processo durante a fase de inicialização. Quanto ao esquema de assinatura, foram implementadas as funções de geração e verificação de assinaturas baseando-se nos conceitos do algoritmo ElGamal de assinatura. Durante a geração da chave de sessão, são contabilizadas algumas estatísticas relevantes para a análise do protocolo ao final da execução. A figura 22 mostra que a chave de sessão já foi obtida, ou seja, já estão sendo gerados então os arquivos de resultados e das chaves. Por fim, ao gravar as informações nos arquivos de saída, são impressas em tela as estatísticas calculadas, finalizando a execução (figura 23).

Deve-se ressaltar que o protocolo foi implementado com o intuito de se levantar o maior número de informações relevantes possível, a fim de se estudar de uma forma 


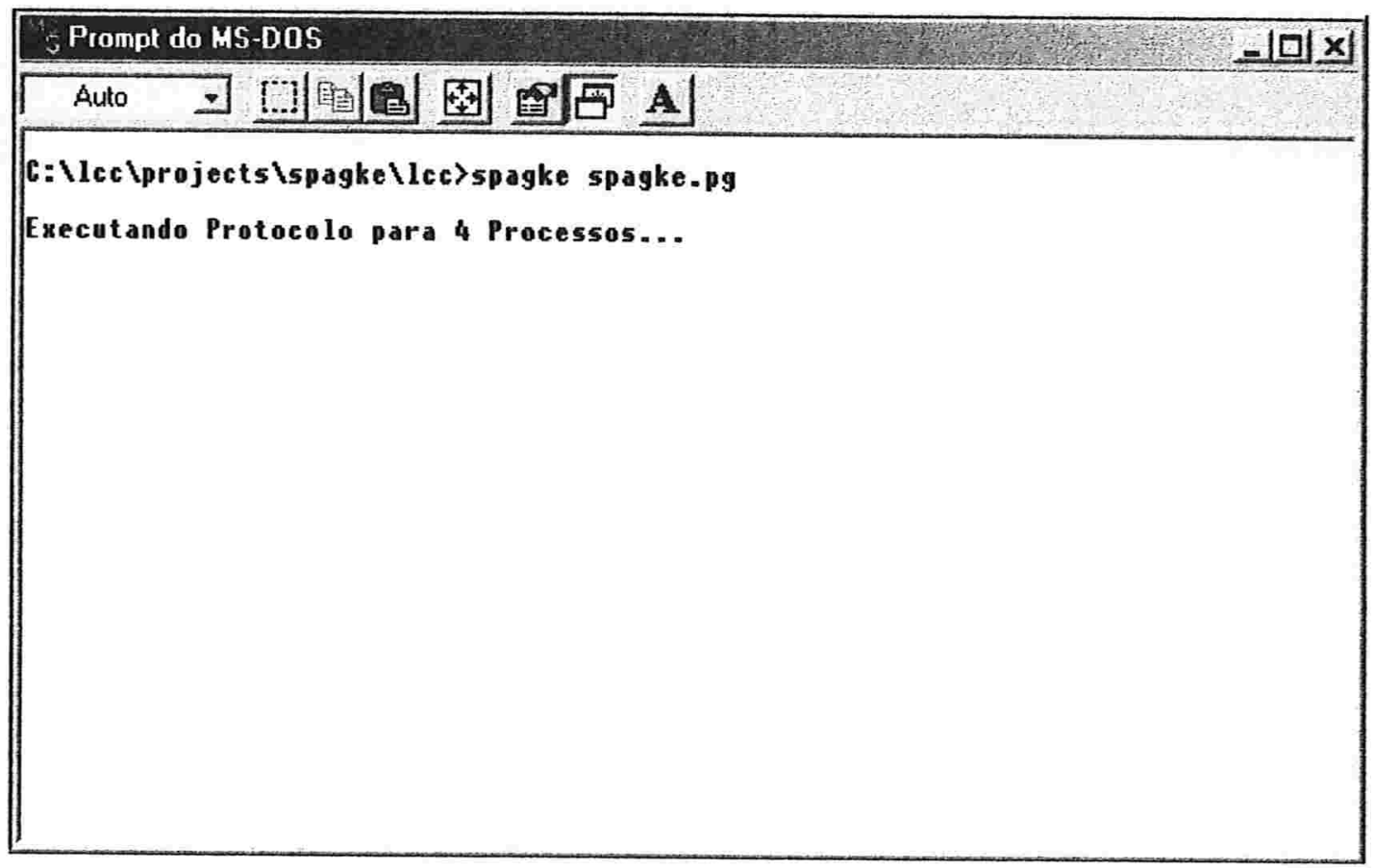

Figura 21: Execução do Protocolo - Reconhecimento do número de participantes

mais detalhada, ou seja, em uma situação real, a maioria destas informações não são mostradas, por motivos de segurança e privacidade. Além disso, este protocolo deve ser implementado de tal forma que a chave de sessão seja encaminhada diretamente para o sistemas de criptografia simétrica, que passará a garantir a segurança da informação trocada entre os processos.

\subsection{Análise dos Resultados Obtidos}

Para que fosse possível estudar de uma forma mais detalhada o funcionamento do protocolo, foram incluídas medidas estatísticas no meio do código implementado, cujos resultados destas foram gravados nos dois arquivos de saída: o "pkchaves.txt" e o "result.txt".

Estes dois arquivos são criados pelo programa de tal forma que, a cada execução do protocolo, sejam concatenadas as informações novas com as informações já gravadas. Por exemplo, as figuras 24 e 25 mostram o conteúdo dos arquivos depois da primeira execução do protocolo, e as figuras 26 e 27 mostram o conteúdo após mais de uma execução.

Através da leitura do conteúdo do arquivo "result.txt", que armazenava as informações de todas as execuções feitas durante os testes de execução do protocolo implementado (indo desde a execução do protocolo para dois processos participantes até a execução 


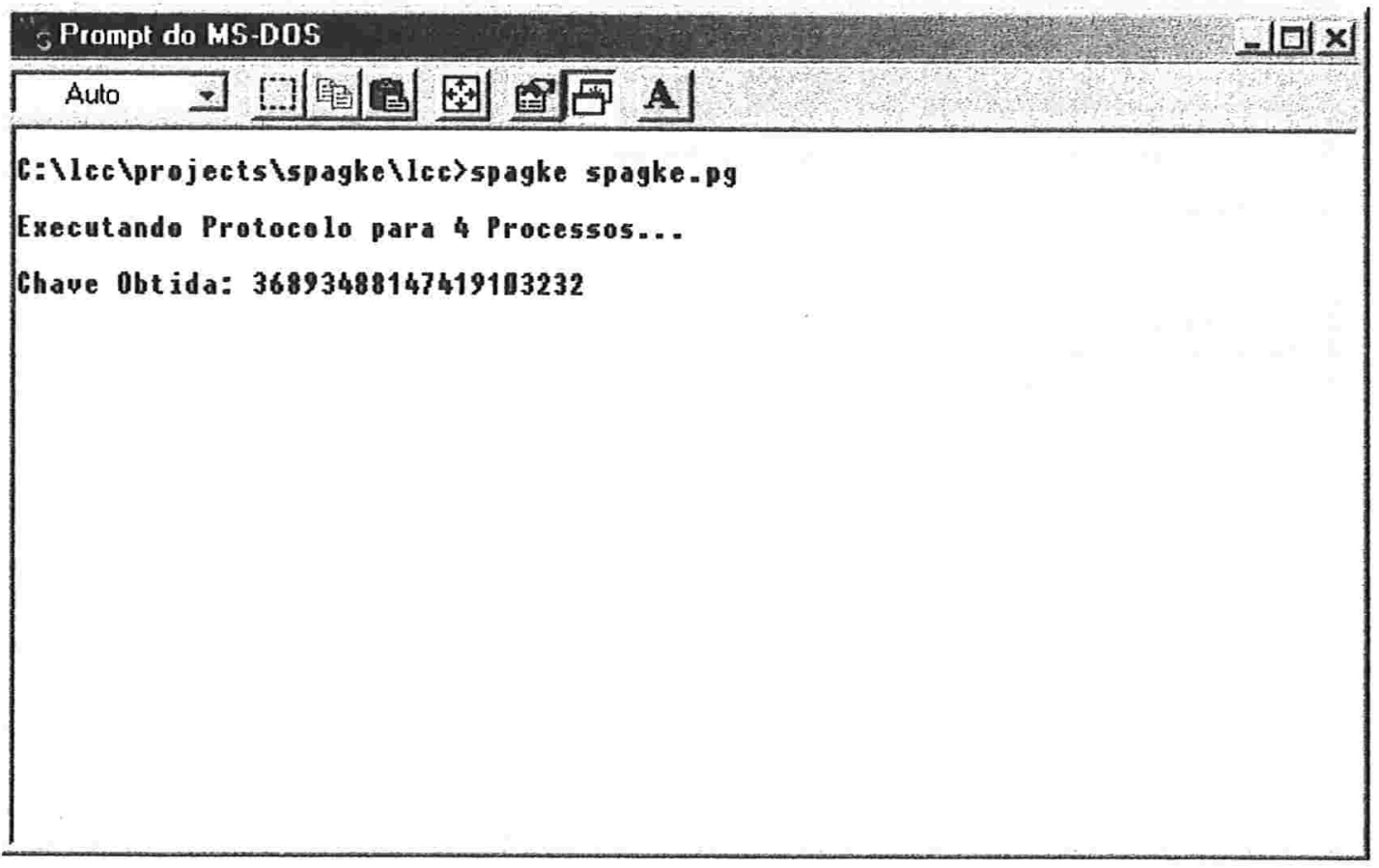

Figura 22: Execução do Protocolo - Cálculo da Chave de Sessão

para cinqüenta e cinco processos), é possível montar um gráfico de desempenho em cima do tempo de execução (Número de participantes x Tempo), conforme mostra a figura 28. Este gráfico, construído com informações do arquivo "result.txt" através de um aplicativo do Microsoft Word para gerar gráficos (os dados foram incluídos manualmente), serve para facilitar a visualização do desempenho do protocolo de Katz e Yung, embora este desempenho esteja relacionado diretamente com o desempenho do processador e com as limitações de memória da máquina utilizada durante a fase de testes, ou seja, a linha de tempo obtida nesta situação é totalmente relativa, uma vez que, utilizando um processador melhor e uma quantidade maior de memória, é possível melhorar consideravelmente este tempo de execução.

\subsection{Execução dos programas}

A seguir são descritos os passos para se utilizar os programas desenvolvidos para facilitar a análise do protocolo de Katz e Yung. Como já foi dito anteriormente, ambos foram implementados para que sejam executados em uma plataforma Windows. 


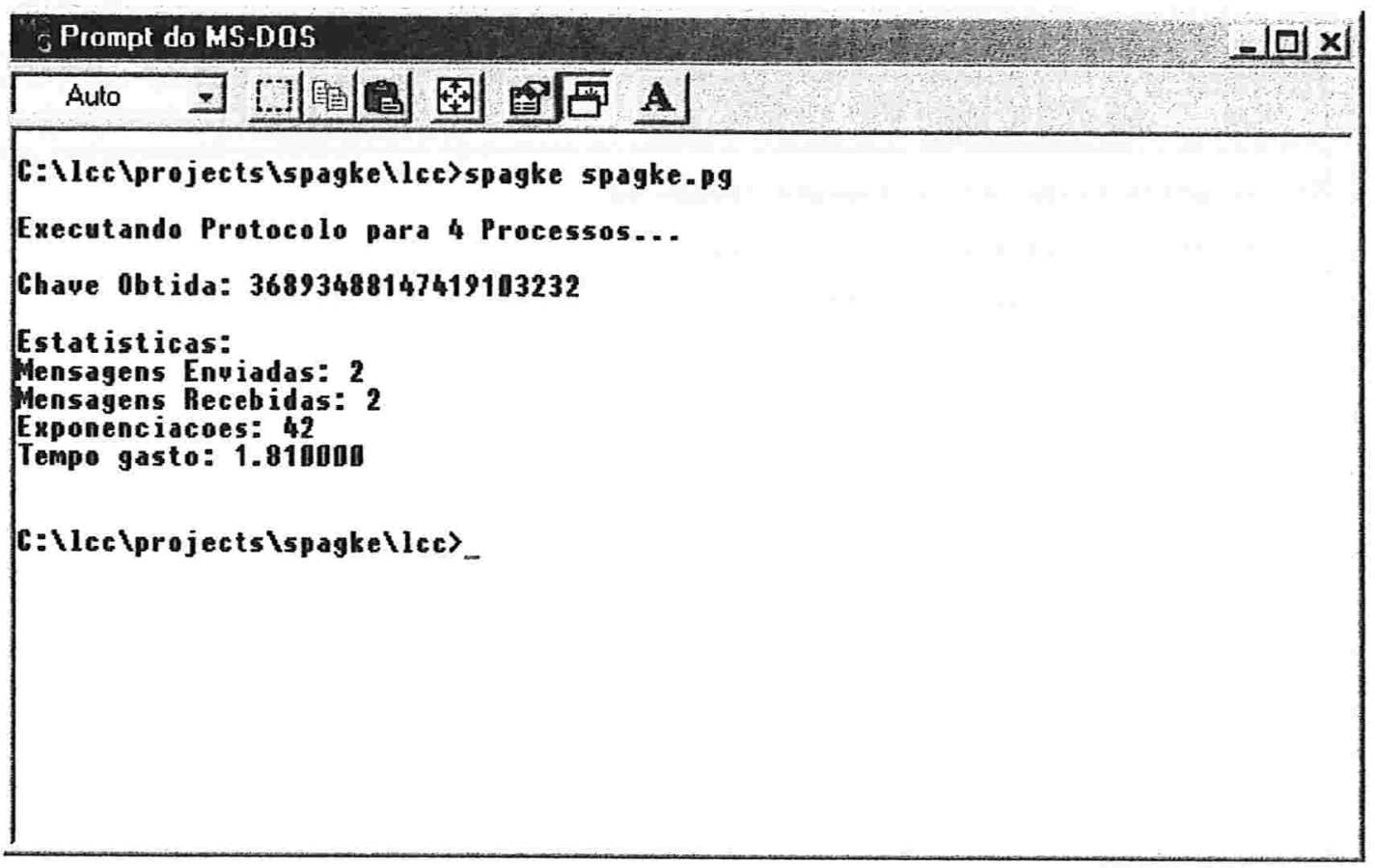

Figura 23: Execução do Protocolo - Dados Estatísticos

\subsubsection{O programa spagke.exe}

O programa spagke ${ }^{9}$ exige que seja criado um arquivo de texto (com extensão "pg", como por exemplo, "spagke.pg") cujo conteúdo tenha, na primeira linha, o seguinte texto: "local n", onde " $n$ " é um número inteiro entre 1 e 55, que representa o número de processos participantes. Uma vez criado este arquivo, a execução deste programa fica simples: basta chamá-lo da linha de comando (prompt do MS-DOS), passando como parâmetro o nome do arquivo criado (por exemplo, "spagke spagke.pg"). Este programa simplesmente executa o protocolo de Katz e Yung para o número de processos passado como parâmetro através do arquivo de extensão ".pg".

\subsubsection{O programa pkres.exe}

O manuseio do programa pkres ${ }^{10}$ é bem simples: basta clicar no botão "Carregar Dados", localizar e abrir o arquivo 'result.txt", e aguardar a carga das informações. Feito isto, é possível visualizar todas as informações em uma tabela localizada na guia Dados e em um gráfico de "Tempo de Execução x Número de Participantes", localizado na guia

\footnotetext{
${ }^{9} \mathrm{O}$ termo SPAGKE significa "Scalable Protocols for Authenticated Group Key Exchange", representando assim as iniciais do nome dado por Katz e Yung ao estudo feito por eles

${ }^{10}$ Este programa deve ser executado somente após a execução do programa spagke.exe, que gera o arquivo "result.txt", necessário para a execução do pkres.exe
} 


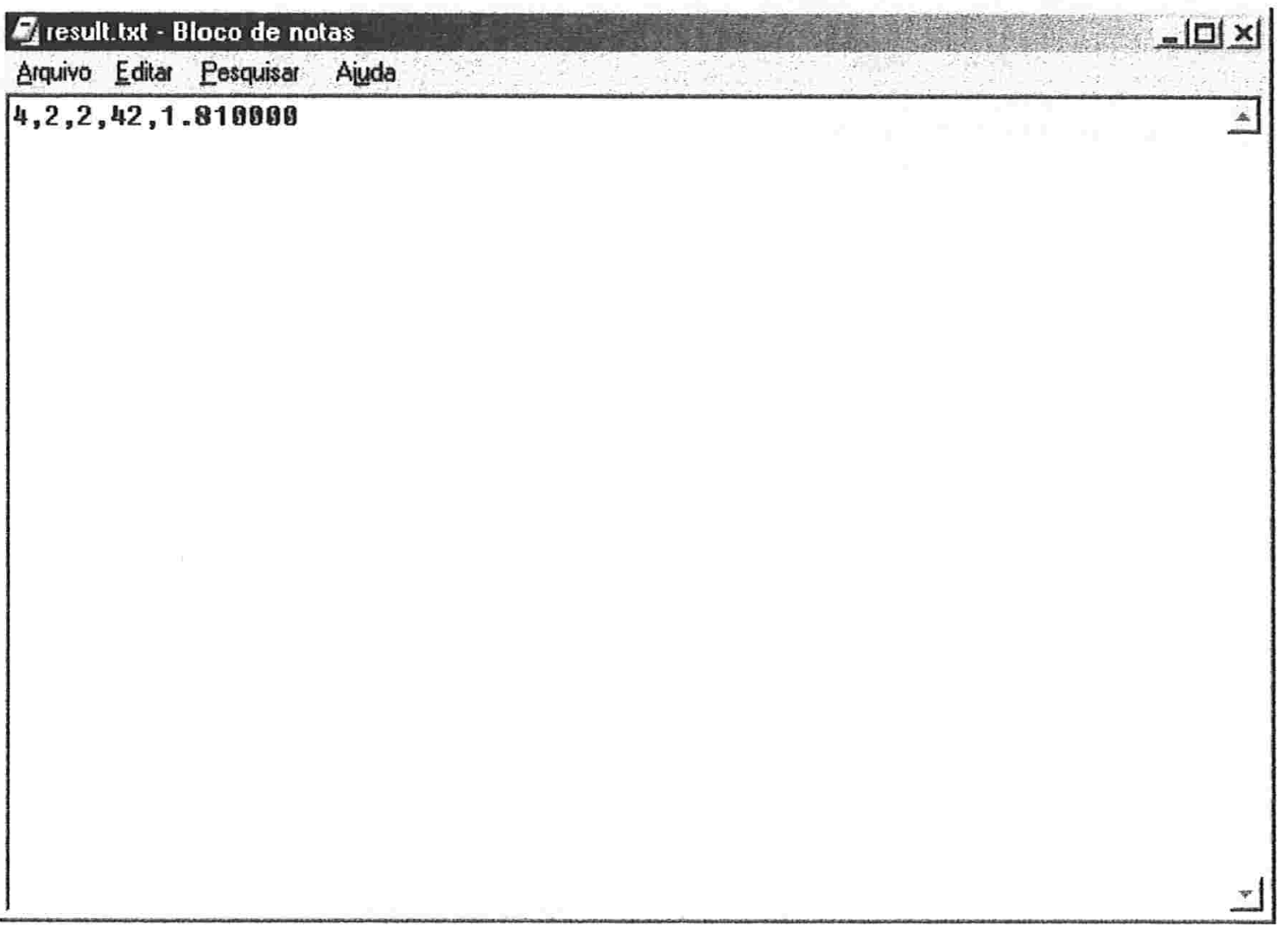

Figura 24: Análise dos Resultados Obtidos - Arquivo result.txt

Gráfico, conforme as figuras 29 e $30^{11}$.

\subsection{Dificuldades encontradas}

Apesar de ser utilizada uma linguagem flexível, com um compilador que gera um código executável praticamente compatível com as plataformas Windows e Unix, e com bibliotecas auxiliando no desempenho, foram encontradas algumas dificuldades durante a implementação do protocolo de Katz e Yung. Dentre elas, podemos citar os problemas de adaptação das bibliotecas - no momento de codificar o protocolo com o compilador utilizado - como sendo a principal dificuldade encontrada. Esta dificuldade de adaptação ocorreu principalmente por não existirem arquivos das bibliotecas MPI e GMP compatíveis com o ambiente de programação utilizado.

Outros problemas encontrados, como a falta de máquinas disponíveis para testes que

\footnotetext{
${ }^{11}$ A curva do tempo de execução exibida pelo gráfico é exponencial pelo fato da comunicação ser broadcast e de todos os processos participantes utilizarem a mesma máquina (com um único processador), fazendo com que o tempo aumentasse conforme o aumento do número de processos
} 


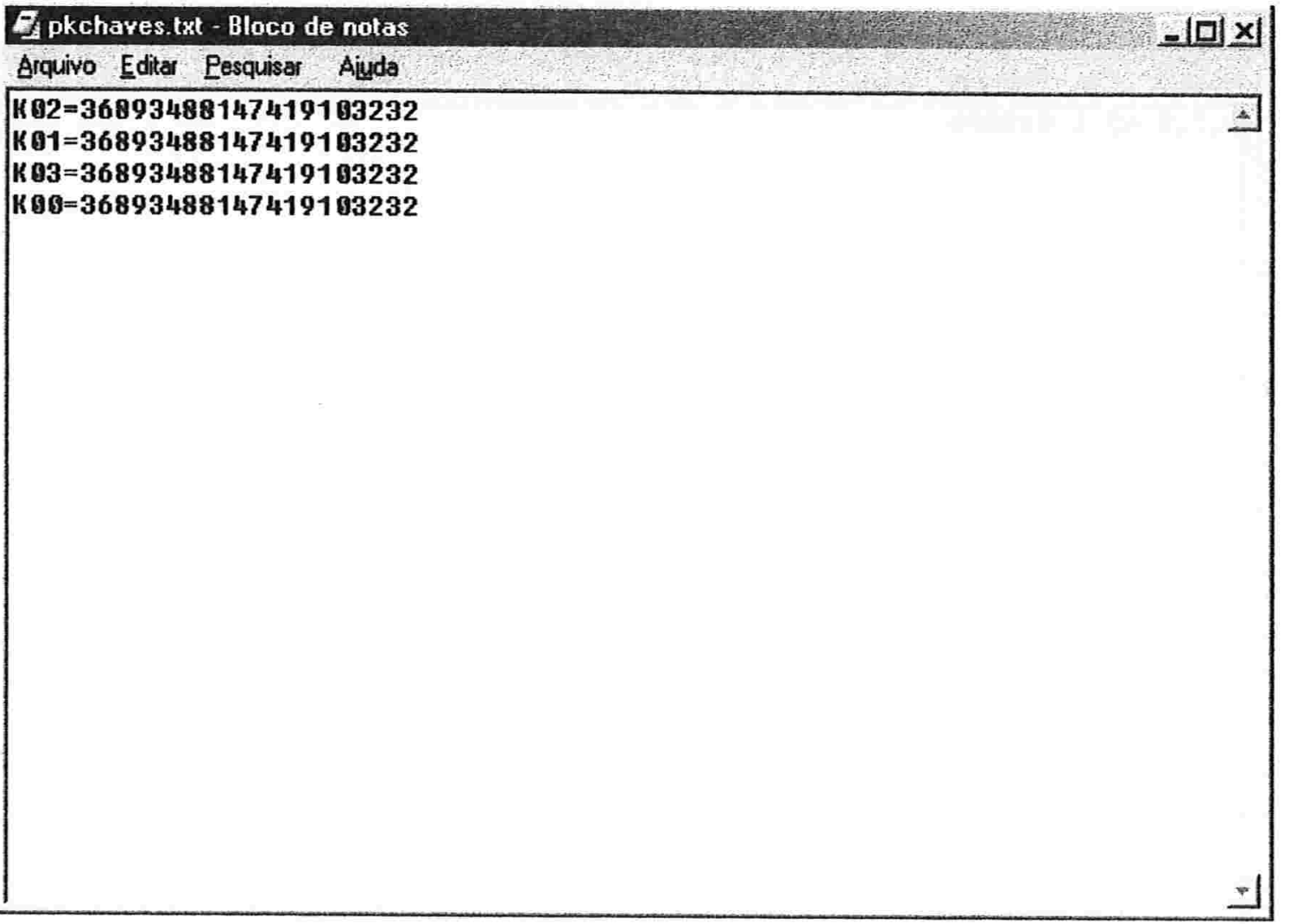

Figura 25: Análise dos Resultados Obtidos - Arquivo pkchaves.txt

possuíssem um melhor desempenho e que trabalhassem não apenas em plataforma Windows, mas também em plataforma Unix, não chegaram a afetar o tempo gasto para a fase de implementação, mas afetaram a fase de análise, que ficou mais restrita, já que foram feitos testes apenas em máquinas com plataforma Windows instalada. 


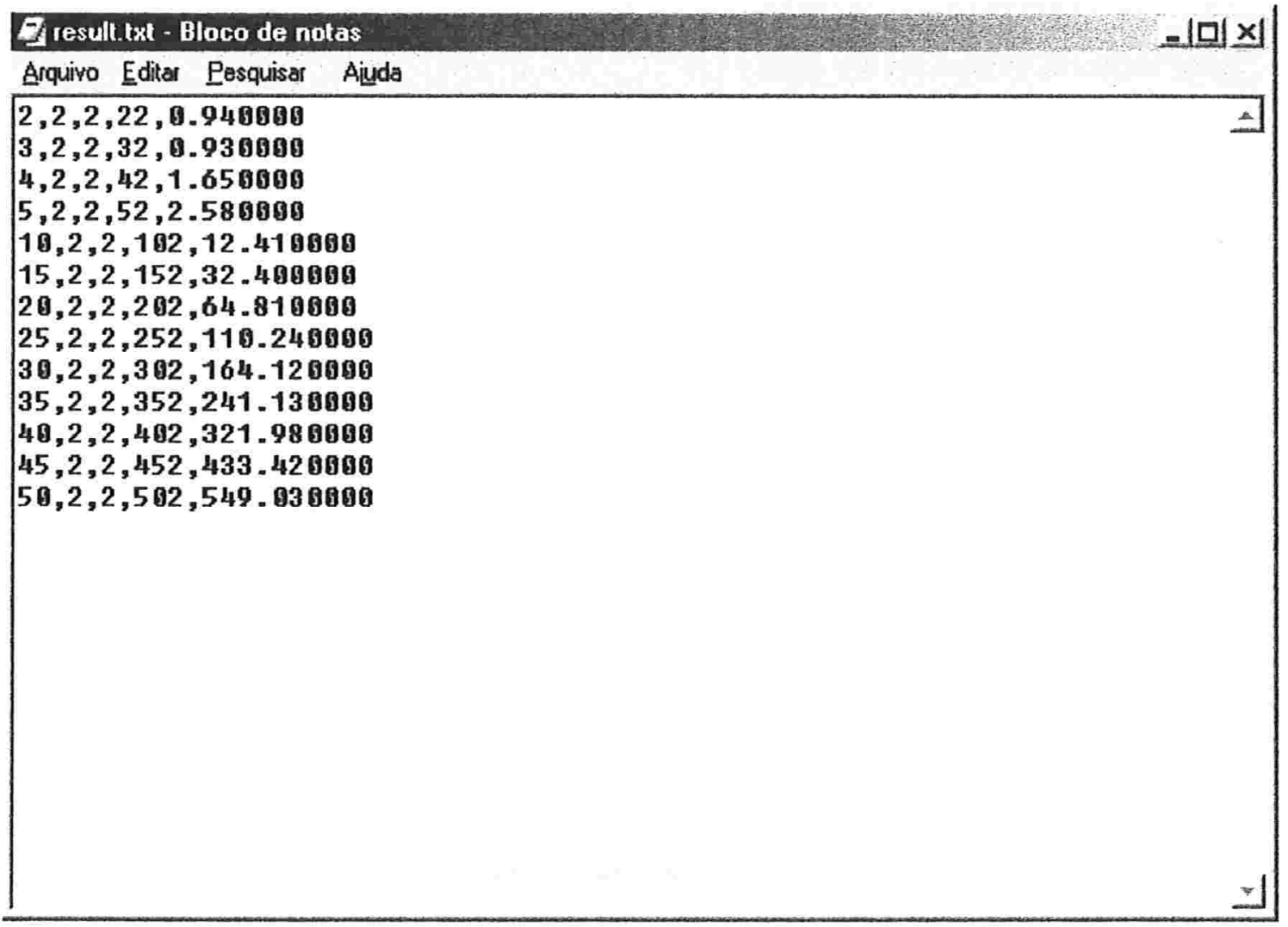

Figura 26: Análise dos Resultados Obtidos - Arquivo result.txt depois de várias execuções 


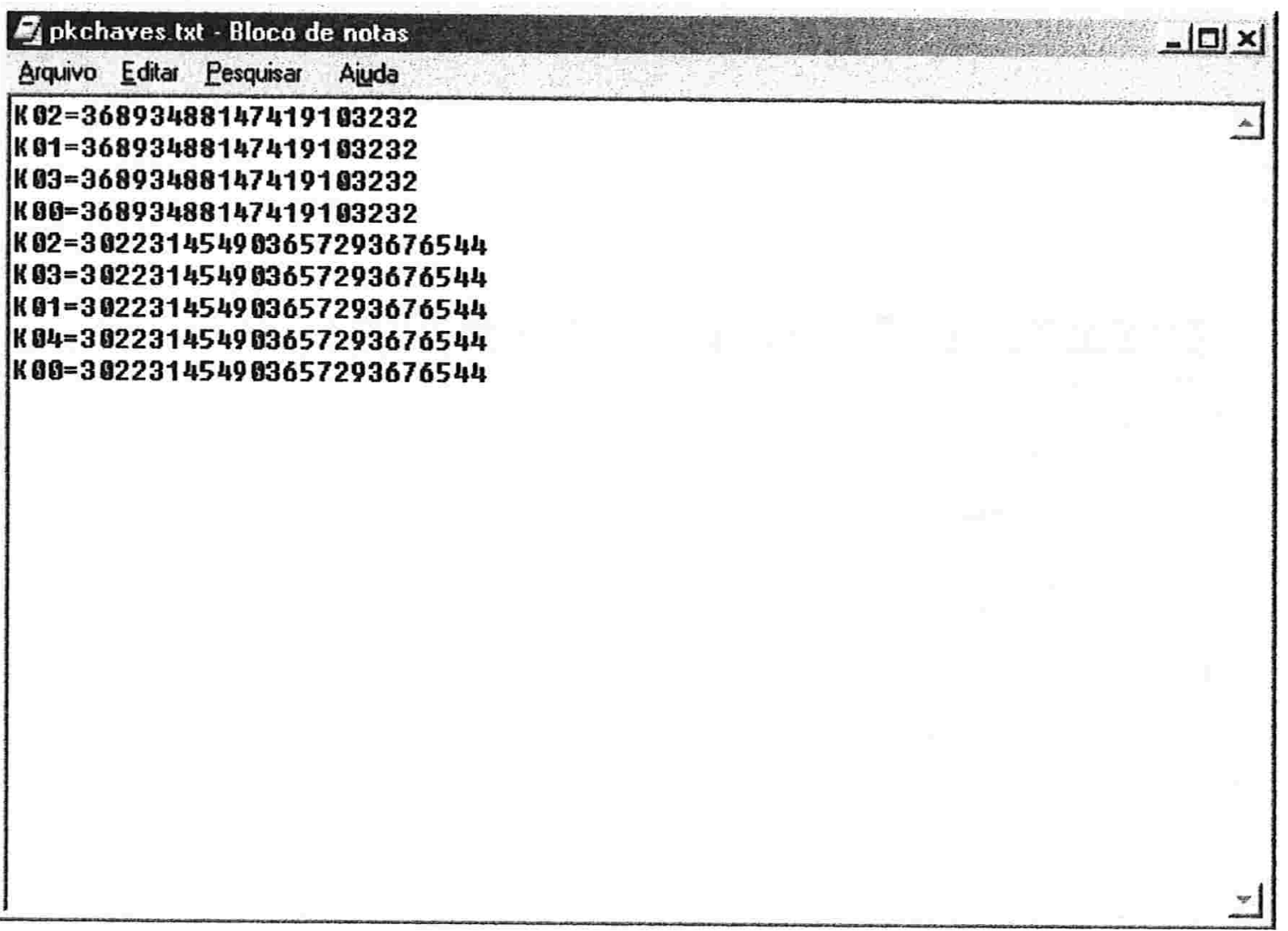

Figura 27: Análise dos Resultados Obtidos - Arquivo pkchaves.txt depois da segunda execução

\section{Análise de Desempenho}

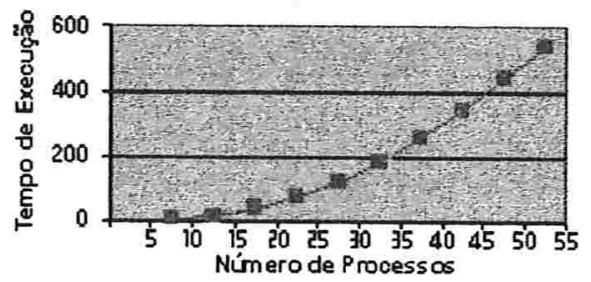

Figura 28: Análise dos Resultados Obtidos - Gráfico de desempenho 


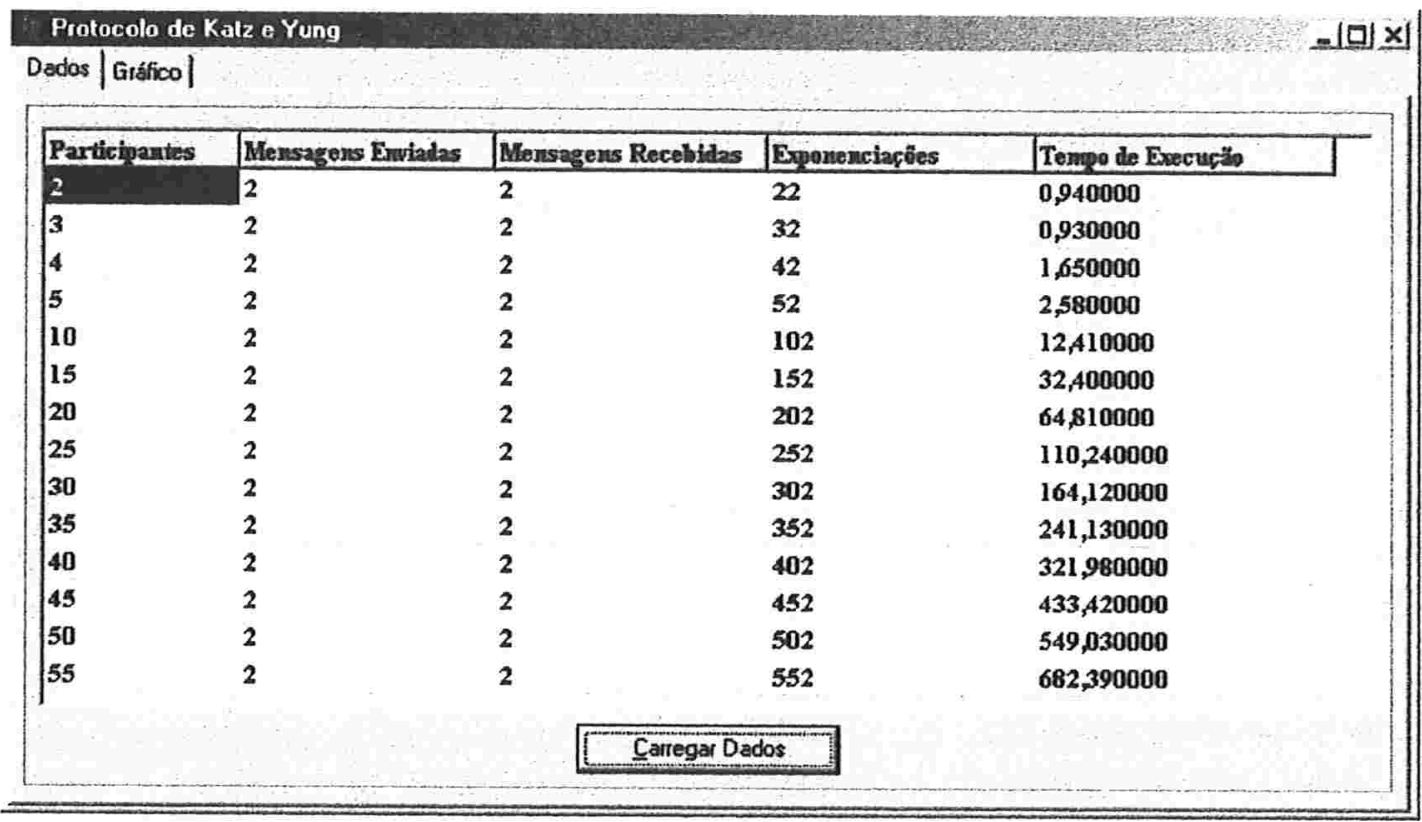

Figura 29: Pkres - Guia 'Dados"

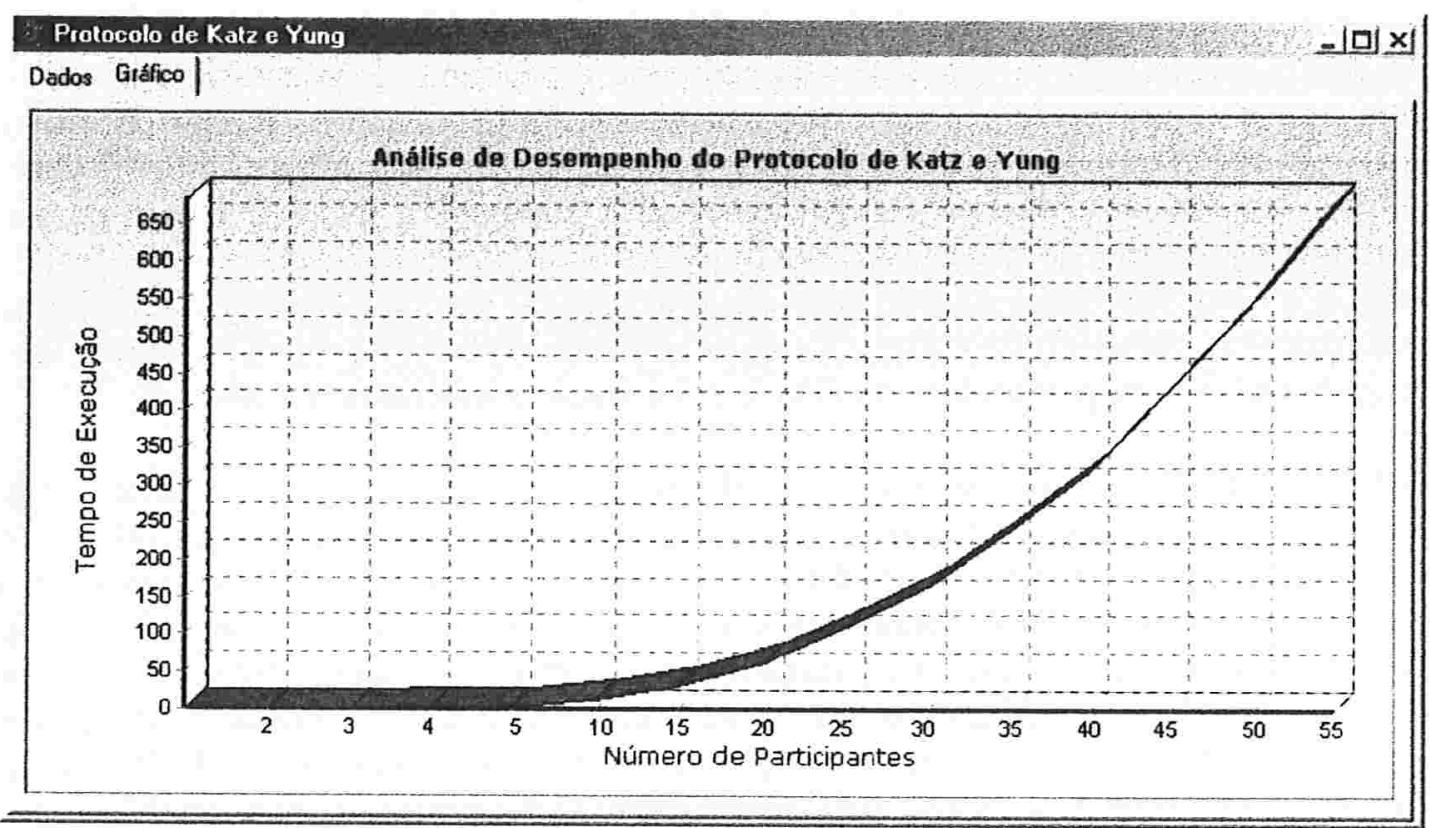

Figura 30: Pkres - Guia "Gráfico" 


\section{Conclusão}

Durante todo este trabalho foram levantadas informações a respeito dos protocolos de estabelecimento de chaves de grupo, focalizando principalmente nas características, no funcionamento, na segurança e na análise de desempenho do protocolo de Katz e Yung, sendo considerado inclusive o histórico dos protocolos anteriores que influenciaram o mesmo.

Através da implementação foi possível verificar cada uma de suas características, e neste capítulo serão apresentadas, de uma forma mais clara, todas as informações relevantes que foram obtidas durante a construção e durante a análise de execução do protocolo, informações estas que poderão contribuir com trabalhos futuros, e até mesmo com aplicações práticas deste protocolo em sistemas que utilizam criptografia simétrica.

Primeiramente, foram verificadas durante a implementação os três principais pontos de comparação entre os protocolos de estabelecimento de chaves de grupo: o número de rodadas, a quantidade de passos de comunicação e o número de exponenciações. Dentre estas, apenas o número de exponenciações cresce conforme aumenta o número de usuários, e isto acontece porque foi considerada uma exponenciação que ocorre ao final da terceira e última rodada, no momento em que está sendo calculada a chave de sessão para cada participante. Apesar de não ser constante, o número de exponenciações é razoável e não chega a ser um problema, dependendo da aplicação ou de como será aplicado. De qualquer forma, o protocolo de Katz e Yung obteve um desempenho melhor nestes fatores, comparando-se com protocolos anteriores, informação esta citada na tabela 1 .

Alguns fatores têm influência direta no desempenho do protocolo com relação ao tempo de execução: a máquina utilizada, a biblioteca de comunicação paralela e a biblioteca de auxílio a cálculos matemáticos pesados. Dependendo do que for utilizado, o desempenho pode variar. No caso, foram utilizadas as bibliotecas MPI e GMP, que contribuíram para um bom desempenho do algoritmo implementado. Por outro lado, ocorreram limitações de participantes e de módulo das chaves geradas, relacionadas à limitação de hardware da máquina utilizada. Utilizando um processador desempenho médio (AMD Duron de $900 \mathrm{MHz}$ ), com $128 \mathrm{Mb}$ de RAM, foi possível executar o protocolo para até 55 processos locais participantes, sem afetar o conteúdo da chave gerada, ou seja, a chave de grupo obtida é a mesma para todos os participantes. 
Os estudos feitos com relação à segurança foram voltados mais para o ponto de vista prático, visto que as demonstrações de segurança do protocolo mostradas através dos teoremas estudados nesta dissertação são muito complexos, e exigem que se acumule uma nova carga de tempo e de trabalho para o aprofundamento nos mesmos. Sendo assim, foram feitas pesquisas para verificar se existe algum documento que prove alguma insegurança do protocolo de Katz e Yung, chegando à conclusão de que ninguém provou o contrário à respeito da segurança do mesmo (o protocolo se baseia no PLD, que vem sendo analisado desde 1976 [16]). Além disso, verificou-se que a segurança do protocolo está ligada diretamente ao nível de vulnerabilidade do esquema de assinatura do mesmo, que é ponto chave da segurança do protocolo. Quanto mais difícil for quebrar o esquema de assinatura, mais seguro o protocolo será. E, pensando em termos práticos, isto é possível de se resolver utilizando algum esquema de assinatura que já exista, e que já provou sua segurança. Neste trabalho foi feita uma adaptação do algoritmo de ElGamal para assinatura, que possui um nível de segurança razoável, e sem muitas restrições para utilizá-lo. É possível também adaptar qualquer outro algoritmo de assinatura, ou então criar versões ou adaptações ligeiramente diferentes do esquema de assinatura implementado neste trabalho, embora isto não seja necessário na maior parte das aplicações.

Este trabalho abre caminho para novos estudos ou aprofundamentos. Servem como sugestões para trabalhos futuros: implantação do protocolo em um esquema de criptografia executado em uma Plataforma Unix ou Linux, adaptação de outras bibliotecas de comunicação (por exemplo, os sockets), implantação do protocolo em um esquema de criptografia com participantes se comunicando através de uma rede sem fio (por exemplo, palms ou celulares), detalhamento dos teoremas estudados nesta dissertação, com o intuito de se provar a segurança do protocolo de Katz e Yung, e variação do cálculo da chave de grupo, visando melhorar o desempenho do protocolo, tanto em quantidade de exponenciações quanto em tempo de execução. 


\section{A Listagem do Programa Spagke}

Abaixo é apresentada a listagem do programa spagke.exe, desenvolvido para implementar o protocolo.

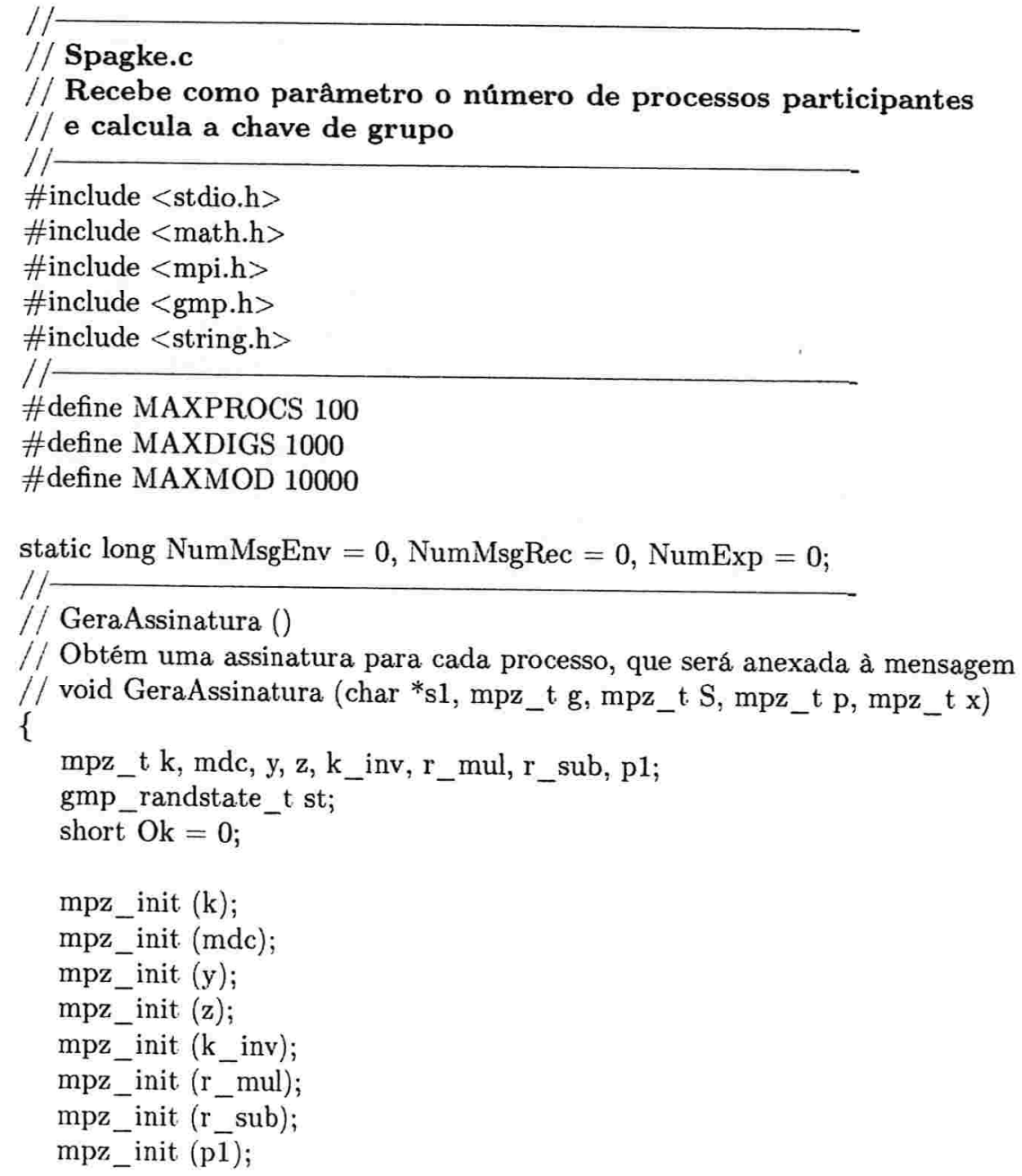




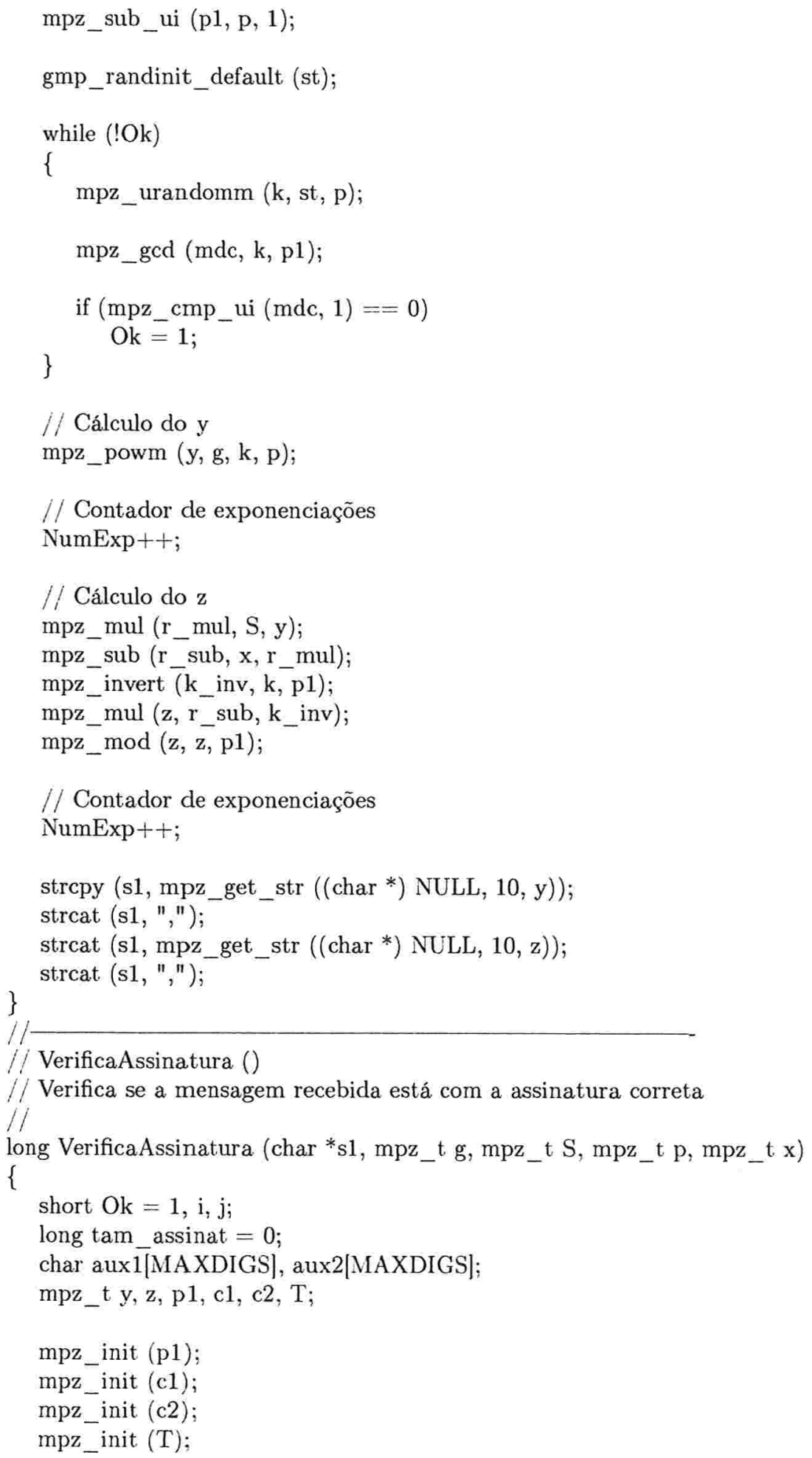




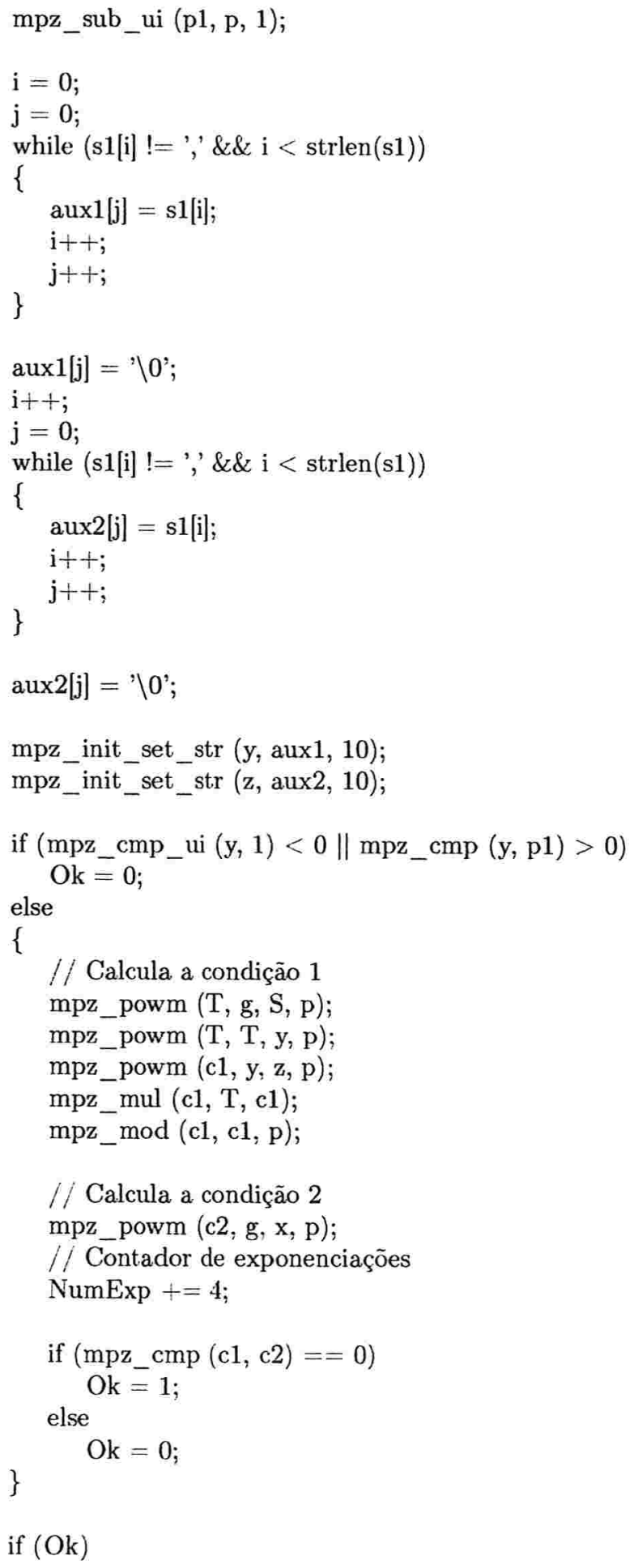




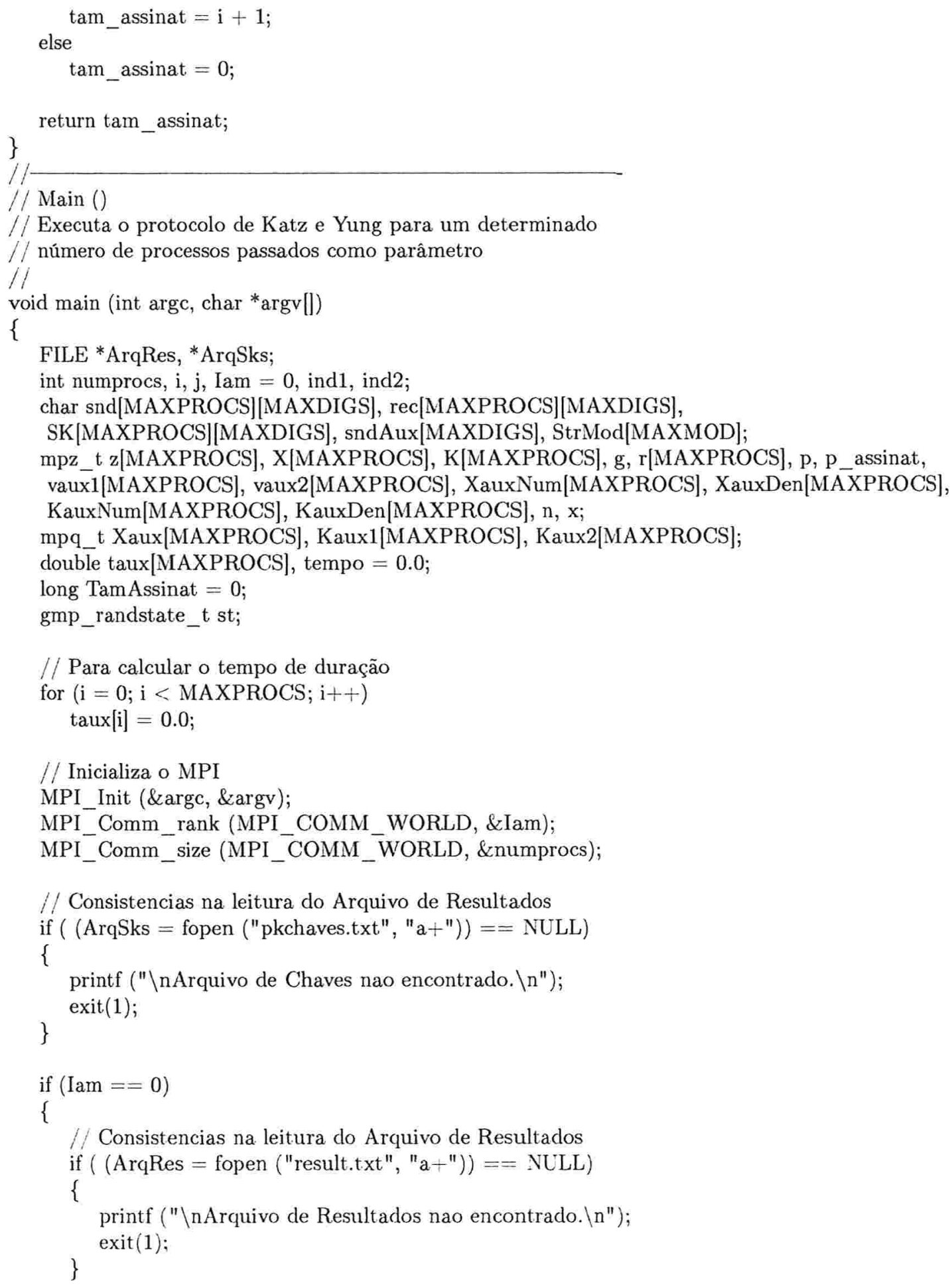



\}

printf ("\nExecutando Protocolo para \%d Processos...\n", numprocs);

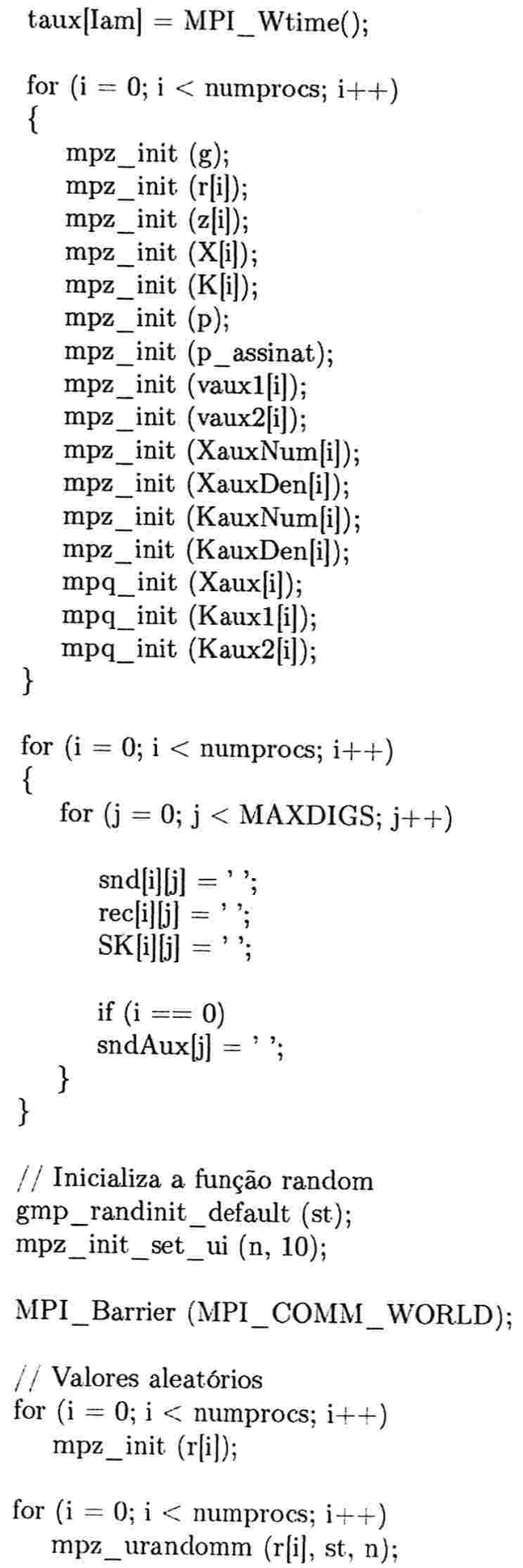




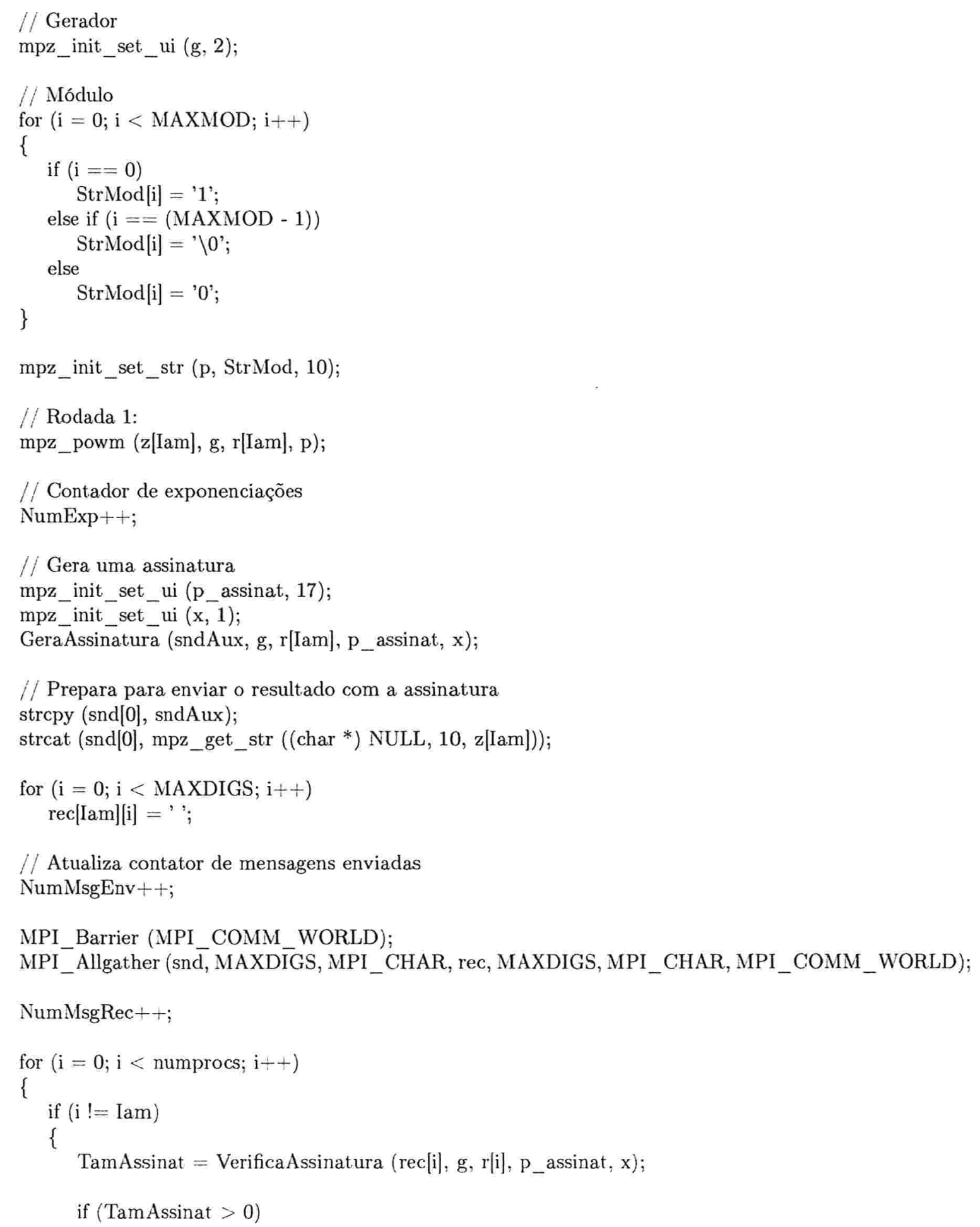




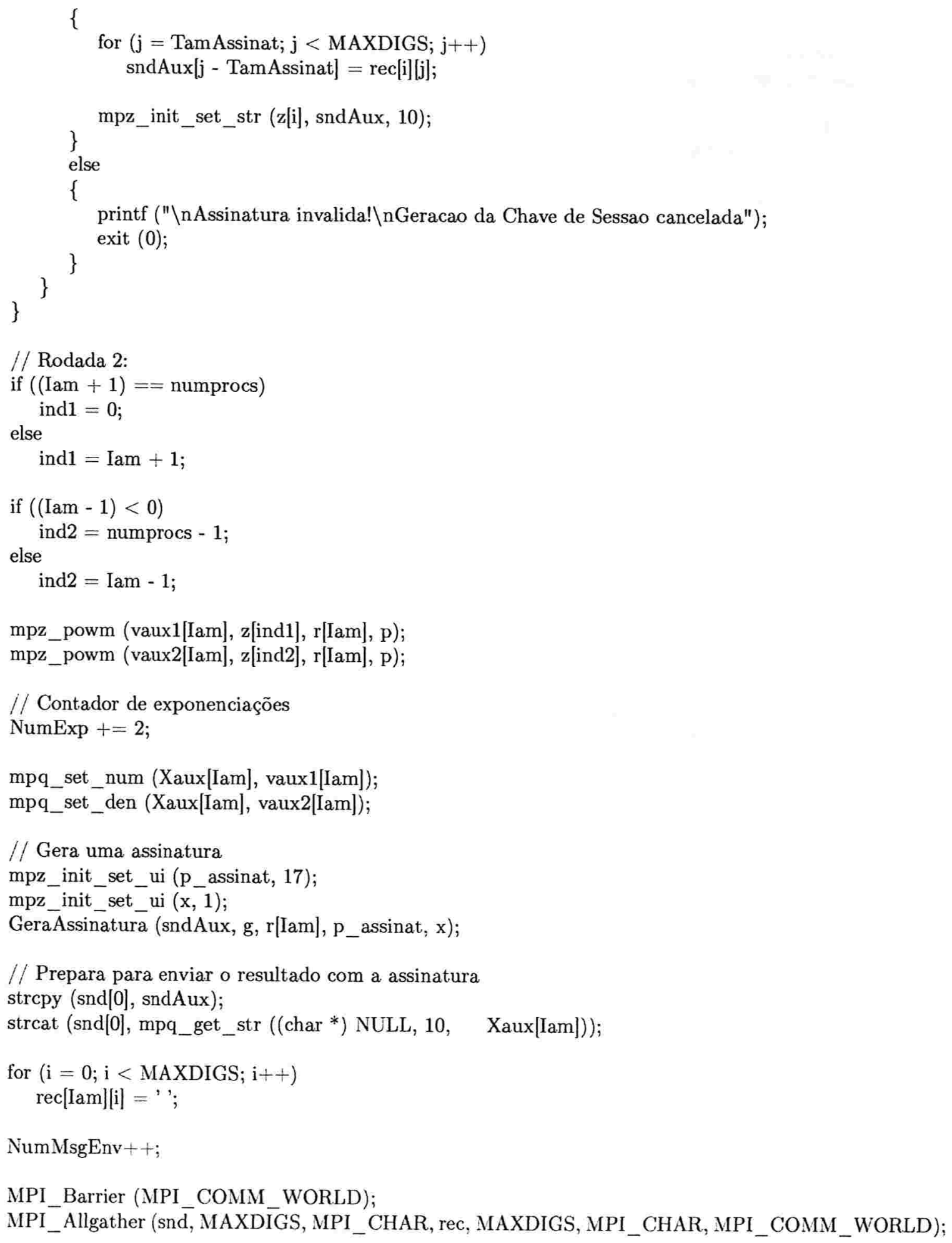




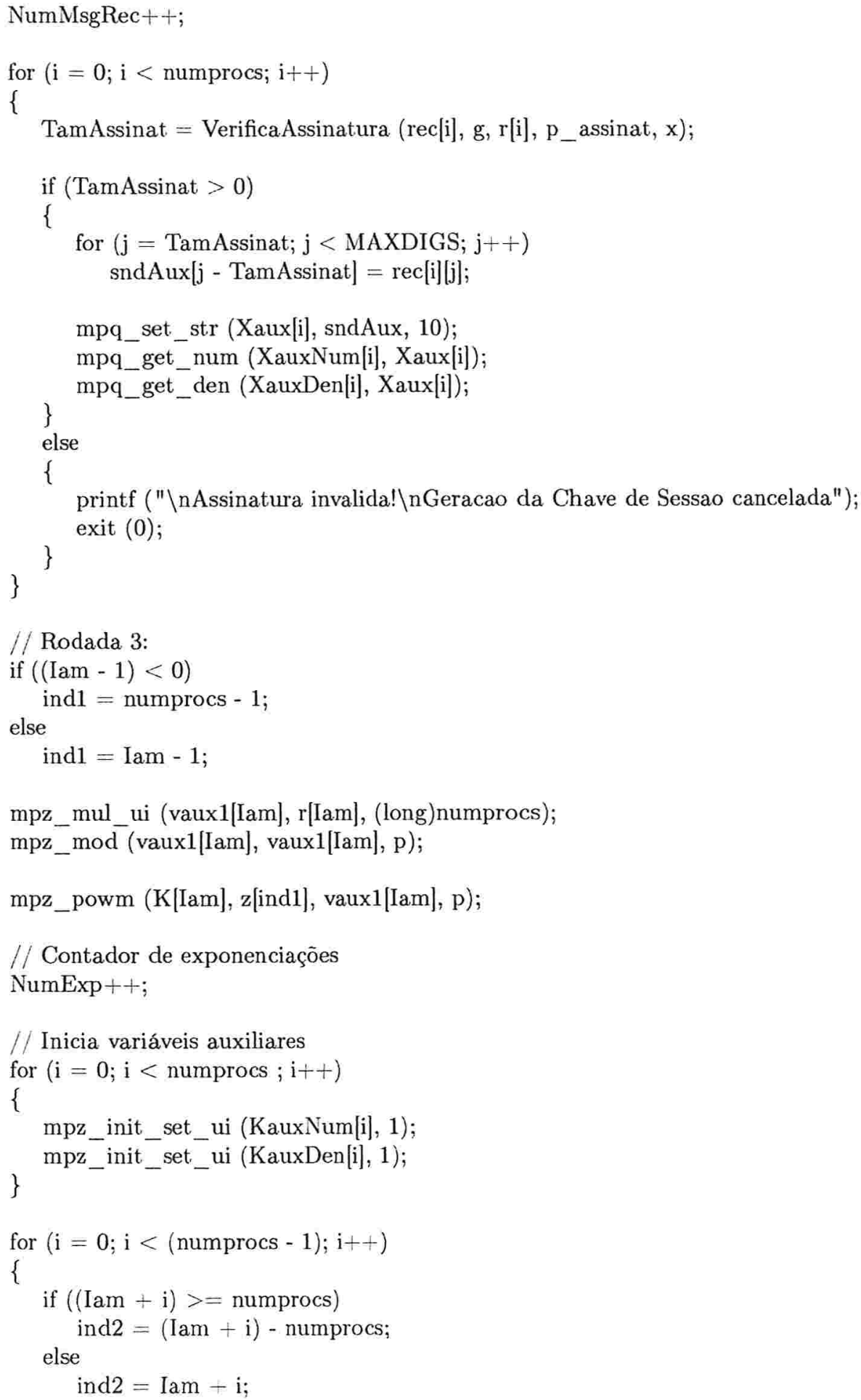




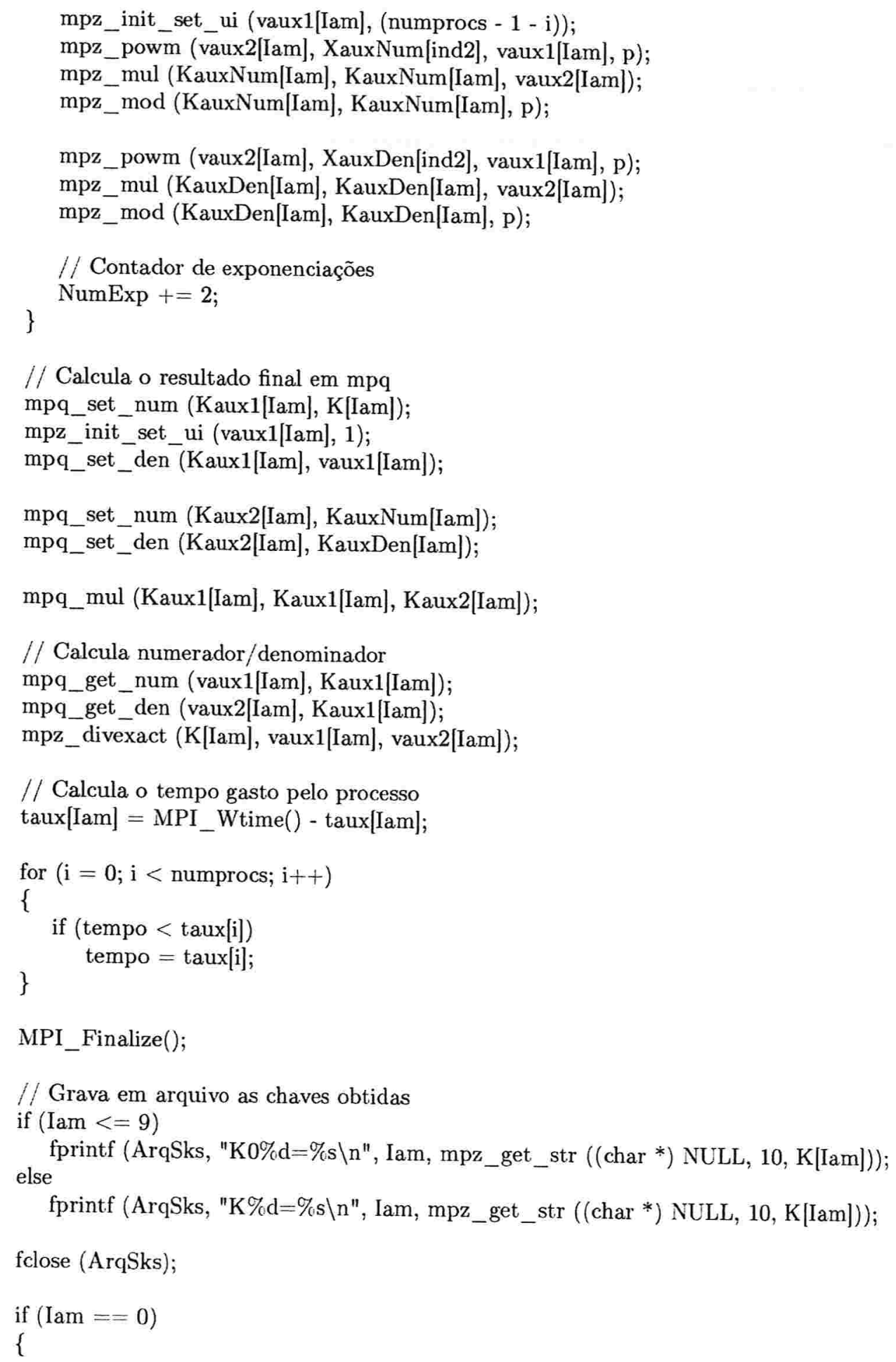


// Chave de Sessão gerada para os participantes

printf ("\nChave Obtida: \%s\n", mpz_get_str ((char *) NULL, 10, K[Iam]));

// Mostra os resultados dos contadores printf ("\nEstatisticas: $\backslash \mathrm{n} "$ );

printf ("Mensagens Enviadas: \%d $\backslash n$ ", NumMsgEnv);

printf ("Mensagens Recebidas: \%d $\backslash n$ ", NumMsgRec);

printf ("Exponenciacoes: \%d\n", NumExp);

printf ("Tempo gasto: \%f $\backslash \mathrm{n} \backslash \mathrm{n}$ ", taux[Iam]);

// Salva no arquivo de resultados

fprintf (ArqRes, "\%d,", numprocs);

fprintf (ArqRes, "\%d,", NumMsgEnv);

fprintf (ArqRes, "\%d,", NumMsgRec);

fprintf (ArqRes, "\%d,", NumExp);

fprintf (ArqRes, "\%丹\n", taux[Iam]);

\}

fclose (ArqRes); 


\section{B Listagem do Programa PKRes}

Abaixo é apresentada a listagem do programa pkres.exe, desenvolvido para visualizar os dados obtidos através da execução do protocolo.

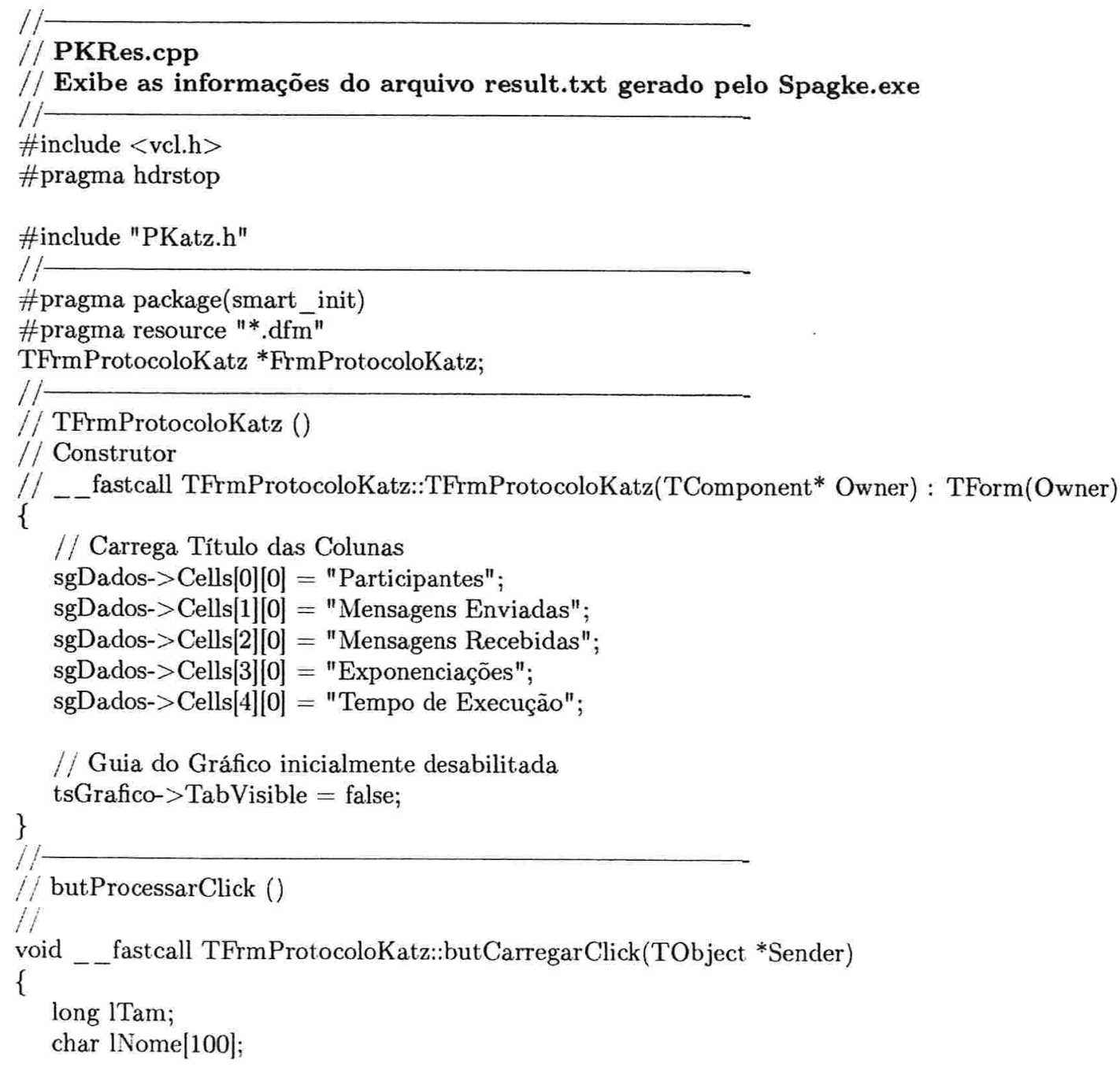




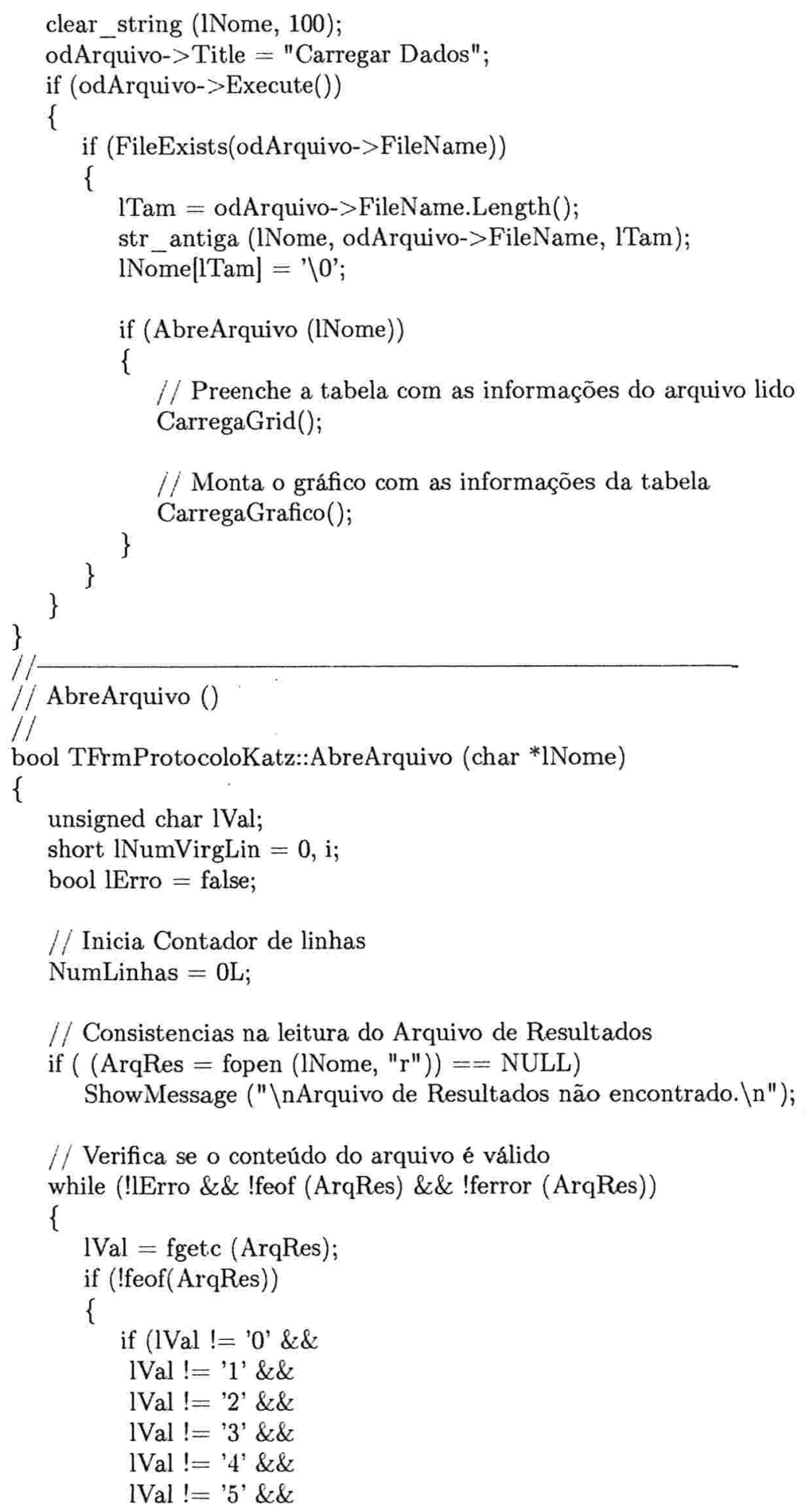




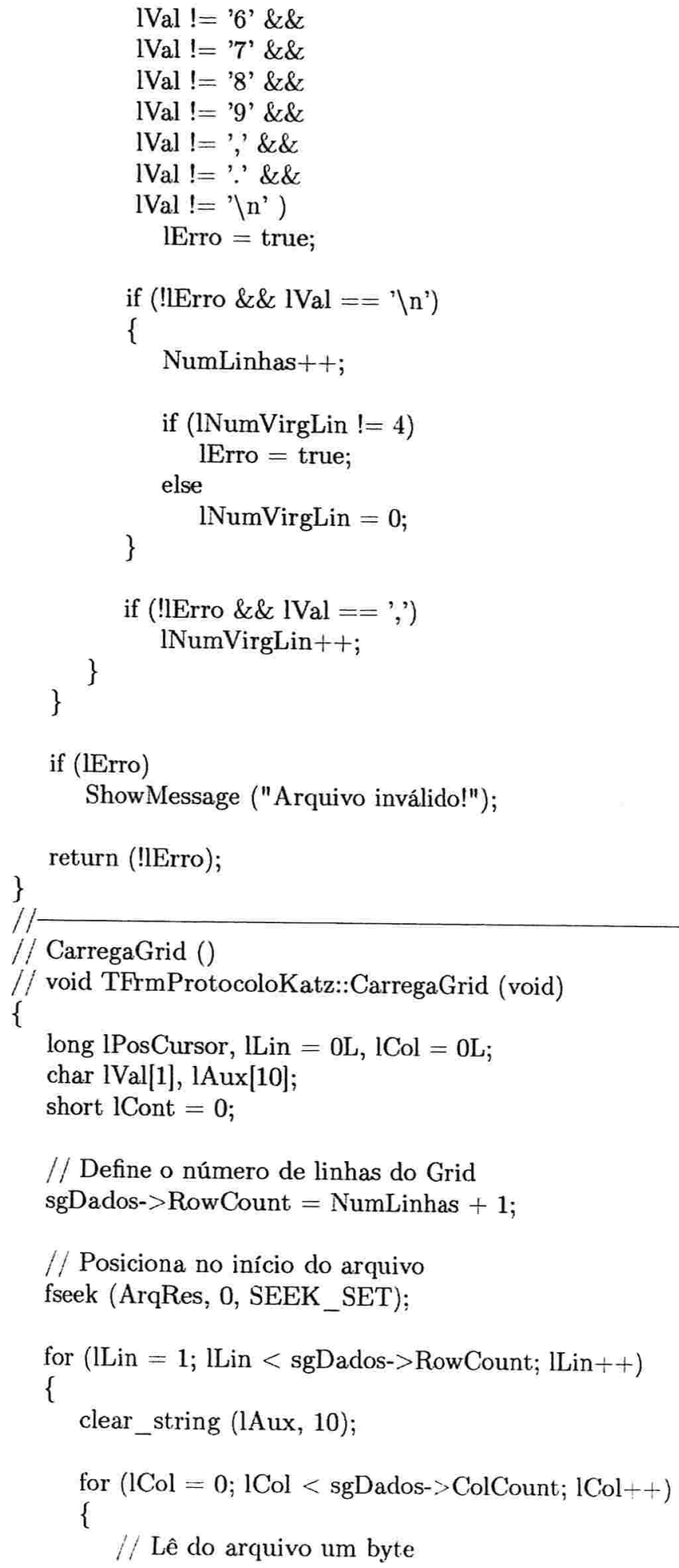




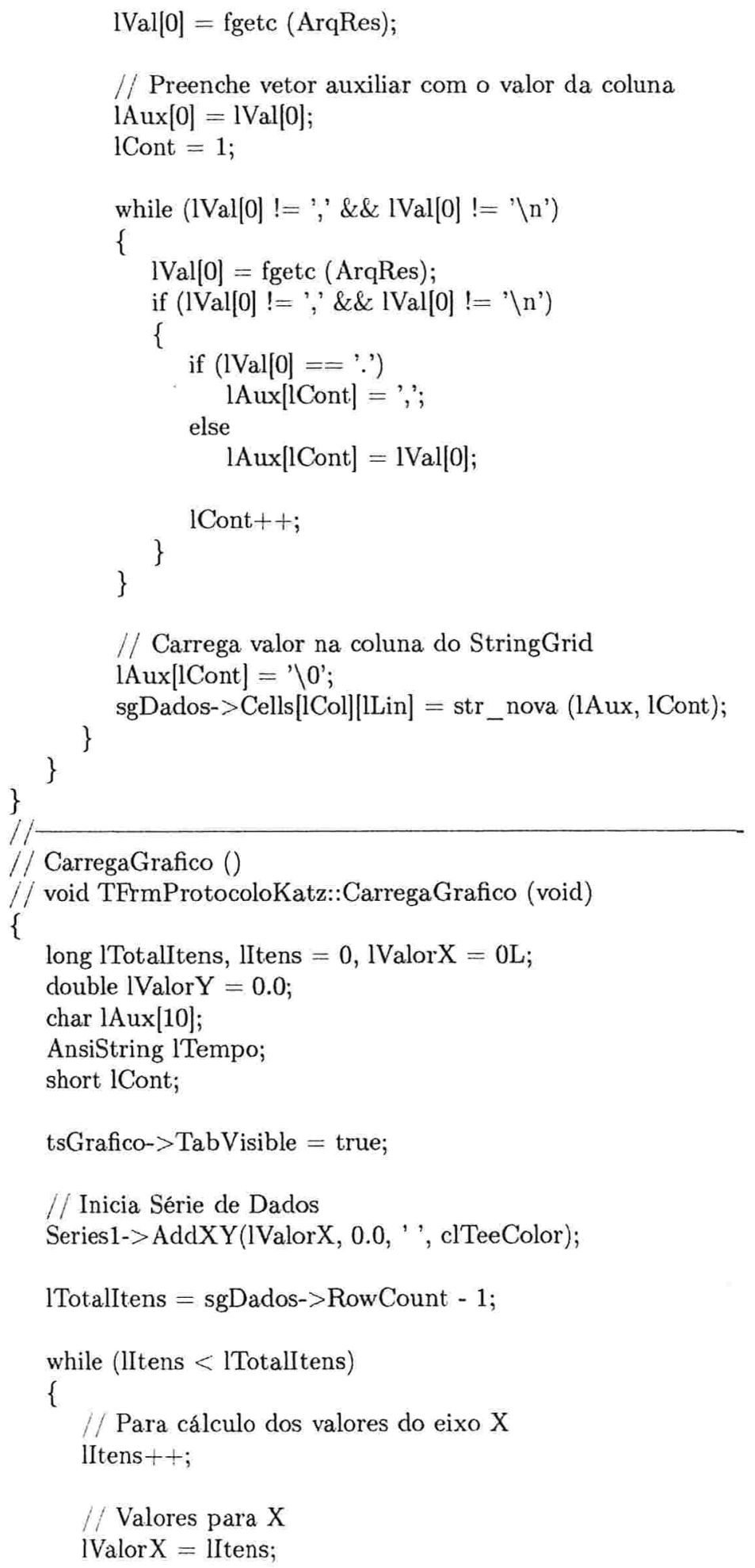




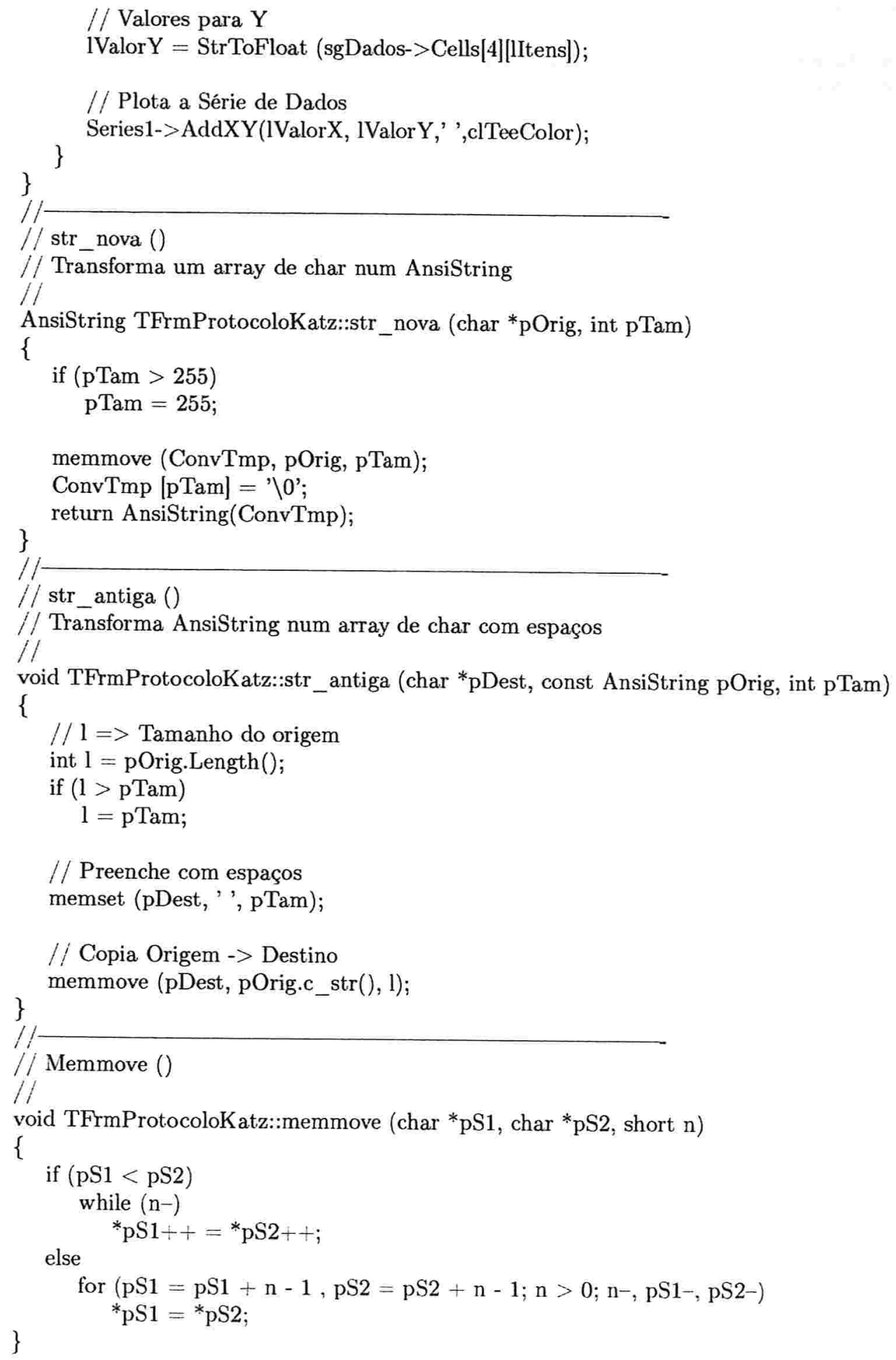



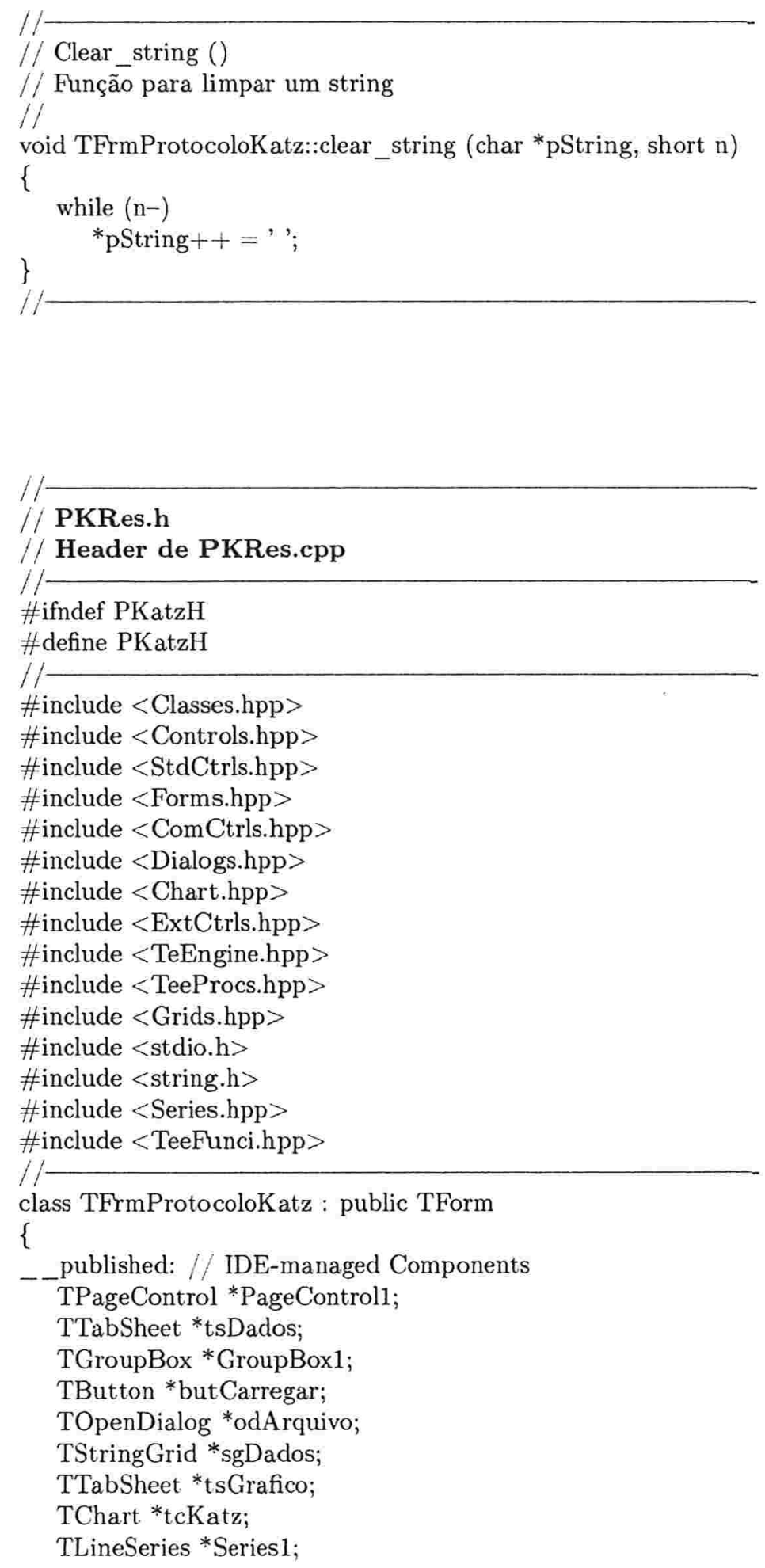
TAddTeeFunction *TeeFunction1;

void __fastcall butCarregarClick(TObject *Sender);

private: // User declarations

FILE *ArqRes;

long NumLinhas;

char ConvTmp [256];

bool AbreArquivo (char ${ }^{*}$ );

void CarregaGrid (void);

void CarregaGrafico (void);

AnsiString str_nova (char *, int);

void str_antiga (char *, const AnsiString, int);

void memmove (char ${ }^{*}$, char ${ }^{*}$, short);

void clear_string $\left(\right.$ char ${ }^{*}$, short);

public: // User declarations

\}

fastcall TFrmProtocoloKatz(TComponent* Owner);

$11-$

extern PACKAGE TFrmProtocoloKatz *FrmProtocoloKatz;

$/ 1$

.\#endif 


\section{Glossário}

Adversário Ativo Tem acesso à todas as informações de um grupo de usuários se comunicando em uma rede pública, podendo fazer consultas ou alterações nas mesmas.

Adversário Passivo Tem acesso à todas as informações de um grupo de usuários se comunicando em uma rede pública, podendo fazer apenas consultas nas mesmas.

Assinatura Codifica uma mensagem através de uma chave pública e uma privada, garantindo segurança e privacidade. Através da chave pública é possível verificar que foi assinada uma determinada mensagem, e o acesso ao conteúdo da mensagem é possível apenas com a chave privada.

Autenticação Processo que autentica um usuário ou host. Essa autenticação pode ser simples e aplicada no nível do aplicativo (exige por exemplo uma senha) ou pode ser complexa (como em diálogos de desafio-resposta entre máquinas, que são geralmente baseados em algoritmos de criptografia).

Autenticar Verificar a identidade de um determinado usuário ou host.

Chave Valor numérico, definido por um usuário ou um host, utilizado por um algoritmo criptográfico para codificar ou decodificar mensagens.

Chave Autenticada Chave segura e confiável de um protocolo.

Chave Pública Chave conhecida não apenas por quem a criou, mas também por todos os outros que participam de uma comunicação em um grupo.

Chave Secreta Chave conhecida apenas por quem a criou. Também chamada de chave particular.

Grupo Cíclico Um grupo $(G, *)$ é um conjunto $G$ com uma operação binária associada ao mesmo. $G$ é cíclico se existir um gerador de grupo, ou seja, se existir um elemento $g \epsilon G$ tal que para qualquer $a \epsilon$ $G$, existe um inteiro $j$ onde $g^{j}=a$.

Rodada Passo ou iteração de um algoritmo. 


\section{Índice Remissivo}

Adversário Ativo, 2, 5, 18, 21

Adversário Passivo, 2, 5, 8, 18, 21, 22

AKE, 1, 2, 19, 21

Assinatura, 2, 11, 20, 21, 28

Autenticação, 1, 11

Bellare, 9, 15

Bresson, 2, 3, 14, 15, 17, 18

Burmester-Desmedt, 9, 15, 24

$\mathrm{CDH}, 6$

Chave Autenticada, 1, 21

Chave de sessão, 1, 6, 9-11, 13, 18, 21, 25

Chave Pública, 21

Chave Secreta, 1, 4, 5, 12, 13, 18, 28

Corrupt, 18, 19, 21, 22

DDH, 6, 24

Diffie-Hellman, 4, 8

Escalabilidade, 5

Execute, 18, 22

Fora-de-banda, 1

Forge, 21-23

Freshness, 19

GMP, 32

Grupo Cíclico, 24

Hardware, 31

IKA.1, 11

IKA.2, 12

Ingemarsson, 8, 15

Katz-Yung, 8, 15, 17, 19
Lema do Aniversário, 6

MPI, 32

NONCE, 20

PLD, 4

Repeat, 21-23

Reveal, 18, 19

Send, 18, 19, 22

Sigilo no futuro, 6,19

Steiner, 11, 15

Succ, 19

Test, 18, 19, 22 


\section{Referências Bibliográficas}

[1] BELLARE, R. C. M.; KRAWCZYK, H. A modular approach to the design e analysis of authentication and key exchange protocols. STOC, 1998.

[2] BELLARE, D. P. M.; ROGAWAY, P. Authenticated key exchange secure against dictionary attacks. Eurocrypt, 2000.

[3] BELLARE, M.; ROGAWAY, P. Entity authentication and key distribution. Advances in Cryptology, 1993.

[4] BELLARE, M.; ROGAWAY, P. Provably secure session key distribution - the three party case. STOC, 1995.

[5] BELLARE, M.; YEE, B. Forward-security in private-key cryptography. FSPKC, 2000.

[6] BRESSON, O. C. E.; POINTCHEVAL, D. Provably authenticated group diffie-hellman key exchange - the dynamic case. Asiacrypt, 2001.

[7] BRESSON, O. C. E.; POINTCHEVAL, D. Dynamic group diffie-hellman key exchange under standard assumptions. Eurocrypt, 2002.

[8] BRESSON, O. C. E.; POINTCHEVAL, D. The group diffie-hellman problems. Eurocrypt, 2001.

[9] BRESSON, O. C. E.; POINTCHEVAL, D. Group diffie-hellman key exchange secure against dictionary attacks. Asiacrypt, 2002.

[10] BRESSON O. CHEVASSUT, D. P. E.; QUISQUATER, J. Provably authenticated group diffiehellman key exchange. ACM CCCS, 2001.

[11] BRESSON O. CHEVASSUT, O. P. D. P. E.; QUISQUATER, J. Two formal views of authenticated group diffie-hellman key exchange. DIMACS, 2002.

[12] BURMESTER, M.; DESMEDT, Y. A secure and efficient conference key distribution system. Eurocrypt, 1994.

[13] CANETTI, R. Decisional diffie-hellman assumption. IBM Research, 2002.

[14] CANETTI, R.; KRAWCZYK, H. Key-exchange protocols and their use for building secure channels. Eurocrypt, 2001.

[15] CORMEN CHARLES E. LEISERSON, R. L. R. T. H. Introduction to Algorithms. The MIT Press: McGraw-Hill Book Company, 2001. 1180 p.

[16] DIFFIE, W.; HELLMAN, M. New directions in cryptography. IEEE Transactions on Information Theory, 1976. 
[17] FOSS, J. An efficient secure authenticated group key exchange algorithm for large and dynamic groups. CSDS, 2000.

[18] GNU MP. GMP. 2002. Disponível em: <http://www.swox.com/gmp>.

[19] INGEMARSSON, D. T. I.; WONG, C. A conference key distribution system. IEEE Transactions on Information Theory, 1982.

[20] KATZ, J.; YUNG, M. Scalable protocols for authenticated group key exchange. Crypto Conference, 2003.

[21] KATZ, J. A forward-secure public-key encryption scheme. 2003.

[22] MPI - Message Passing Interface. 2002. Disponível em: <http://www.mcs.anl.gov/mpi/index.html>.

[23] OSTROVSKY, J. K. R.; YUNG, M. Forward security in password-only key exchange protocols. SCN, 2002.

[24] PEREIRA, O. Modelling and security analysis of authenticated group key agreement protocols. SCN, 2003.

[25] SCHNEIER, B. Segurança.com. Segredos e mentiras sobre a proteção na vida digital. [S.1.]: Editora Campus, 2001. 403 p.

[26] STEINER, G. T. M.; WAIDNER, M. Key agreement in dynamic peer groups. ACM CCCS, 1996.

[27] STEINER, M. Secure group key agreement. Einreichung, 2001.

[28] TERADA, R. Segurança de Dados, Criptografia em Redes de Computador. [S.1.]: Editora Edgard Blücher, 2000. 242 p.

[29] TSUDIK, G.; IRVINE, U. Communication-efficient group key agreement. 2001.

[30] VASCONCELOS, M. A Internet e os Hackers. Ataques e Defesas. [S.I.]: Editora Chantal, 2000. $336 \mathrm{p}$.

[31] ANôNIMO, A. Segurança Máxima. O guia de um hacker para proteger seu site na Internet e sua rede. [S.1.]: Editora Campus, 2000. 826 p. 